San Jose State University

SJSU ScholarWorks

Master's Theses

Master's Theses and Graduate Research

Fall 2011

\title{
Habitat Use of Striped Bass (Morone saxatilis) in the San Francisco Estuary and its Effect on Total Mercury and Heavy Metal Body Burden upon Capture
}

Jonathan Hugh Walsh

San Jose State University

Follow this and additional works at: https://scholarworks.sjsu.edu/etd_theses

\section{Recommended Citation}

Walsh, Jonathan Hugh, "Habitat Use of Striped Bass (Morone saxatilis) in the San Francisco Estuary and its Effect on Total Mercury and Heavy Metal Body Burden upon Capture" (2011). Master's Theses. 4117. DOI: https://doi.org/10.31979/etd.mckv-me6v

https://scholarworks.sjsu.edu/etd_theses/4117

This Thesis is brought to you for free and open access by the Master's Theses and Graduate Research at SJSU ScholarWorks. It has been accepted for inclusion in Master's Theses by an authorized administrator of SJSU ScholarWorks. For more information, please contact scholarworks@sjsu.edu. 
HABITAT USE OF STRIPED BASS (Morone saxatilis) IN

THE SAN FRANCISCO ESTUARY AND ITS EFFECT ON

TOTAL MERCURY AND HEAVY METAL BODY BURDEN

UPON CAPTURE

\author{
A Thesis \\ Presented to \\ The Faculty of the Department of Marine Science \\ San Jose State Univeristy \\ In Partial Fulfillment \\ of the Requirements for the Degree \\ Master of Science \\ by \\ Jonathan Hugh Walsh
}

December 2011 
(C) 2011

Jonathan Hugh Walsh

ALL RIGHTS RESERVED 
The Designated Thesis Committee Approves the Thesis Titled

HABITAT USE OF STRIPED BASS (Morone saxatilis) IN THE SAN

FRANCISCO ESTUARY, AND ITS EFFECT ON TOTAL MERCURY AND HEAVY

METAL BODY BURDEN UPON CAPTURE

\author{
by \\ Jonathan Hugh Walsh \\ APPROVED FOR THE DEPARTMENT OF MARINE SCIENCE \\ SAN JOSE STATE UNIVERSITY
}

December 2011

Dr. Gregor Cailliet

Dr. Kenneth Coale

Dr. David Ostrach
Moss Landing Marine Laboratories

Moss Landing Marine Laboratories

Ostrach Consulting 


\begin{abstract}
HABITAT USE OF STRIPED BASS (Morone saxatilis), IN THE SAN FRANCISCO ESTUARY, AND ITS EFFECT ON TOTAL MERCURY AND HEAVY METAL BODY BURDEN UPON CAPTURE

by Jonathan Hugh Walsh
\end{abstract}

Striped Bass (Morone saxatilis) is a nearshore, anadromous fish in the San Francisco Estuary (SFE). A notable aspect of Striped Bass populations in general is yearly migrations, but there has been considerable disagreement over the homogeneity of these movements within the SFE. Additionally, since Striped Bass spend their entire lives in estuarine and nearshore environments, they likely encounter contaminants due to their proximity to anthropogenic pollution sources, a known concern with this species.

The purpose of this study was to clarify habitat use, movements of Striped Bass in the SFE, and potential dangers to Striped Bass and consumers from contaminants by utilizing two sets of analyses, presented in separate chapters. Otolith microchemistry analysis was used to provide evidence of freshwater residency, identify distinct groups within the SFE system, and determine if ontogeny and gender affect movements and habitat utilization. Tissue chemistry analysis was then used to determine metal concentrations in Striped Bass fillets and examine correlations between these concentrations and habitat use. These analyses clearly show that resident subpopulations exist in the SF Delta and that yearly migrations are rare. Additionally, though almost all metals were below human consumption screening levels for contaminants, a few concentrations (mercury, selenium, and cadmium) in fillets were of concern. 


\section{ACKNOWLEDGEMENTS}

This master's thesis was completed through the help of several individuals. My thesis committee, Drs. Gregor Cailliet, Kenneth Coale, and David Ostrach, were extremely patient and exceptional in helping me with all aspects of this work. This project benefitted immensely from their many contributions. Jay Davis, Jennifer Hunt, and Katie Harrold (SFEI) allowed me access to archived otoliths and tissue, and organized funding for the otolith chemistry portion of the thesis. Mark Stephenson, Billy Jakl, Dylan Service, Jon Negrey, Rusty Fairey, Marco Sigala, Ashleigh Lyman, Aroon Melwani, and Gary Ichikawa (MPSL) caught the Striped Bass used in this project over many days in the field. Stephen Martenuk and Jon Goetzl (MPSL) were instrumental in completing tissue digestions and metals analysis inStriped Bass fillets. Peter Weber and Corey Philis (UC-Berkeley) developed much of the otolith sampling protocols used in this thesis and trained me how to use the equipment to get it done. Shaara Ainsley and Cassandra Brooks (MLML) taught me how to correctly section and polish otoliths. Simon Brown (MLML) helped me enormously with understanding and applying multivariate statistical techniques to my data. Dr. Richard Kraus (Texas A\&M) assisted with validating Striped Bass ages. George Whitman from Dr. Ostrach's lab sat through many long data collection sessions for the otolith part of this project. You all gave your time without hesitation, and helped me incredibly, and I am indebted to you for that.

Several others have supported me during my long journey to completing my master's degree requirements. I have learned immensely from the faculty and staff at Moss Landing about how to conduct scientific research and comport oneself in the 
scientific arena. I have had numerous employers who supported my school schedule. I could not have survived financially without their grace. Past and present Ichthyology lab students assisted me on several smaller projects and kept me sane in difficult times.

Roommates during my tenure at MLML have put up with late night study habits and kept me laughing when frustrating obstacles in grad school life occurred. And I would be lost without the tremendous love and support of my parents, Hugh and Joanne, brother Joe, sisters Kate and Carrie, my large yet tight-knit extended family, and my girlfriend, Rachel. I do not have the words or the space here to express my deep gratitude for your sacrifices in getting me here. I hope you enjoy the results of your inspiration.

This thesis was made possible through funding from San Francisco Estuary Institute, and The David and Lucile Packard Foundation. Thank you for your support. 


\section{TABLE OF CONTENTS}

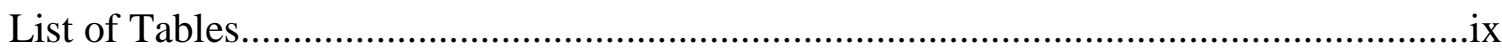

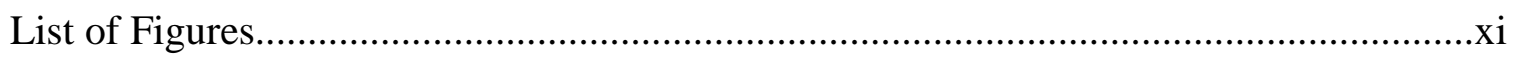

Chapter 1: Otolith Chemistry Analysis............................................................................

Otolith Chemistry Methods.......................................................................................

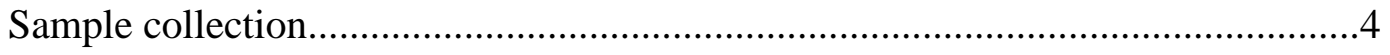

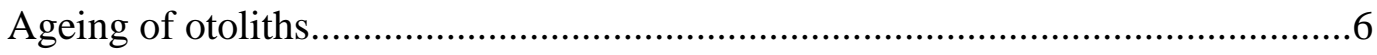

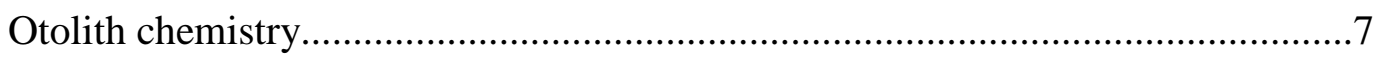

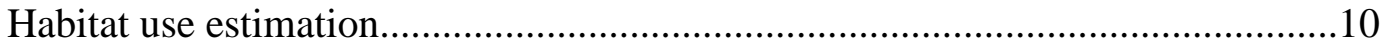

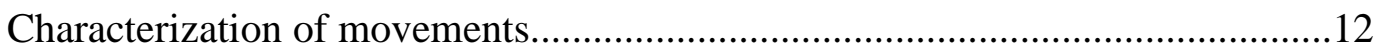

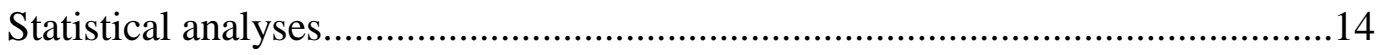

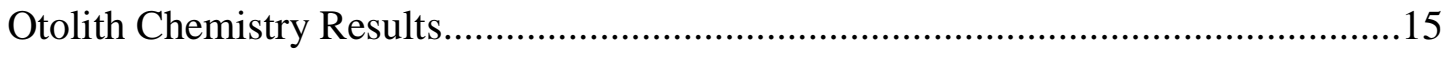

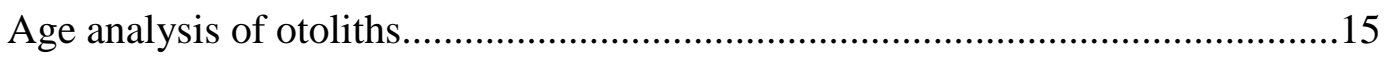

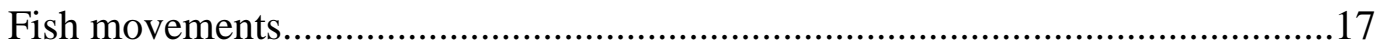

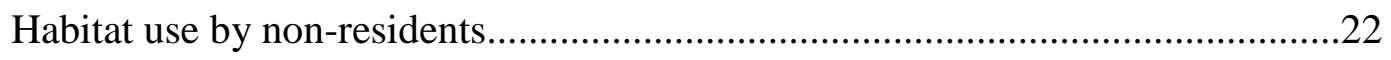

Otolith Chemistry Discussion.................................................................................24

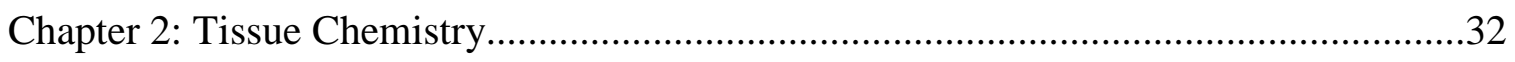

Tissue Chemistry Methods.......................................................................................

Sample collection..............................................................................................

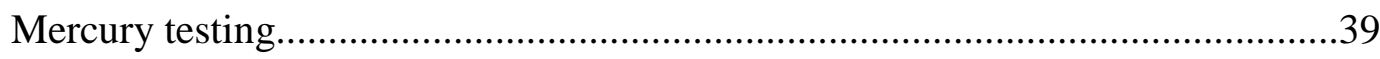

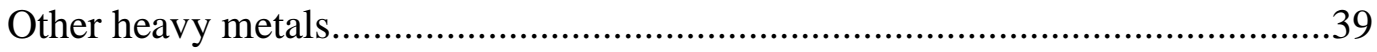

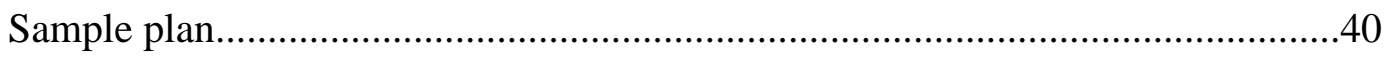


Sample preparation, digestion, and testing ..............................................42

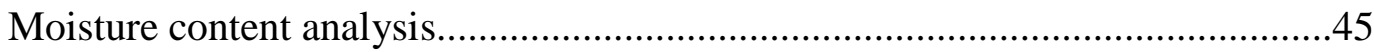

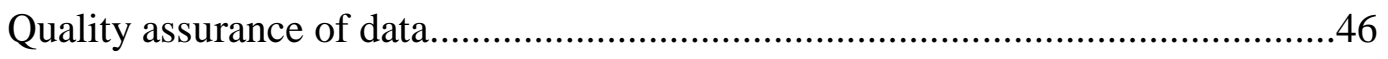

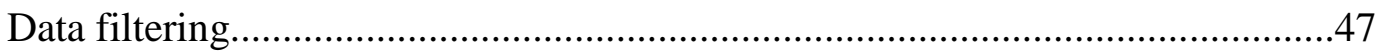

Metal concentration comparisons...........................................................49

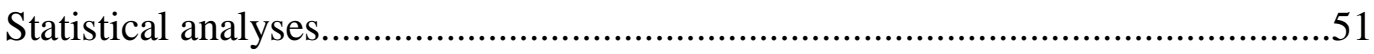

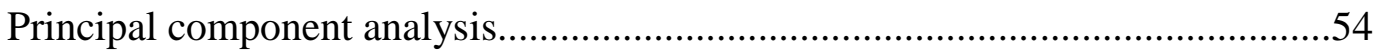

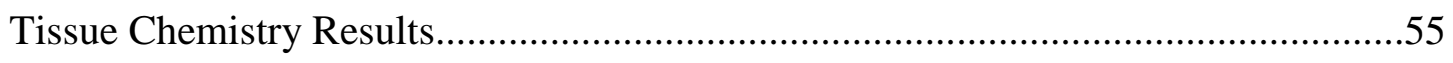

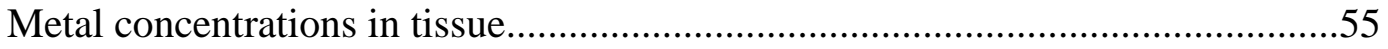

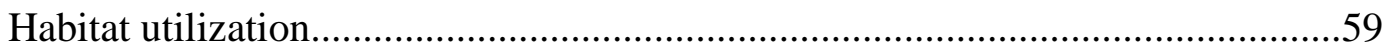

Metal concentrations by catch locations...................................................65

Changes in mercury concentrations with time............................................68

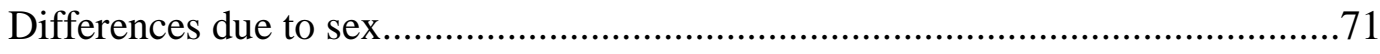

PCA

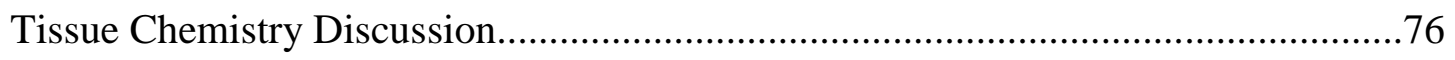

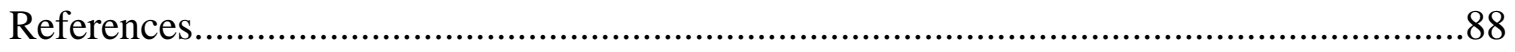




\section{List of Tables}

Table 1: Water masses with associated salinities in wet and dry seasons and their respective mean strontium isotope ratios and $\Delta \mathrm{Sr}$ values.

Table 2: Numbers of individuals for each type of movment pattern by catch location with total sample sizes for each catch location. Location codes are as follows: $\mathrm{CC}=$ Clifton Court, $\mathrm{KL}=$ Knights Landing, $\mathrm{LI}=$ Liberty Island, $\mathrm{NBAY}=$ North Bay, SBAY $=$ South Bay, CBAY $=$ Central Bay

Table 3: Chemical concentrations for three outliers that were removed from analysis. Average chemical concentrations for detections are listed for comparison. Values in red were below detection limits while those in blue were below method detection limits.

Table 4: Minimum detection limits (in red), method detection limits (in blue), number of detections and percent detetcted for each chemical concentration measured. Metals with percent detections in red were not used in analyses due to low detection rates.

Table 5: Screening levels (SLs) and mean concentrations. SLs were derived using the Mid-Atlantic Risk Assessment Calculator. 55

ix 
Table 6: Meals per month (MPM) calculations for As, Cd, Hg, and Se. These represent conservative estimates of the amount needed to reach levels of concern (LOC) for each type of consumer. 58

Table 7: Mean metal concentrations for residents and non-residents along with p-values for t-tests comparing differences. Samples sizes for power of 0.8 , if applicable, represent total sample sizes if all groups have equal numbers. 61

Table 8: Average concentrations of metals for Bay-caught non-residents, Delta-caught non-residents, and Delta residents along with p-values from ttests comparing differences. 64

Table 9: Numbers and frequencies of individuals above the screening level for mercury. 66

Table 10: Mean concentrations and p-values for each metal examined. Sample sizes for power of 0.8 , if applicable, represent total sample sizes if all groups have equal numbers. Asterisk on mercury indicates sample sizes of $n=27$ for females and $n=36$ for males. 


\section{List of Figures}

Figure 1: Map of SFE. Color denotes average salinity of water bodies in area (orange $=20-32 p p t$, yellow $=4-20 p p$, green $=1-5 p p t$ aqua $=0-2 p p t)$. Petagons indicate collection areas with number of Striped Bass caught at each location. 5

Figure 2: Transverse section of otolith. Strontium ratio measurements occurred at each spot in transect from core of otolith to the edge in direction of red arrow.Black lines emphasize the terminations of band pairs used to estimate age of the fish 9

Figure 3: $\triangle \mathrm{Sr}$ correlation with salinity in SFE (adapted from Ingram \& Sloan 1992). Fig A shows complete correlation for the whole SFE. Fig B shows the top portion of the correlation where salinity varies from 5 pt to $32 \mathrm{ppt}$. 10

Figure 4: Strontium isotope ratio estimates of a $840 \mathrm{~mm}$ total length, 8 year old male caught in Clifton court. Mean strontium isotope ratios are indicated by colored dotted lines. Black dashed line in track indicates hypothetical movement to capture location denoted by the star. 13

Figure 5: Difference in age estimates among 3 reads. 16 
Figure 6: Comparison of age estimates for two reads. Yellow diagonal line indicates where reads would be in agreement.

Figure 7: Strontium isotope ratio estimates of a $535 \mathrm{~mm}$ total length, 4 year old female caught at Liberty Island. Mean ratios for water bodies are indicated by colored dotted lines. Black dashed line in track indicates hypothetical movement to capture location. 18

Figure 8: Strontium isotope ratio track of a $497 \mathrm{~mm}$ total length Striped Bass of undetermined sex caught in Clifton Court. Colored dotted lines indicate mean strontium isotope values for each water body in the SFE. Black dashed line indicates hypothesized movement to catch location. 19

Figure 9: Graph of proportion of non-residents for each major catch location (bay locations have been grouped here). The numbers in parantheses indicate the total number of fish caught at those locations 21

Figure 10: Average age of estaury residents and non-residents. Error bars indicate $95 \%$ confidence intervals. 22

Figure 11: Comparison of p-values amongst catch locations. Numbers in red indicate significant differences. 23 
Figure 12: Two regressions of size $(\mathrm{TL}=$ total length $)$ by mercury content by years of sampling $(A=1997, B=2000)$.

Figure 13: Map of sample locations. Numbers in hexagons represent total individuals from locations. Red numbers depict locations where at least most samples collected were analyzed for all metals examined. Colors of water bodies also indicate salinity (orange $=13-32 \mathrm{ppt}$, yellow $=4-12 \mathrm{ppt}$, green $=1-5$ ppt, aqua $=0.2-2 \mathrm{ppt})$ 38

Figure 14: Average concentration of mercury with $95 \%$ confidence intervals for all samples analyzed $(n=115)$. Red dotted line denotes screening level for mercury $(0.4 \mathrm{ug} / \mathrm{g} \mathrm{ww})$ 56

Figure 15: Average concentrations with 95\% confidence intervals for all 2006 samples without outliers $(n=70)$. 57

Figure 16: Mean mercury concentrations for resident s and non-residents with 95\% confidence intervals. Red dotted line denotes screening level for mercury (0.4 ug/g ww). 
Figure 17: Other average metal concentrations with $95 \%$ confidence intervals

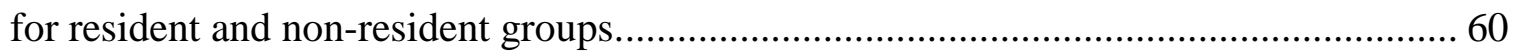

Figure 18: Mean mercury concentrations for Bay-caught non-residents, Deltacaught non-residents, and Delta residents with associated 95\% confidence intervals. Red dotted line denotes screening level for mercury $(0.4 \mathrm{ug} / \mathrm{g} \mathrm{ww})$. 62

Figure 19: Averages of other metal concentrations with 95\% confidence intervals for Bay-caught non-residents, Delta-caught non-residents, and Delta residents. 63

Figure 20: Average mercury concentrations with $95 \%$ confidence intervals for all catch groups. Red dotted line denotes screening level for mercury $(0.4$ $\mathrm{ug} / \mathrm{g}$ ww) 65

Figure 21: Mean concentrations of other metals for all catch groups with associated $95 \%$ confidence intervals. 67

Figure 22: Average mercury levels with 95\% confidence intervals of fish caught in San Pablo Bay by catch year. Asterisk indicates that 2000 was significantly lower than other catch years. Trendline is shown with $r^{2}$ value and slope. 69 
Figure 23: Plot of mercury concentration with total length for each individual.

Figure 24: Plot of mercury concentration with age estimate for all individuals

Figure 25: Mean mercury concentrations with $95 \%$ confidence intervals for individuals with gender information. Red line denotes screening level for mercury $(0.4 \mathrm{ug} / \mathrm{g} \mathrm{ww})$

Figure 26: Averages of other metals concentrations with associated $95 \%$ confidence intervals for each gender (when available)

Figure 27: Principal component analysis diagram depicting relation of factors to one another. Factors which are orthogonal to one another are not correlated. Axes together represent $99.7 \%$ of total variability in data set. 


\section{Chapter 1: Otolith Chemistry}

Native to the east coast of the United States, Striped Bass (Morone saxatilis) were introduced to these waters twice, in 1879 and again in 1882, and supported a commercial fishery merely ten years after introduction (Raney et al., 1952). Although the commercial fishery was closed in 1931 (Smith \& Wells, 1977), Striped Bass are still the most important sport fish in the area (SFEI 2000), prized for their size, flesh, and fighting ability. Striped Bass are an apex predator in the ecosystem and thus have a great impact on other organisms in the estuary and rivers (Setzler et al., 1980).

A notable aspect of Striped Bass populations in general are the migrations that occur on a yearly basis, moving into fresh waters in the early spring and back to more saline waters immediately after spawning in late spring or early summer. Historically, these movements occur in large runs, similar to those of salmon, and these migrations have been recorded on both coasts (Raney 1952). There has been, however, considerable disagreement as to the homogeneity of these movements within populations.

Disagreements exist as to whether individuals migrate on an annual basis, if migration lengths contrast among individuals of different sizes, and if individuals from different spawning locations migrate separately (Stevens 1977; Dorazio et al., 1994; Secor \& Piccoli, 1996). Researchers have published conflicting results with tagging studies when tackling these questions. Research on east coast populations of striped bass has indicated that movements are different among spawning groups, where each spawning group shows a great deal of fidelity in its movements (Merriam 1941). Some studies have shown that 
larger fish migrate farther from spawning sites into more saline waters (McLaren et al., 1981), where others have found movement unrelated to size and sex (Clark 1968).

To add to the confusion, small tagged Striped Bass in the San Francisco Bay exhibited diffusion rather than a strong movement from a release site (Clark 1936), but other tagging studies with larger fish in the area have shown strong migratory behavior, including recaptures in oceanic environments (Stevens et al., 1985). Based on these later studies, Striped Bass on the west coast, like their east coast cousins, have been assumed to have strong yearly movements upon maturation (Calhoun 1952; Secor \& Piccoli 1996). Recent studies have challenged this assumption for the SFE population of Striped Bass indicating that the majority of this Striped Bass population utilize the habitats in the delta regions upstream of the Carquinez straits and occasionally move to the ocean to feed in the late spring and summer (Ostrach 2007; Ostrach et al., 2009; Phillis et al., 2011).

Analyses of otolith microchemistry have shown promise for elucidating questions about the movements of Striped Bass. These analyses are especially helpful because they do not rely upon the common impediments and biases associated with tag-and-recapture studies. Tag-and-recapture studies assume that the tag has no effect on movement, and they require many individuals to be tagged due to low recapture rates. Data collected upon recapture often includes no information on movements between release and capture, and to estimate the overall movements of a population, data from several individuals often has to be combined (Ricker 1975, Waldman et al., 1990, Hilborn and Walters 1992). These problems do not invalidate these studies, but they do reduce the ability to 
discern individual variation in movements, especially over the life span of the individual. Studies on the east coast using microchemistry of Striped Bass otoliths have generated complete movement patterns for individuals over their entire lifespan when movements occur between waters of differing salinity (Secor 1992; Secor 1999; Kraus \& Secor 2003; Zlokovitz et al., 2003). Recent studies have documented complete life history patterns for the SFE population of Striped Bass (Ostrach et al., 2009; Phillis et al., 2011). This allows the researcher to look at movements of individuals over longer periods of time than previously possible, without any bias from a tag, and avoids combining movement information from several individuals when interpreting data.

Use of strontium isotopes in microchemistry analysis yields additional benefits to tracing movements of Striped Bass individuals. Strontium isotope ratios are unique to an individual watershed in the SFE and correlate very closely with salinity (Ingram \& Sloan 1992). Since strotium has similar chemical properties to the calcium carbonate matrix of the otolith (Campana \& Nielson 1985) and is acquired almost entirely from respiration (Kalish 1991, Kennedy et al., 1997, Thorrold et al., 1997b; Campana \& Thorrold, 2001), estimates of residency and movement within the SFE can be made. Although estimates of location are more specific in freshwater, analyzing strontium isotopes does allow for enumerating forays into and out of the SFE with great precision.

Microchemistry studies on Striped Bass in east coast populations indicate that movement patterns vary with age and that distinct freshwater subpopulations are present (Secor \& Piccoli 1996), which may be the reason for confounded results among tagging studies in west coast populations. Some results have also shown that individuals tend to 
migrate farther into saline waters after spawning as they grow larger, and females tend to migrate farther into saline waters than males, although considerable variability among individuals was present. There is also evidence that distinct contingents in spawning runs exist, where individuals in a contingent have similar movement patterns (Secor et al., 2001). To date, there are few published studies examining the entire life history of Striped Bass individuals on the U.S. west coast, but recent data indicate a resident freshwater population in the Delta system (Ostrach et al., 2009; Phillis et al., 2011). Previous to this study, it was unknown if individuals in the San Francisco Bay and Sacramento Delta show the same tendencies in movements as east coast populations.

The purpose of this study was to provide clarification of habitat use and potential migratory behavior of Striped Bass in the SFE. Specifically, this study aimed to show further evidence of the presence of freshwater resident subpopulations, if ontongeny or gender affect movements and habitat utilization, and if distinct spawning groups exist in the San Francisco Estuary system.

\section{Methods}

Sample collection. Striped Bass used for this project were collected in 2000, 2003, and 2006 by the California Department of Fish and Game as part of the Fish Mercury Project (FMP) and Regional Monitoring Project (RMP). Striped Bass were collected in the South Bay, Central Bay (adjacent to Berkeley, CA), San Pablo Bay, 
Suisun Bay, Sacramento Delta and the Sacramento River (Fig. 1).

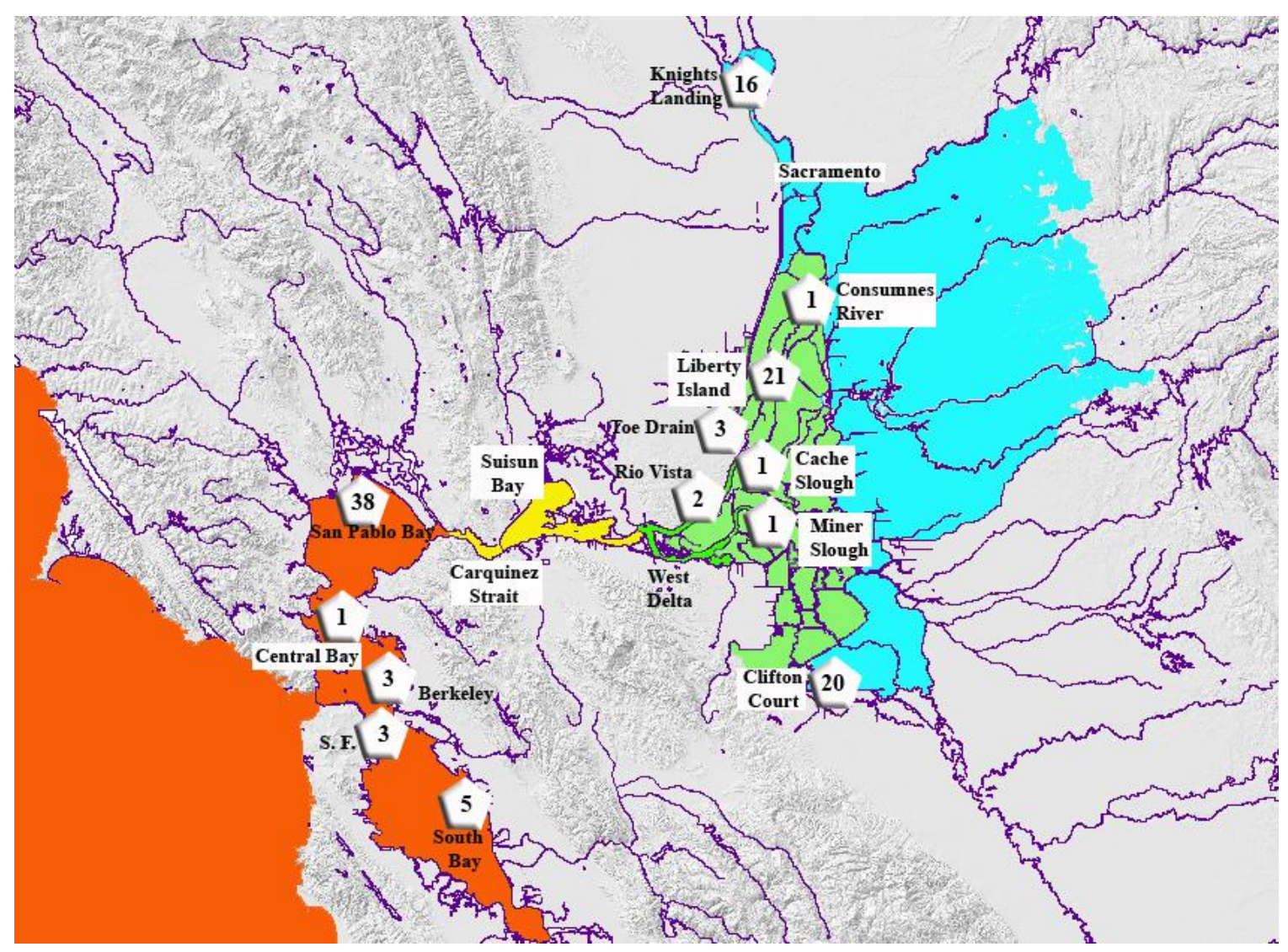

Figure 1: Map of SFE. Color denotes average salinity of water bodies in area $($ orange= 20-32ppt, yellow=4-20

pp, green =1-5ppt, aqua=0-2ppt). Petagons indicate collection areas with number of Striped Bass caught at each location.

A total number of 115 individuals were captured using an electrofishing boat and/or fyke nets by Department of Fish and Game personnel.

Trace-metal-clean field methods were used in all cases. Upon capture, contact of fish with uncontaminated surfaces was limited by handling fish with polyethylene gloves and wrapping caught fish in trace-metal-clean Teflon sheeting. For each individual, total length, wet weight, and sex (in most cases) were recorded. Most fish were frozen whole on dry ice for use in the laboratory; the heads and mid-body sections were collected for 
especially large individuals. All individuals were stored in a $-20^{\circ} \mathrm{C}$ freezer at the Marine Pollution Studies Laboratory in Moss Landing, California. All sampling was done in accordance with IACUC protocol \#2007-G.

Ageing of otoliths. Sagittal otoliths from individuals caught in 2006 were extracted in a trace-metal-clean environment, rinsed with trace-metal-grade hydrogen peroxide $\left(\mathrm{H}_{2} \mathrm{O}_{2}\right)$ to remove adhering tissue, washed with $18 \mathrm{M} \Omega$ Milli-Q water (Millipore Corporation, Billerica, Massachussets), and stored in acid-cleaned plastic microcentrifuge tubes. Individuals caught prior to 2006 had already been processed, and their otoliths were available in archives.

One otolith of each otolith pair was prepared for section analysis. Each otolith was embedded in epoxy and transversely sectioned through the core with a slow speed, diamond-bladed saw. The section was mounted on a cut glass slide $(\sim 2.5 \mathrm{~cm}$ length $\mathrm{x} \sim 1$ cm width), ground to the core using 600 and 1200 grain sand paper on a Ecomet III Grinder, and polished with $9 \mu \mathrm{m}$ and $3 \mu \mathrm{m}$ lapping paper to remove pits and abrasions from the section surface. The section was cleaned of minute fragments by rinsing thoroughly with de-ionized water, sonicated in a $0.5 \%$ Micro $^{\mathrm{TM}}$ bath for $15-20 \mathrm{~min}$, rinsed again with Milli-Q water, and dried in a class 100 laminar flow hood before storage in clean bulk slide containers.

Individual Striped Bass otoliths were aged using light microscopy. To accurately estimate ages, otolith growth bands were counted during at least three separate readings. For Striped Bass, a translucent band and an opaque band together, hereafter referred to as a band pair, represent a year in age (Secor et al., 1994; Secor \& Picoli 1996). The opaque 
band was used for counts because of visibility and known representation of the winter months (Secor and Picoli 1996). Each reading consisted of counting band pairs from the core to the edge along the anterior margin of the sulcus groove. If band pairs were blurred from polishing in this area or due to some other defect, counts were taken from the core to edge along the posterior margin of the sulcus groove. Sample labels were hidden while counting avoid reader bias. In addition, images of five transverse sections were sent to experienced agers, Drs. Richard Kraus of George Mason University, Dave Secor and Lisa Kerr of Chesapeake Bay Laboratory, University of Maryland, to verify band pair counts as an additional quality control measure for the counting technique.

Fish were assigned the most common age if at least two reads were in agreement. For instance, if a fish was aged on Read 1 as 4+ years, Read 2 as 5+ years, and Read 3 as $5+$ years, than the assigned age for the fish was $5+$. If no ages were in agreement, a fourth reading was taken and the most common reading was assigned. All samples had agreement in at least two readings using this method. The precision of each reading was calculated by the average percentage error (Beamish \& Fourier 1981) and the coefficient of variation (Chang 1982) methods.

Otolith chemistry. Once prepared, otoliths were analyzed for otolith chemistry. Strontium isotope ratios were measured $\left({ }^{87} \mathrm{Sr} /{ }^{86} \mathrm{Sr}\right)$ using a Nu Plasma High Resolution Inductively Coupled Plasma mass spectrometer with a multi-collector (ICPMS -MC), based at UC-Davis. These isotopes were chosen because they are stable over time and the methodology to measure them has been well described. The ICPMS-MC was equipped with a New Wave Research UP-213 laser ablation system with an Nd:YAG 
deep UV (213 nm) laser (New Wave Research, Inc, Fremont, California). Analyses were sampled using a $60 \mu \mathrm{m}$ spot size, $80-100 \%$ laser power, and $10 \mathrm{~Hz}$ repetition rate. Two to six Volts for ${ }^{88} \mathrm{Sr}$ were obtained during the analyses. To maximize sensitivity and minimize sample deposition at the ablation site, helium gas was used a carrier for ablated material. Helium gas was also mixed with additional argon after the laser sample cell, prior to dispatching aerosols to the plasma source. Gas blank and background signals were monitored until ${ }^{84} \mathrm{Kr}$ and ${ }^{86} \mathrm{Kr}$ stabilized after the sample change for at least 30 seconds and were measured for 30 seconds. These gases were also measured for at least 30 minutes after opening of the chamber to retrieve or deploy samples. A reference material consisting of a section of homogenous marine coral $\left({ }^{87} \mathrm{Sr} /{ }^{86} \mathrm{Sr}=0.709188 \pm\right.$ 0.000016, $\mathrm{n}=196$ ), was sampled concurrently to estimate precision and monitor system performance.

Ablation time was 30 seconds for each sample. Background signals were subtracted from the measured signals automatically by machine software. The ${ }^{86} \mathrm{Sr} /{ }^{88} \mathrm{Sr}=$ 0.1194 was used to correct for instrumental fractionation in accordance with the exponential law. The ${ }^{85} \mathrm{Rb}$ peak was monitored to correct for any ${ }^{87} \mathrm{Rb}$ interference on ${ }^{87} \mathrm{Sr}$. If any interference was detected, the data collected was not used. The peak intensities for ${ }^{88} \mathrm{Sr},{ }^{87} \mathrm{Sr},{ }^{86} \mathrm{Sr},{ }^{85} \mathrm{Rb}$, and ${ }^{84} \mathrm{Sr}$ were measured simultaneously with this instrument and plotted over time using machine software. Data used in this study is the result of taking an integration of these plots to provide the ratio of ${ }^{87} \mathrm{Sr}$ to ${ }^{86} \mathrm{Sr}$ with its associated 2-sigma values (analogous to $95 \%$ confidence intervals for the ratio). These integrations also provided average strontium volts for the samples, which was used as an 
additional quality control. If strontium volts dipped below one strontium volt, the data were not used.

Transect lines of $60 \mu \mathrm{m}$ diameter spots at $60 \mu \mathrm{m}$ intervals were taken for each otolith from the core to the edge along the sulcus groove (Fig. 2).

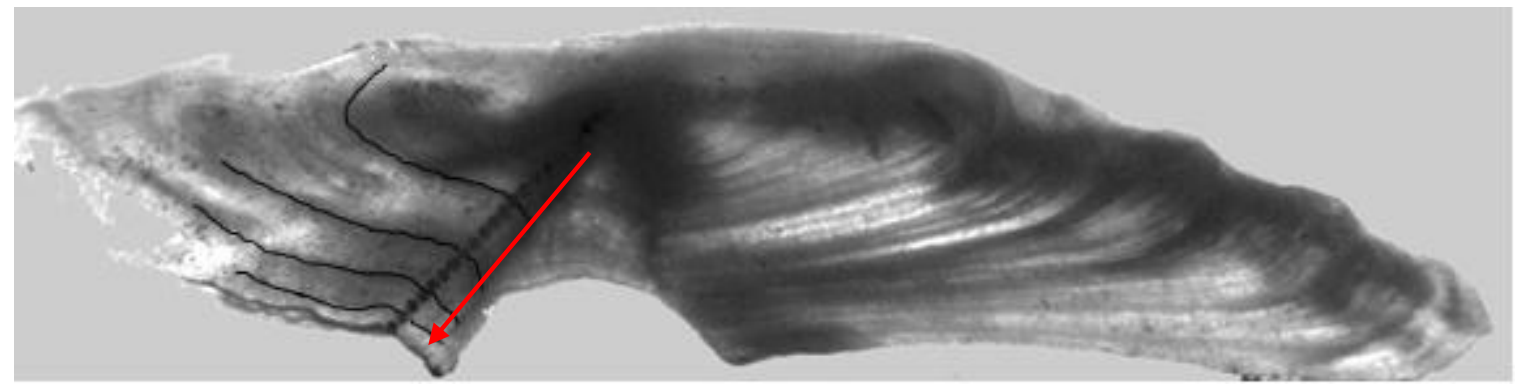

Figure 2: Transverse section of otolith. Strontium ratio measurements occurred at each spot in transect from core of otolith to the edge in direction of red arrow.Black lines emphasize the terminations of band pairs used to estimate age of the fish.

These spot sizes and intervals were chosen to provide a near continual representation of the strontium ratio while maintaining good signal integrity with at least one spot per annulus. Sharp changes in the strontium isotope ratio that were not sustained for more than one spot in a sequence were verified by sampling a $60 \mu \mathrm{m}$ diameter spot adjacent to the spot in question perpendicular to the transect line. Additionally, any spots that were disqualified due to low strontium volts or interference detected from $\mathrm{Kr}$ isotope intensities were re-sampled in the same manner.

Spots for each transect were then assigned to a specific annulus for each individual. This was done by observing transects under light microscopy. Each spot was assigned to a specific annulus for each fish, using the total age that had been assigned to that individual. If a spot partially overlapped two band pairs, it was assigned to the 
younger band pair. This only occurred four times. Spot assignment was done three times per transect for each individual. Spot assignments were finalized when two assignments were in agreement. All spots had agreement for assignments for at least two of the three trials. These spot assignments were then used to match up strontium ratio data with specific band pairs.

Habitat use estimation. Habitat use was inferred from strontium ratios.

Strontium ratios of water masses are tightly correlated with salinities in the San Francisco Estuary system (Fig. 3) (Ingram and Sloan 1992).

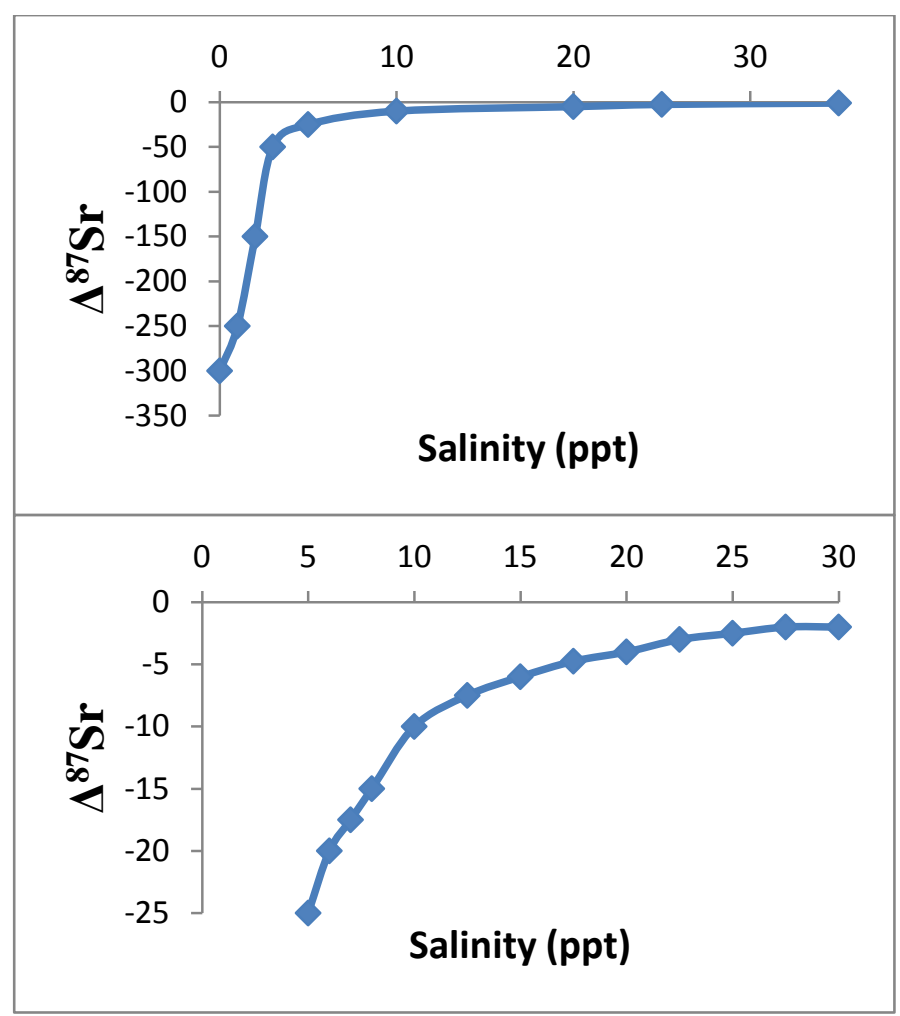

Figure 3: $\Delta$ Sr correlation with salinity in SFE (adapted from Ingram \& Sloan 1992). Fig A shows complete correlation for the whole SFE. Fig B shows the top portion of the correlation where salinity varies from 5 ppt to 32 ppt. 
It is known that chemistry of the water mass a fish encounters dominates all other sources of trace metals that accrete to otoliths (Walther \& Thorrold 2006), and once material is accreted to the otolith, it is not reabsorbed (Campana 1999). Due to the extraordinary sensitivity of the ICPMS to slight changes in the isotope ratio, detection of movements into the Delta east (upstream) of the Carquinez Bridge could be detected. Movements west of Carquinez Bridge could not be determined because the change in the ratio from San Francisco Bay waters to Pacific Ocean water was too small in relation to the inherent error in the measurements of the strontium ratios. Using this technique, the laser ablation allowed sampling that provided information on the water mass that a fish inhabited over a specific period in its lifespan. Periods of time less than a year were difficult to precisely demarcate, therefore all spots within a band pair had their strontium ratios and associated error averaged.

The strontium ratios for each band pair were converted to Delta strontium (referred hereafter as $\Delta \mathrm{Sr}$ ) to normalize the data. This was done using the following formula:

$$
\Delta S r=(0.7092-S r \text { ratio }) * 100,000
$$

Associate error for the strontium ratios for each band pair was converted to $\Delta \mathrm{Sr}$ format using the following formula:

Standard deviation of $\triangle S r=(0.7092-(0.7092-S D$ Sr ratio $)) * 100,000$

Habitation in different water masses in the SFE could be estimated based on $\Delta \mathrm{Sr}$ values. This is possible because these water masses have specific $\Delta \mathrm{Sr}$ tightly correlated with salinities (Table 1). 
Table 1: Water masses with associated salinities in wet and dry seasons and their respective mean strontium isotope ratios and $\Delta \mathrm{Sr}$ values.

\begin{tabular}{|c|c|c|c|c|}
\cline { 2 - 5 } \multicolumn{1}{c|}{} & \multicolumn{2}{c|}{ Salinity (ppt) } & \multicolumn{2}{c|}{ Mean Values of Sr } \\
\hline Water Mass & Wet & Dry & ${ }^{87} \mathbf{S r}:{ }^{\mathbf{8 6}} \mathbf{S r}$ & $\boldsymbol{\Delta} \mathbf{S r}$ \\
\hline Central Bay & 20 & 30 & 0.7092 & 0 \\
\hline San Pablo Bay & 13 & 24 & 0.7092 & 0 \\
\hline Carquinez Strait & 8 & 20 & 0.7091 & 10 \\
\hline Suisun Bay & 4 & 12 & 0.7088 & 40 \\
\hline West Delta & 1 & 5 & 0.708 & 120 \\
\hline Upper Delta & 0.2 & 2 & 0.707 & 220 \\
\hline Fresh Water & 0 & 0 & 0.7064 & 280 \\
\hline
\end{tabular}

Strontium is more abundant in saline waters, resulting in stronger signals during analyzation. However, as stated previously, $\Delta \mathrm{Sr}$ is more disparate in fresher waters. Therefore, fish habitation west of the Carquinez strait could not be differentiated, and estimates were more specific with proximity to SF Bay Delta fresh water sources.

Habitation for each individual for its entire lifespan was calculated by averaging $\Delta \mathrm{Sr}$ and $\mathrm{SD}$ of $\Delta \mathrm{Sr}$ of every band pair in its life. Assessing the variability of habitat use was calculated by taking the average $\Delta \mathrm{Sr}$ and dividing it by the average $\mathrm{SD}$ of $\Delta \mathrm{Sr}$.

Characterization of movements. The number of lifetime movements into and out of the SF Bay Delta were assessed by looking at the sequence of $\mathrm{Sr}$ ratio or $\Delta \mathrm{Sr}$ for each spot in otolith analysis. If an individual had a value which placed it in the Carquinez or Bay water mass $(>0.7090$ for $\mathrm{Sr}$ ratio, $<20$ for $\Delta \mathrm{Sr}$ ), when the previous spot was in more fresh water, it was deemed to have moved out of the SF Bay Delta. Conversely, if it an individual had a value that indicated habitation in a more fresh water 
mass $(<0.7090$ for $\mathrm{Sr}$ ratio, $>20$ for $\Delta \mathrm{Sr})$ when the previous spot was in more saline waters, it was deemed to have moved into the SF Bay Delta. The number of movements was totaled for each individual. If the catch location indicated that individual had moved over the Carquinez boundary from its last spot, one movement was added to this total. An example of this is provided in Fig. 4 for further clarification.

\section{Track of CC6226}

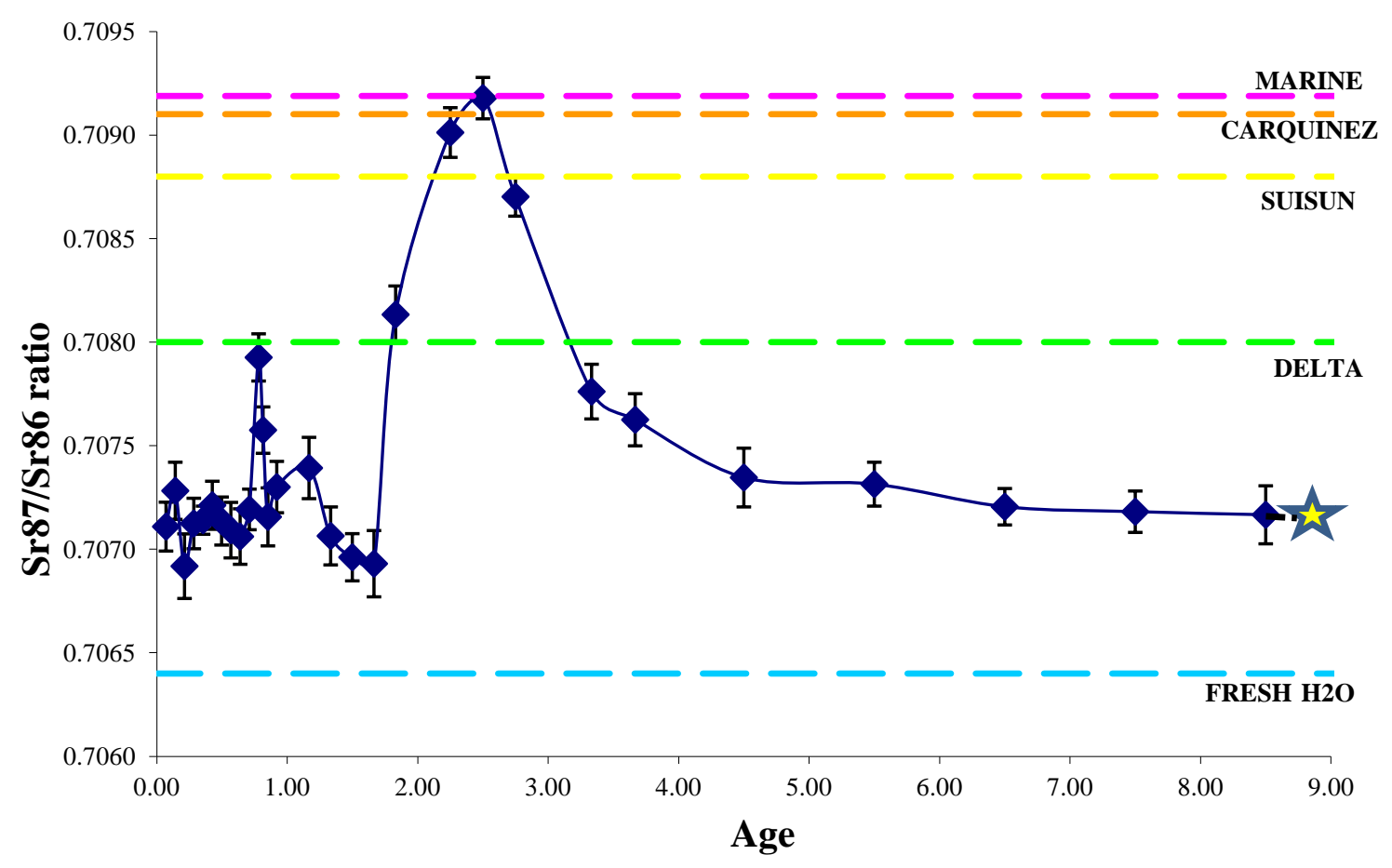

Figure 4: Strontium isotope ratio estimates of a $840 \mathrm{~mm}$ total length, 8 year old male caught in Clifton court.

Mean strontium isotope ratios are indicated by colored dotted lines. Black dashed line in track indicates hypothetical movement to capture location denoted by the star.

Individuals who had no movements across the Carquinez boundary throughout their life span were designated as estuary residents. Those that had at least one movement across the Carquinez boundary were designated as non-residents. Ratio of non-residents for 
each catch location was determined by dividing the number of non-residents by the total number of individuals caught at that location.

Statistical analyses. All factors in statistical analyses were assessed for normality in SYSTAT using the one sample Kolmogorov-Smirnov test for normal distributions. In the rare occasion where data were found to be non-normal, as in number of movements, the data in question was transformed by the base $10 \log$ of each data point and rechecked for normality again using the same Kolmogorov-Smirnov test. All factors were also checked for homoscedacity using the Bartlett and Leven test available under the equality of variances hypothesis testing option in SYSTAT. All factors used in an ANOVA passed for equal variances.

For purposes of many analyses, Striped Bass collected in the Delta were subdivided into four groups based on catch location: Knights Landing, Liberty Island, Clifton Court and Miscellaneous. Miscellaneous was used because there were several catch locations where three or fewer individuals were captured and all of these locations were in close proximity to one another in the mid-Delta. Striped Bass collected in San Francisco Bay and San Pablo Bay were compared to determine if differences were present in habitat use between catch locations and year of capture. An ANOVA showed that no differences existed between years collected (F-ratio $=0.347, \mathrm{df}=2, \mathrm{p}=0.709$ ) so fish from all years were pooled for each location. An ANOVA was performed to determine if there was a collection location effect. Associated pairwise comparisons showed that the South Bay fish were significantly different in habitat use than the rest of the fish caught in San Francisco and San Pablo Bay (F-ratio $=5.422$, df $=3, \mathrm{p}=0.003)$. 
They are referred to as "South Bay" fish. All other collection locations in the Bay (SF Waterfront, Berkeley, San Pablo Bay), were not significantly different from one another so they were pooled for further analyses as referred to herein as "North Bay" fish. "Other" fish designation refers to the fish caught within the Delta but not at the main collection sites (contains fish caught at Toe Drain, Rio Vista, Cache Slough, Miners Slough, and Consumnes River).

\section{Otolith Chemistry Results}

Age analysis of otoliths. Analysis of otolith ageing showed that most individuals sampled were relatively young. Average age of Striped Bass sampled was 4 years old with a standard deviation of 1.7 years. Out of the 115 individuals sampled, only 12 were greater than 5 years old, the oldest being a female of 16 years caught in Clifton Court. No gender data were available for several individuals (52 out of the 115 sampled), so no trend was seen in older individuals being male or female.

Virtually all reads were within 2 years of each other, with over $60 \%$ in complete agreement (Fig. 5). 


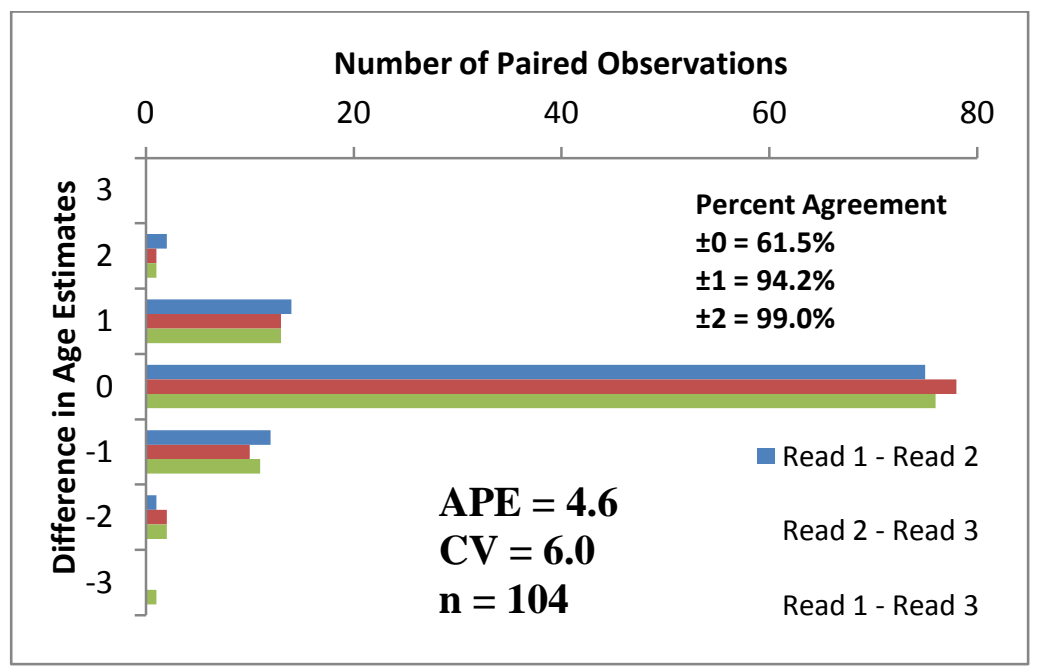

Figure 5: Difference in age estimates among 3 reads.

Average percent error was $4.6 \%$, meaning that reads of individuals on average were under one year $(4$ years x $0.046=0.186$ years $)$.

Additionally, there was no bias associated with any set of reads, as demonstrated in Fig. 6. 


\section{Age Class Read 3}

\begin{tabular}{|c|c|c|c|c|c|c|c|c|c|c|c|c|c|c|c|c|c|}
\hline & 0 & 1 & 2 & 3 & 4 & 5 & 6 & 7 & 8 & 9 & 10 & 11 & 12 & 13 & 14 & 15 & 16 \\
\hline 0 & & & & & & & & & & & & & & & & & \\
\hline 1 & & & & & & & & & & & & & & & & & \\
\hline 2 & & & 3 & & & & & & & & & & & & & & \\
\hline 3 & & & 1 & 31 & 8 & & & & & & & & & & & & \\
\hline 4 & & & & 8 & 28 & 4 & 1 & & & & & & & & & & \\
\hline 5 & & & & & 2 & 13 & 1 & & & & & & & & & & \\
\hline 6 & & & & 1 & 1 & & 5 & 1 & 1 & & & & & & & & \\
\hline 7 & & & & & & & 1 & & & & & & & & & & \\
\hline 8 & & & & & & & & & 3 & & & & & & & & \\
\hline 9 & & & & & & & & & & & & & & & & & \\
\hline 10 & & & & & & & & & 1 & & & & & & & & \\
\hline 11 & & & & & & & & & & & & & & & & & \\
\hline 12 & & & & & & & & & & & & & & & & & \\
\hline 13 & & & & & & & & & & & & & & & & & \\
\hline 14 & & & & & & & & & & & & & & & & & \\
\hline 15 & & & & & & & & & & & & & & & & & 1 \\
\hline 16 & & & & & & & & & & & & & & & & & \\
\hline
\end{tabular}

Figure 6: Comparison of age estimates for two reads. Yellow diagonal line indicates where reads would be in agreement.

There are an equal amount of discrepancies in reads on both sides of the 1:1 agreement line labeled in yellow, showing again that no bias among reads exist.

Fish movements. There was a wide variety of fish movements observed in strontium isotope ratio analysis. However, three general movement types were observed. The first type was when individuals left the Delta after the first year of life and did not return to fresh water at all or until just before capture. They made only one movement out of the Delta and, at most, one movement back into the Delta. An example of this type can be seen in Figure 4 above. This was the most common type observed, referred hereafter as a Type I non-resident, in a total of 44 individuals. 
The second most common type was similar to Type I non-residents, except they made more than one foray into and out of the Delta (Fig. 7).

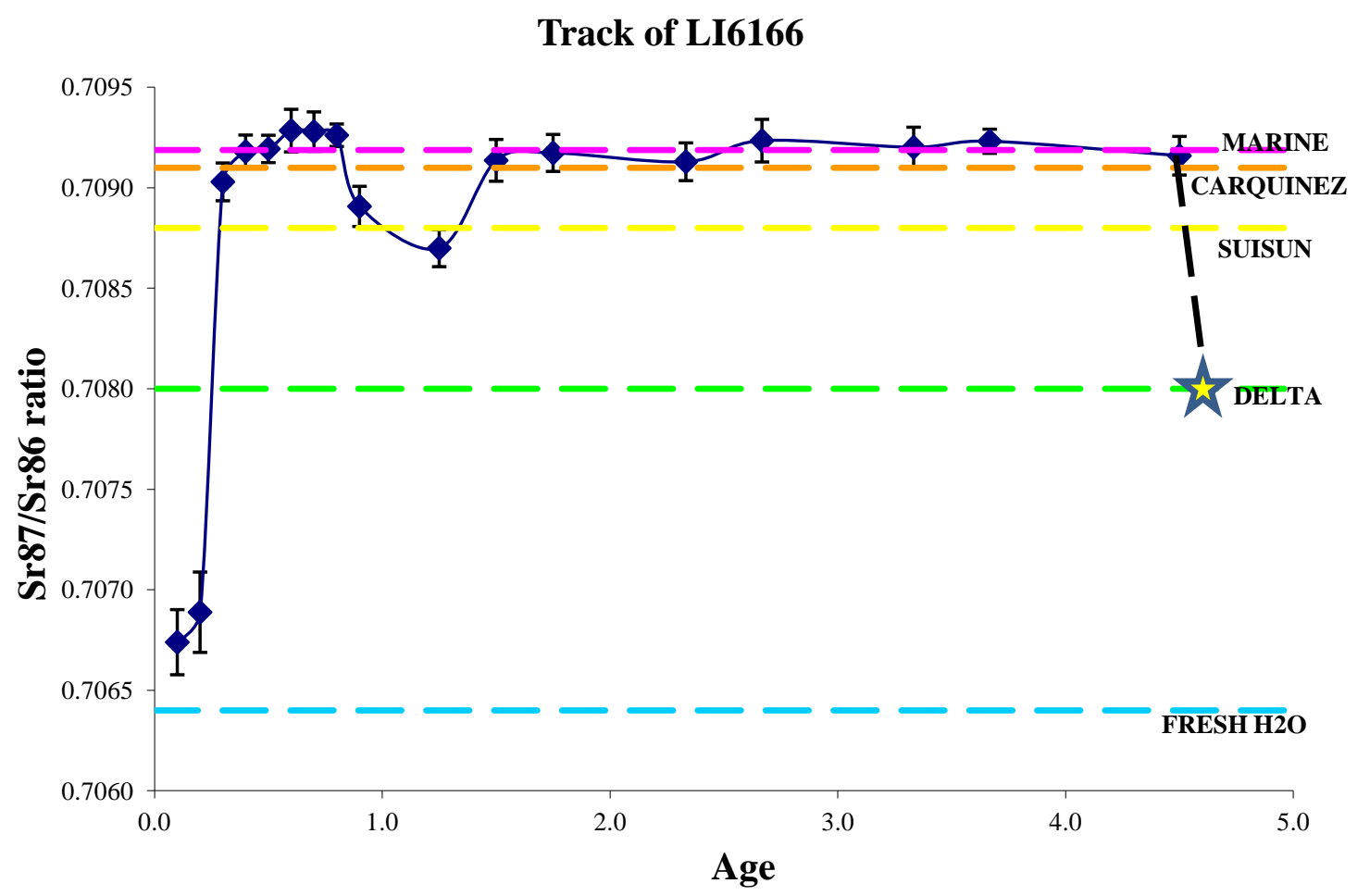

Figure 7: Strontium isotope ratio estimates of a $535 \mathrm{~mm}$ total length, 4 year old female caught at Liberty Island. Mean ratios for water bodies are indicated by colored dotted lines. Black dashed line in track indicates hypothetical movement to capture location.

Individuals exhibiting this type of movement, hereafter referred to as Type II nonresidents, used saline habitats more than once in their lifetime, meaning they entered the Delta at least twice before they were caught. Thirty-eight individuals exhibited this movement pattern.

Otolith chemistry analysis was also able to show that a third type of movement, known hereafter as estuary residents, existed in each location sampled. Estuary resident habitat use tracks were distinct in that they never showed a Sr ratio signal throughout their 
lifetime that would occur outside of Delta waters. A typical track for an estuary resident is shown in Fig. 8.

\section{Track of CC6177}

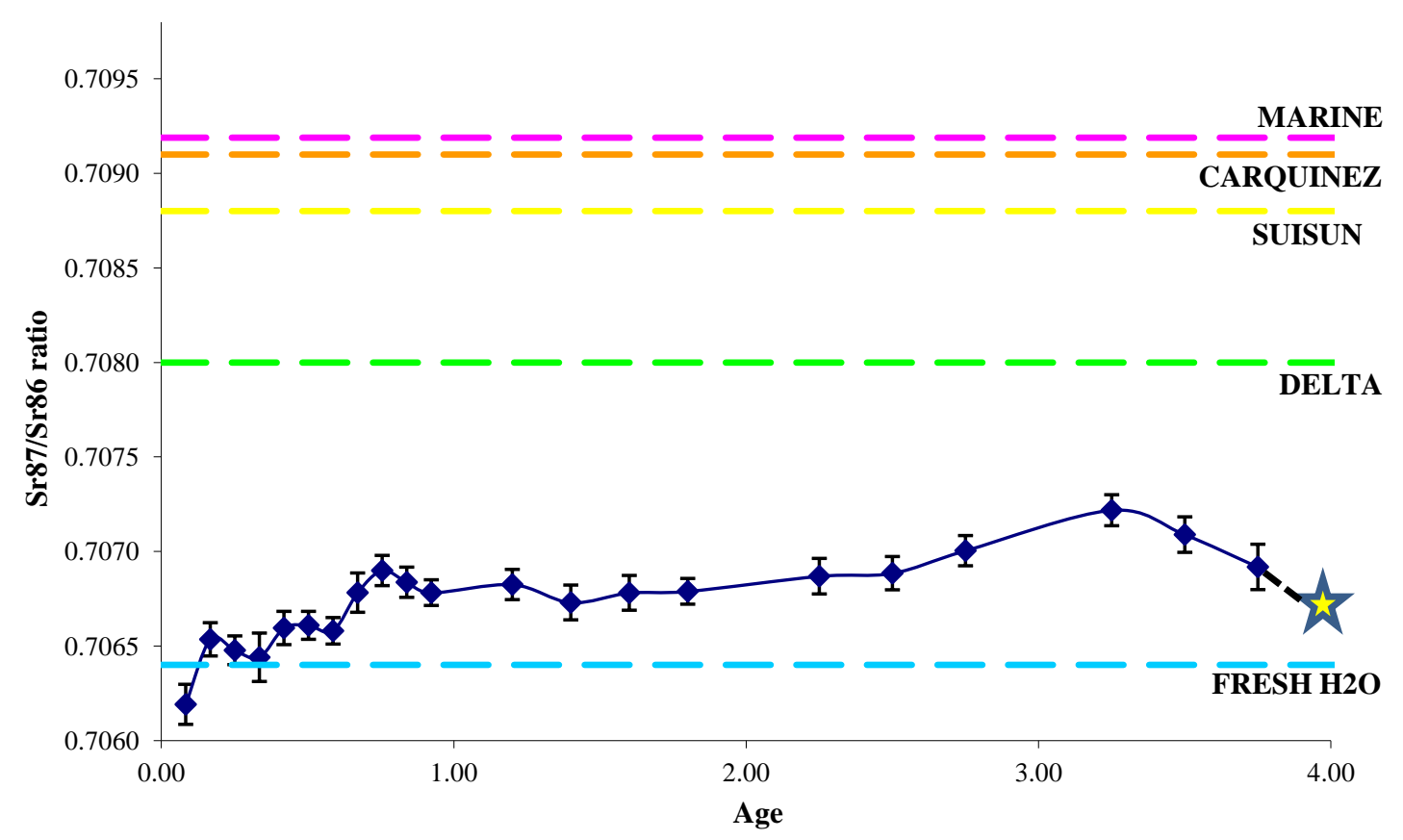

Figure 8: Strontium isotope ratio track of a $497 \mathrm{~mm}$ total length Striped Bass of undetermined sex caught in Clifton Court. Colored dotted lines indicate mean strontium isotope values for each water body in the SFE. Black dashed line indicates hypothesized movement to catch location.

Thirty-one individuals exhibited this movement pattern.

All of these movement patterns were well represented in just about every catch location. Type I and Type II non-residents were seen most often in North Bay Catch locations, but were also observed in every catch location in the Delta (Table 2). 
Table 2: Numbers of individuals for each type of movment pattern by catch location with total sample sizes for each catch location. Location codes are as follows: $\mathrm{CC}=$ Clifton Court, $\mathrm{KL}=\mathrm{Knights}$ Landing, $\mathrm{LI}=\mathrm{Liberty}$ Island, NBAY= North Bay, SBAY = South Bay, CBAY = Central Bay.

\begin{tabular}{rccccc}
\multicolumn{5}{c}{ Non-Resident } & \\
Catch Location & Type I & Type II & Resident & $\underline{\mathbf{n}}$ \\
\cline { 3 - 6 } CC & 4 & 1 & 15 & 20 \\
KL & 5 & 3 & 8 & 16 \\
LI & 5 & 10 & 6 & 21 \\
Other & 2 & 4 & 2 & 8 \\
& & & & \\
NBAY & 24 & 18 & 0 & 42 \\
SBAY & 4 & 1 & 0 & 5 \\
CBAY & 0 & 1 & 0 & 1
\end{tabular}

Only two individuals examined did not fit into the three types of movement above. Both of these indivduals were caught in San Pablo Bay and exhibited no evidence of fresh water habitation.

The ratio of estuary residents to non-residents differed among catch locations. According to proportion, most estuary residents existed in the Clifton Court catch group, where the least amount were in the SF Bay samples (Fig. 9). 


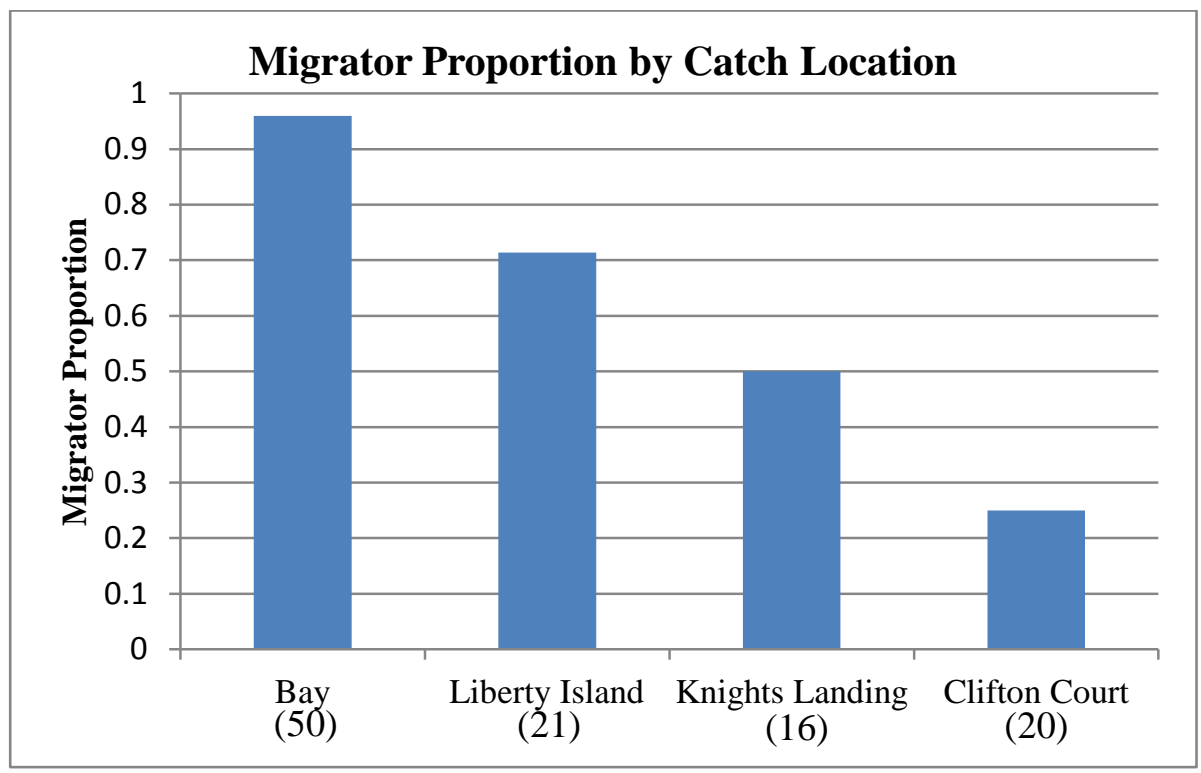

Figure 9: Graph of proportion of non-residents for each major catch location (bay locations have been grouped here). The numbers in parantheses indicate the total number of fish caught at those locations.

There was a significant difference in $\Delta \mathrm{Sr}$ among estuary residents and non-residents $(\mathrm{T}$ value $=12.847, \mathrm{df}=111, \mathrm{p}=0.000)$, although some overlap does exist.

There was no indication that ages differed between estuary residents and nonresident groups. Comparison of average ages showed that they were virtually identical (Fig. 10). 


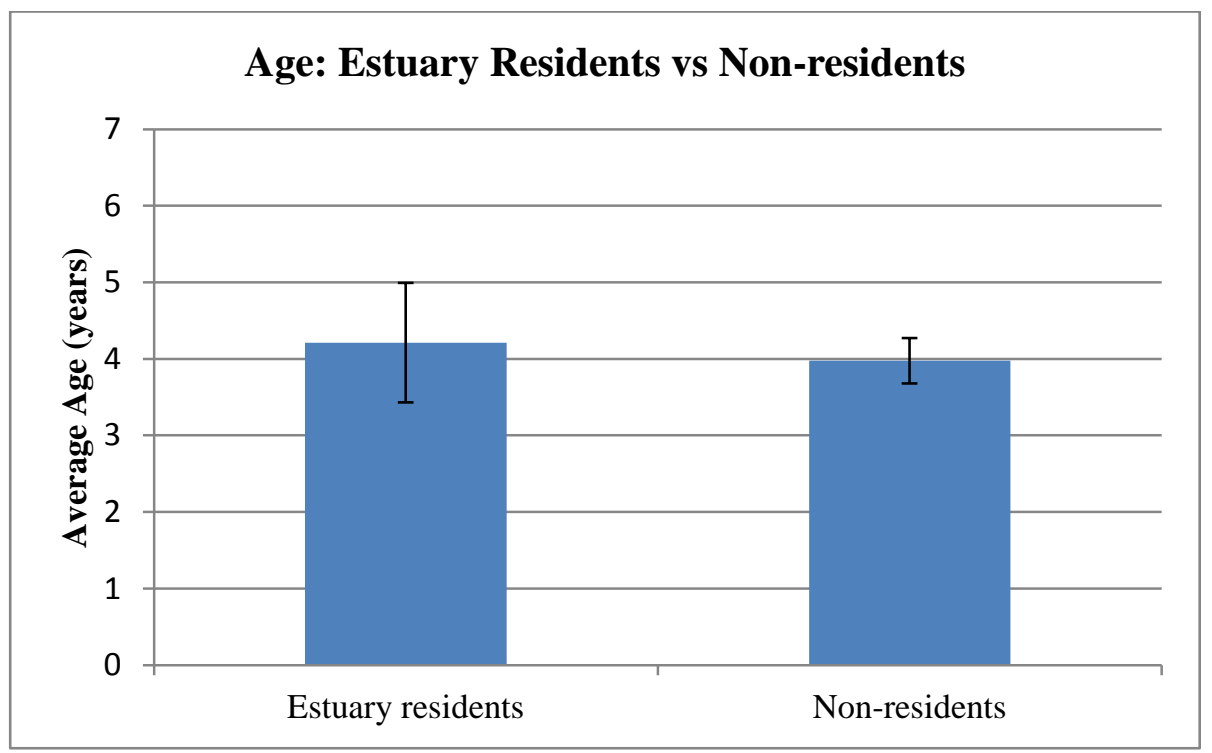

Figure 10: Average age of estaury residents and non-residents. Error bars indicate $95 \%$ confidence intervals.

Habitat use by non-residents. Movement behavior differed in timing (age at movement across the Carquinez boundary) and number of movements into and out of the San Francisco Estuary system. As stated previously, this occurred in two movement types (Figs. 6, 7). The average number of movements for non-residents was $2.6 \pm 1.7$, but the maximum number of movements seen was nine. Although multiple movements were not uncommon, annual movements upon reaching age of maturity were rare.

There was no evidence of annual migratory behavior. The number of movements over a lifespan was compared among age groups, and there was no significant difference $(\mathrm{F}-$ ratio $=1.705, \mathrm{df}=6, \mathrm{p}=0.132)$. Power was deemed sufficient for the majority of age groups sampled (power $=0.8$ at 5 samples per age groups; average samples per age groups $=35)$.

Habitat use was examined among age classes among migrants $(0+$ though $8+)$. An ANOVA found that the first two years of life were significantly different than the rest 
from individuals sampled $(\mathrm{p}$-values $=0.000-0.007$ for age $0+$ and $1+$ compared to ages $2+-8+)$. Age classes $2+$ through $8+$ were indistinguishable with regards to habitat use in migrants $(\mathrm{F}$-ratio $=0.265, \mathrm{df}=6, \mathrm{p}=0.951)$, showing that there was no effect on habitat use due to age of the individual.

Additionally, otolith chemistry ofnon-resident Striped Bass was analyzed to determine if there was any difference in habitat use between catch groups. The ANOVA post-hoc tests indicated that were not significant differences in $\Delta \mathrm{Sr}$ among catch groups in the Delta, but North Bay fish and South Bay fish had significantly different habitat use from the Knights Landing catch group and the Liberty Island Catch group respectively (Fig. 11).

\begin{tabular}{|c|c|c|c|c|c|c|c|}
\hline & NB & SB & u & KL & $\mathrm{CC}$ & Other & Location Codes: \\
\hline NB & & & & & & & NB $=$ North Bay \\
\hline SB & 0.01 & & & & & & SB = South Bay \\
\hline LI & 0.99 & 0.05 & & & & & LI = Liberty Island \\
\hline $\mathrm{KL}$ & 0.05 & 0.93 & 0.25 & & & & $\mathrm{KL}=$ Knights Landing \\
\hline CC & 0.42 & 0.82 & 0.71 & 1.00 & & & Other $=$ all other fish \\
\hline Other & 0.53 & 0.64 & 0.83 & 0.98 & 1.00 & & caught in Delta \\
\hline
\end{tabular}

Figure 11: Comparison of p-values amongst catch locations. Numbers in red indicate significant differences.

North Bay and South Bay fish were also significantly different from one another, where the South Bay fish used more saline environments over their lifetime demonstrated by the higher average $\Delta \mathrm{Sr}$ for South Bay fish $(\mathrm{p}=0.000)$. Additionally, the $\Delta \mathrm{Sr}$ value for the one individual caught in the central bay was compared with catch groups from the Delta, Bay and South Bay catch groups. The single fish caught in the central bay was 
found to have a significantly different $\Delta \mathrm{Sr}$ than all other catch group distributions, where the Central Bay individual used more saline waters than the other two groups over its lifetime indicated by the significant result from one sample t-tests comparing the $\Delta \mathrm{Sr}$ of the Central Bay caught fish against the other two Bay groups $(\mathrm{p}=0.008)$.

Differences in habitat use were examined among the sexes using a t-test on average $\Delta \mathrm{Sr}$ values. Males on average used fresher water than females and there was a significant difference in the two sample t-test for means of $\Delta \mathrm{Sr}$ amongst sexes, where females tended to inhabit more saline waters $(\mathrm{p}=0.002)$.

\section{Otolith Chemistry Discussion}

When comparing results of this study with studies using similar methodology on east coast Striped Bass populations, the data shows that there is a great deal of individual variability in habitat use and movements of Striped Bass in the Sacramento Estuary system. However, this study was able to detect differences in habitat use due to gender. On the East coast, researchers were able to detect differences in movements among sexes, where females were inhabiting increasingly saline waters as they grow older and larger (Secor and Picoli 1996). We detected a similar trend, where females tended to stay closer to the Bay than males among migrants that are mature enough to spawn. But, we did not have enough samples of older ages to determine if this effect increased with age. Previous work on Striped Bass in the spawning grounds in the Delta (Ostrach et al., 2009) has indicated that older females show no preference for more saline waters throughout their life. It could be argued, although sample sizes were small in that study 
as well, that this previous finding may represent how non-resident females are using the Delta more accurately. However, more samples are needed to defend this reasoning.

The data also show that at least three contingents, or groups displaying similar movements and habitat use, may exist. There is a definite difference between habitat use of South Bay fish and North Bay fish, with a possible third contingent in the Central Bay. But, all of these contingents are using the Delta in their movements and it is unclear exactly where these contingents go when moving into fresher waters. It is likely they are mixing while in the Delta, as shown by the very high p-values among most post-hoc pairwise comparisons with Bay caught fish and many of the Delta-caught fish. However, there is some evidence that the North Bay and South Bay contingents have some fidelity within in the Delta as both were significantly different with habitat use of fish in one Delta location. North Bay fish habitat use was significantly different from fish caught in Knights Landing, as did South Bay fish with Liberty Island caught fish. These results suggest that these groups do not use those areas, or at the very least utilize the fresh water areas very differently. How much fidelity exists within these groups is unclear, so it is possible that there is some mixing in areas in brackish waters where isoptopic signatures are more variable. The data do not give an indication of how far these contingents may disperse in the Delta or overlap with one another, and no known genetic data on groups of Striped Bass in the SFE. More definitive conclusions on this matter from the data presented here again could be hampered again by sample size, or that fine movements of fish cannot be evaluated with the methodology used in this thesis. However, since a similar number of fish were sampled in an east coast study examining movements of 
Striped Bass (Secor and Picoli 1996), it suggests that more variability exists in the Sacramento Estuary system than seen on the east coast.

The results indicating that more habitat use complexity exists in San Francisco Estuary Striped Bass than in east coast populations has been suggested before and this study corroborates earlier findings. Radovich 1963 showed that Striped Bass tend to have more irregular movements than East coast Striped Bass, possibly due to the influence of more irregular temperature ocean changes than seen in the East coast. However, we did see some differences in Striped Bass movements than observed in previous studies in the San Francisco Estuary system. There was not a strong inclination for annual movements among the majority of individuals in the population, even when only looking at fish caught in the Bay. Annual movements were the exception rather than the rule. Instead, many partial movements were seen, where individuals would move to the lower Delta some years instead of into San Francisco Bay and oceanic waters. Perhaps more variation in water temperatures, fresh water flows are to blame, which theoretically could be affected by more variable winters, rainfall, and even water diversion practices. More information is needed to investigate the influence of Striped Bass movements from these factors.

The data collected in this study clearly do show that residents exist in the Delta region of the San Francisco estuary (East/upstream of Carquinez strait). Presence of residents is a well known phenomenon in East coast populations of Striped Bass, where resident contingents were detected in Hudson River, NY (Secor et al., 1994), St. Johns River, FL (Barkuloo 1970), Savannah River, GA (Dudley et al., 1977), and Cooper River, 
SC (Scruggs and Fuller 1955; Scruggs 1957). However, with the exception of recent studies studies (Ostrach et al., 2006; Ostrach et al., 2007; Ostrach et al., 2009), no studies conducted in the San Francisco Estuary discuss the presence of estuary resident subpopulations. This study found estuary resident subgroups of the population in every location sampled, and there was a trend in the proportion of estuary residents increasing with distance from the outlet of the Delta into the San Francisco Bay, or in locations where strong flows induced from man-made structures were present (Clifton Court and the Toe Drain in the upper Sacramento Delta).

Previous studies that attempt to elucidate the reasons for Striped Bass movements center on three possibilities: temperature cues, fresh water flows, and food availability. Radovich (1963) thought that a drop in oceanic temperatures from the norm represented a barrier to migration, causing Striped Bass to stay closer to brackish waters. Turner and Chadwick (1972), Chadwick (1967), and Turner (1976) argue that movement within the Delta is driven by the fresh water flows dominated by the Sacramento River, where more movement was seen in lower flow years. Orsi (1971) proposed that reduced migrations to oceanic waters were due to decreases in herring abundance in the late 1960s. These factors are interrelated, as it has been discussed in great detail that food availability in Suisun Bay and the upper Delta are greatly affected by fresh water flows and salt water intrusion into the Delta (Callahan et al., 1982).

It is outside the scope of this study to definitively determine why the type and variety of movement patterns are occurring in the San Francisco Estuary system . But, some factors that may influence these movements have more support from evidence than 
others. The vast majority of Striped Bass collected in the study lived their entire lives during relatively low flow years as compared to high flow years that occurred prior to the beginning of state and federal management of Delta outflows in the 1960s and 70s, so it is not possible to compare annual movements of Striped Bass under different flow regimes in this study. Striped Bass are also generalist and opportunistic feeders exploiting the entire San Francisco estuary system therefore it is difficult to assess annual food availability over the study period. However, it is an interesting and potentially important finding that the ratio of residents increased in areas where flows are more directed, especially in areas where they are drastically controlled by man-made structures likely due to the entrapment of high concentrations of prey and their availability near the structures.

The highest ratio of estuarine residents to non-residents observed in this study was at the Clifton Court Forebay, which may be due to food concentration at that site. This area is somewhat like a shallow lake, and serves as the inlet to pumping activities for the California Aqueduct system. It is likely that fish in this area do not need to venture far afield to feed due to pumping activities that are known to bring vast quantities of prey for Striped Bass directly to the inlet of Clifton Court Forebay. It is well known that pumping activity leads to entrainment of the pelagic fish that live in the SFE such as: Delta Smelt (Hypomesus transpacificus); Threadfin Shad (Dorosoma petenense); Longfin Smelt (Spirinchus thaleichthys); salmonids (Onchorhynchus tshawytscha, Onchorynchus mykiss) as well as juvenile Striped Bass and Striped Bass eggs and Striped Bass larvae (Stevens et al., 1985; CDFG 1987; Jassby et al., 1995). It was found that dissolved 
oxygen content and temperatures did not affect movements as much as State Water Project operations (Bolster 1986). Furthermore, Striped Bass tend to be concentrated near the intake gates (Bolster 1986) where food is most abundant in the area. This might also be the reason that estuary resident to non-resident ratio increases with distance from the San Francisco Bay, as lower volume flows upriver might enhance concentration of food in some areas of the upper Delta and Sacramento River. This is an issue that should be explored if Striped Bass are sampled in the future as it could provide a better understanding of Striped Bass habitat utilization and lack of annual movements.

Effects of temperature and salinity appear to have weaker influence over Striped Bass movements. The isohaline that occurs near the mouth of the Delta may accumulate planktonic food for juvenile Striped Bass, but there seemed to be no long term residency of adults in this area. Likewise, movements of Striped Bass did not seem tied to temperature fluctuations from fresh water flows. Freshwater flows were low throughout the lives of all individuals collected, yet movements into and out of the Delta were highly variable depending on the individual. Though temperature and salinity may be able to explain some nuances in movements of a few individuals, they appear as weak predictors of Striped Bass movements when looking at the entire population.

It is also unlikely that genetic predisposition is a factor in determining movements of Striped Bass. Although there was no genetic analysis in this study, it is well known that all Striped Bass on the west coast are descended from no more than 450 individuals (Raney et al., 1952). This genetic bottleneck occurred just over 100 years ago, hypothetically resulting in a fairly gentically homogenous Striped Bass population in the 
SFE today. And given the great overlap of movements within the SFE shown in this study, it would be surprising that enough genetic isolation exists for a genetic predispostion to have formed over so short a time period.

The data provided by this study on Striped Bass movements do have implications for management of Striped Bass in the Sacramento Delta. Most Striped Bass adult population estimates have relied upon the Petersen method, where fish are tagged and population estimates are based upon the proportion of tagged fish that are recaptured. One of the assumptions in this methodology is that all fish have the same chance of being recaptured. This study clearly shows that estuary resident and non-resident fish exist together at all locations in the Delta at times of sampling for these estimates, so it is likely that individuals from both groups could be tagged. This is a violation of an assumption in the Peterson estimates which assume no immigration or emigration of individuals from the population. Tagged estuary residents likely have a higher chance of being recaptured the subsequent year than tagged non-residents. And since some non-residents are moving more than others and differentially using the Delta, and females are usually in more saline waters than males, it furthers complicates estimates based on this method due to a potentially serious nonrandom sampling bias. If certain individuals are being overrepresented due to unequal catchability, especially if some individuals have almost no chance of being caught upon recapture if they are not present during the recapture portion of a census (Seber 1970).

Future population estimates, based on tag recapture of adults, should use open population estimation techniques that would avoid violations of immigration and 
emigration assumptions in Petersen estimates. If Petersen estimates must be used, sampling effort should be focused in areas where non-residents and residents are equally mixed (Liberty Island) to limit bias. Additionally, since this study presents convincing evidence that more than one contingent of spawning adults exist, further studies should evaluate the size of these contingents and their contribution to the overall reproductive success of spawning runs. If a bias exists in sampling mature residents or a particular spawning contingent, it could bias population estimates and/or estimates of other important life history parameters like fecundity. 


\section{Chapter 2: Tissue Chemistry}

Striped Bass spend their entire lives in estuarine and nearshore environments encountering concentrated contaminants due to their proximity to anthropogenic pollution sources. Several studies have shown that these contaminants affect Striped Bass populations (Thompson et al., 2007; Bielmeyer et al., 2006; Brim et al., 2001; Winger et al., 2000; Wang 1998; Bennett et al., 1995; Mehrle et al., 1987; Polgar et al., 1985), particularly mercury (Hg) contamination (Davis et al., 2000). In the San Francisco Estuary, there is evidence that these contaminants have contributed in the reduction of the Striped Bass population over the past decade (Spearow et al., 2011; Ostrach et al., 2009; Ostrach et al., 2008; Ostrach 2006). Additionally, recent studies in San Francisco Bay reveal that mercury content in Striped Bass is above screening limits (Greenfield et al., 2005), values that serve as benchmarks of tissue concentrations that would be of potential health concern for human consumption. Furthermore, the level of mercury in the Striped Bass population here does not appear to be decreasing in the population with time (Thompson et al., 2000). This has prompted the California State Office of Environmental Health Hazard (OEHHA) to consider mercury in Striped Bass to be a considerable public health threat (OEHHA 1997), and California Department of Fish and Game strongly suggests limiting consumption of Striped Bass to no more than twice a month and no consumption of Striped Bass greater than 27 inches in length (CDFG 2006). There is evidence in the literature (Leppard 1983) that the presence of one high concentration of a metal can be indicative of dangerous levels of other heavy metals in fish populations though many of these metals have been tested for infrequently. 
Metals affect human health as determined by a host of factors besides concentration. Some metals, like aluminum, silver, cadmium, mercury and lead, are not required for normal metabolism. These metals, known as non-essential or toxic metals, affect health negatively with increasing doses or if the doses occur over long periods of time. However, many trace metals are needed for normal metabolism, like arsenic, copper, manganese, nickel, selenium and zinc. These metals are known as essential metals and are often found in trace quantities in the environment. Although needed for bodily processes, high doses of these metals are toxic (Sasso et al., 2010; Robson 2003). Other factors that can affect toxicity of a metal are the size of the individual, the exposure time and dose, the valence state of the element, immune status of the individual, gender, and age. Typically the elderly, the young, and pregnant women are most at risk.

At toxic levels, metal poisoning can lead to a host of frightening effects on humans. These chemicals can cause a host of respiratory and neurological problems, disrupt the endocrine system, affect the kidneys, impair senses and speech, and lead to problems in coordination and muscle weakness in adults as well as impair neurological development of children, infants, and fetuses (ATSDR 1999). The Environmental Protection Agency (EPA) has derived screening levels (SLs) for fish populations to help managers better estimate potential health risks to populations (EPA 2000). But concentrations of these metals, with the exception of mercury, have been infrequently studied in the literature for Striped Bass, especially in the San Francisco Bay-Sacramento Delta. 
Because of the impact of mercury on the local ecosystem, many researchers have sought to determine the origin of mercury contamination. Mercury enters the Bay and Delta environment from two main sources, primarily sediment runoff from obsolete mining operations for gold and mercury operated during the Gold Rush era in California (Domalgalski 2001, Alpers \& Hunerlach 2000) and, to a lesser extent, atmospheric deposition (Rolfhus \& Fitzgerald 1995; Mason et al., 1994). Although it usually enters the Bay-Delta system in elemental form, most mercury is only biologically available as methylmercury (MeHg) (Wiener and Spry 1996). Methylmercury is a product of complex processes performed by sulfate-reducing bacteria in anoxic sediments that transform inorganic mercury $\left(\mathrm{Hg}_{0}, \mathrm{Hg}^{+}, \mathrm{Hg}^{2+} \mathrm{Hg}_{\mathrm{I}}, \mathrm{Hg}_{\mathrm{II}}\right)$ to the organic form $(\mathrm{MeHg})$ (Benoit et al., 2003), by a process called methylation.

Methylation is strongly controlled by $\mathrm{pH}$ and the availability of the dissolved organic carbon (DOC) (Snodgrass et al., 2000). High rates of methylation occur when $\mathrm{pH}$ is low and the level of DOC is high (Snodgrass et al., 2000). However, ultraviolet light, if present, can break down MeHg to biologically unavailable inorganic forms (Byington 2007; Snodgrass et al., 2000), reducing MeHg concentrations. Therefore, methylmercury is a problem only in environments where the rate of methylation is greater than the conversion of methylmercury to its inorganic relatives (Benoit et al., 2003; Gilmour et al., 1992). In the San Francisco Bay Estuary, particularly in the Delta region, $\mathrm{pH}$ is low and abundant $\mathrm{DOC}$ is present in wetlands. Additionally, high turbidity limits penetration of ultraviolet light in these areas, causing these wetlands to have very high methylation rates (Byington 2007; Domalgalski 2001; Marvin-DiPasquale \& Agee 
2000; Korthals \& Winfrey 1987). Additionally, these areas are where Striped Bass spend the majority of their lives, particularly as juveniles (Stevens et al., 1985; Feyrer et al., 2007).

Fish are exposed to mercury and other heavy metals primarily through their diet rather than absorption through respiration or external tissues (Hudson et al., 1994) and accumulate the contaminant through a process called "biomagnification". Methylmercury and other contaminants are concentrated at higher trophic levels due to repeated ingestion of contaminants in prey items. These contaminants are also difficult to be removed once ingested. This can result in much greater than ambient contaminant concentrations in species at higher trophic levels (Suedel et al., 1994). Many contaminants are lipophilic, which concentrates them in the muscle and fatty tissue of the fish, often found in the portion eaten by humans. Because of this, their concentrations are not affected by filleting or cooking the meat (EPA 2001; Bloom 1992) and often there are no visual cues that can warn consumers of fish with high concentrations, especially with mercury which is invisible at toxic levels.

There have been some significant health epidemics due to high metal concentrations. Itai-Itai disease, a painful affliction due to consuming high levels of cadmium, occurred in the Jintsu river basin from eating contaminated water and rice (Yamagata 1973). In Minamata Bay, Japan, it was found that dumping of mercury was the cause for 2,200 cases of poisoning in over a 30 year period, resulting in more than 40 deaths (Katsuna 1968). The cause of this outbreak was from eating fish with high levels of methyl-mercury due to the dumping. It took several years of research to determine the 
cause of the outbreak, initially thought to be a contagious form of cerebral palsy (Katsuna 1968).

Since contaminated fish are difficult to detect, and toxicological tests of every fish caught for consumption is untenable due to both cost and manpower, regulatory bodies have relied upon what is known of biomagnifications to provide advisories to protect the public. In theory, larger older fish have had more time to accumulate mercury and other toxins than smaller younger ones, so larger older individuals should be more dangerous to consume. Mercury contamination levels in Striped Bass in the San Francisco Bay and Delta region (Fig. 12) increase with age.
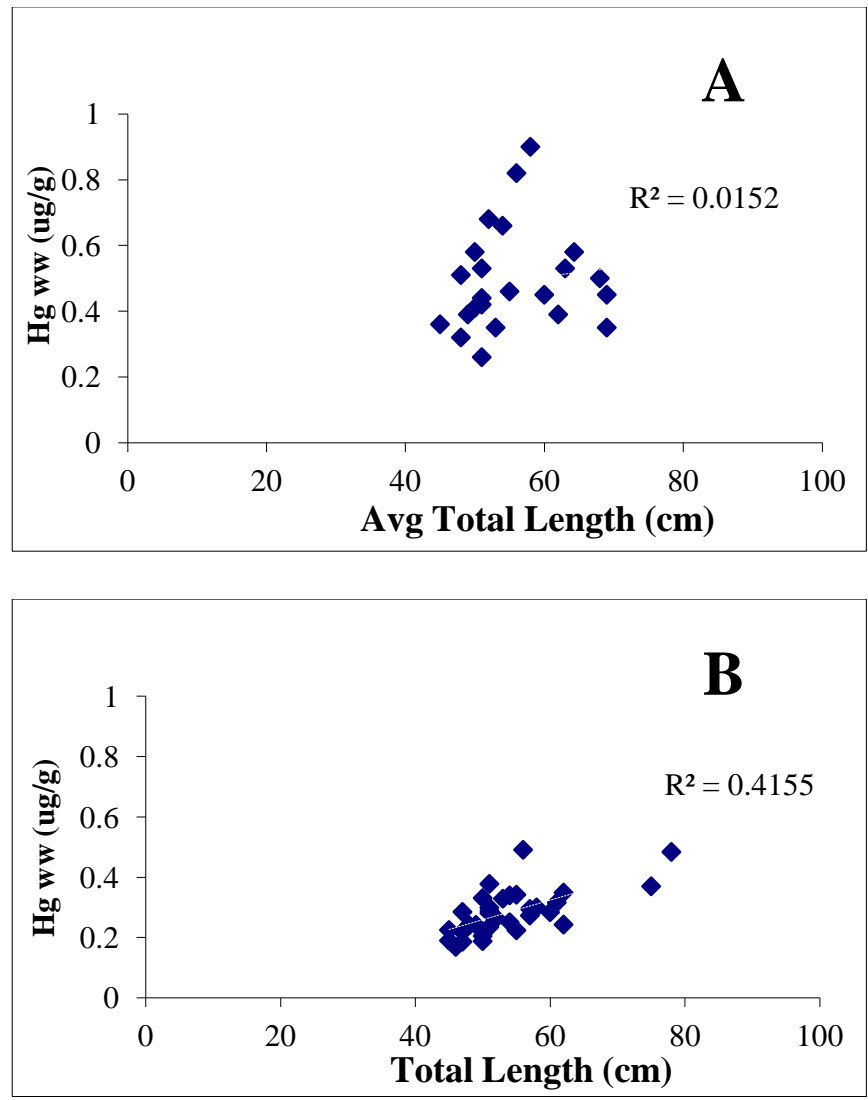

Figure 12: Two regressions of size $(\mathrm{TL}=$ total length $)$ by mercury content by years of sampling $(A=1997, B=$ 2000). 
However, the relationship is between age and mercury concentration in muscle tissue is not a strong one. Additionally, mercury content in Striped Bass varies annually (Greenfield et al., 2005). This has led researchers to hypothesize what other factors could be affecting levels of contaminants in Striped Bass.

Striped Bass are ingesting contaminants and significant research in the last decade has been dedicated to determining where Striped Bass and other sport fish are acquiring mercury contamination from point sources in the Delta and San Francisco Bay, as methylation is thought to be localized (Snodgrass et al., 2000). Since Striped Bass are anadromous and are known to exploit the entire SFE ecosystem, researchers have sought to trace their movements relative to known point sources of mercury contamination (Davis et al., 2002).

Habitat use has already discussed in detail the problems associated with validating movements of Striped Bass. Data collected by this thesis project were able to show movement pattern in the Striped Bass population in the SFE. In addition to evaluating metal concentrations in Striped Bass fillets, this chapter uses otolith chemistry data to determine if there are relationships in movements with levels of mercury and other metals.

\section{Tissue Chemistry Methods}

Sample collection. As stated in chapter one of this thesis, Striped Bass were collected in 2000, 2003, and 2006 by California Fish and Game as part of the Fish Mercury Project (FMP) and Regional Monitoring Project (RMP) funded by the San Francisco Estuary Institute (SFEI). They were collected in the South Bay, Central Bay 
(adjacent to Berkeley, California), San Pablo Bay, Suisun Bay, Sacramento Delta and the Sacramento River locations (Fig. 13).

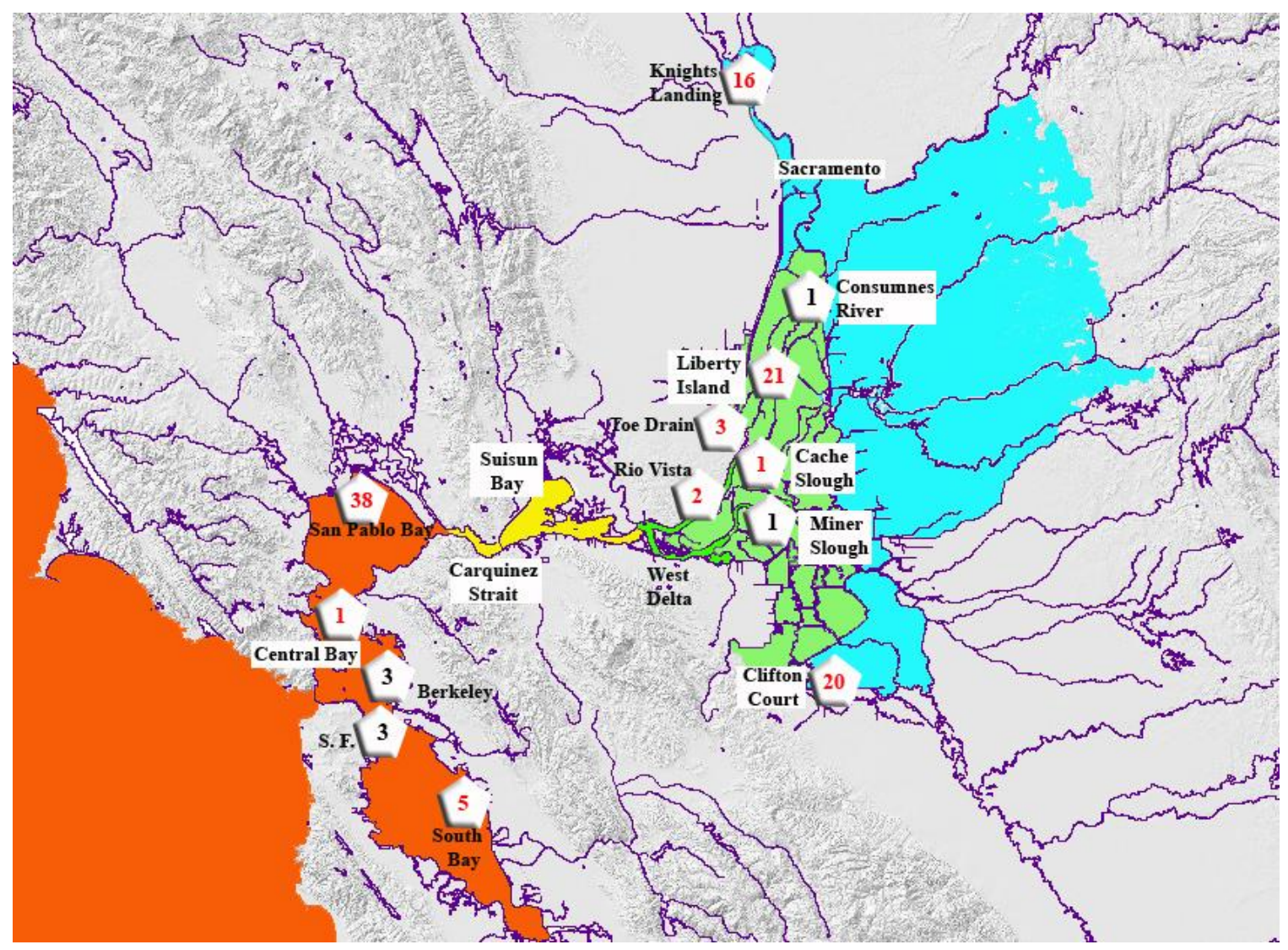

Figure 13: Map of sample locations. Numbers in hexagons represent total individuals from locations. Red numbers depict locations where at least most samples collected were analyzed for all metals examined. Colors of water bodies also indicate salinity (orange $=13-32 \mathrm{ppt}$, yellow $=4-12 \mathrm{ppt}$, green $=1-5 \mathrm{ppt}$, aqua $=0.2-2 \mathrm{ppt}$ ).

In total, 115 individuals were used from fish captured using an electrofishing boat and/or fyke nets by Department of Fish and Game personnel.

Trace-metal-clean field methods were used in all cases. Upon capture, contact of fish with uncontaminated surfaces was limited by handling fish with polyethylene gloves and wrapping caught fish in trace-metal-clean Teflon sheeting. For each individual, total length, wet weight, and sex (in most cases) was recorded. Most fish were frozen whole 
on dry ice for use in the laboratory; the heads and mid-body sections were collected for especially large individuals. All individuals were stored in a $-20^{\circ} \mathrm{C}$ freezer at the Marine Pollution Studies Laboratory (MPSL) in Moss Landing, California. All sampling was done in accordance with IACUC protocol \#2007-G.

Mercury testing. Mercury body burden was measured by the MPSL for all individuals collected. Fish were prepared for analysis by removing the skin and filleting 5 to $10 \mathrm{~g}$ of muscle tissue with trace-metal-clean Teflon forceps and stainless steel knives in a clean room environment. The tissue was then homogenized with a Büchi Mixer B400 or a Brinkman Polytron mixer. Aliquots of the samples were digested with nitric/sulfuric acid (70:30) and analyzed with a Flow Injection Mercury System. Quality assurance measures checked standard reference materials, lab duplicates and matrix spikes. All data were of sufficient quality as specified by the RMP Quality Assurance Plan (Lowe et al., 1999).

Mercury concentrations were available for all 115 individuals collected. However, since many catch locations had either low sample numbers overall or were not sampled in each collection year, only fish collected from San Pablo Bay were used to examine changes in mercury concentrations over time. Changes in mercury concentrations over time in other catch locations could not be examined with the samples available.

Other heavy metals. Testing tissues for heavy metal samples were extracted from fish caught in 2006 only. Tissues from individuals prior to 2006 were not made available for use by this thesis project. The total number of fish analyzed for other heavy 
metals totaled 73 individuals, 14 of which were caught in San Pablo Bay, 20 in Clifton Court, 15 in Liberty Island, 16 in Knights Landing, 3 at the Toe Drain, 2 at Rio Vista, and single individuals at Catchment Slough, Central Bay and South Bay (Fig 3). Each individual was measured for concentrations of 11 heavy metals: silver (Ag), aluminum $(\mathrm{Al})$, arsenic (As), cadmium $(\mathrm{Cd})$, chromium $(\mathrm{Cr})$, copper $(\mathrm{Cu})$, manganese $(\mathrm{Mn})$, nickel $(\mathrm{Ni})$, lead $(\mathrm{Pb})$, selenium $(\mathrm{Se})$, and zinc $(\mathrm{Zn})$. The Inductively Coupled Plasma Mass Spectrometer (ICP-MS) Elan 9000 (manufactured by Perkin Elmer Sciex, Waltham, Massachussets), located at Moss Landing Marine Laboratories (MLML) - Norte Lab was used to perform the analyses. This type of analysis requires that sample materials are digested (i.e., liquefied) and following methods for sample digestion are discussed in detail in the description of sample preparation.

Sample plan. Samples collected for this study could not be prepared at the same time due to limitations of lab time, lab materials and space within sampling equipment. It was determined that all samples (73 individuals) with at least 5\% quality assurance of samples could be accomplished in two batches. The first batch included 45 of the individuals; the remaining 28 individuals were in the second batch. In addition, each batch included 8 quality assurance samples: two standard reference material samples (SRMs), two blanks, a duplicate sample for one individual, a matrix spike for one individual, a matrix spike duplicate for one individual, and a blank which had a matrix spike added to it (discussed in greater detail below). Total material analyzed plus quality control measures resulted in 53 samples processed in the first batch and 35 samples in the second batch. 
As part of quality assurance of results, two SRMs of known metal concentrations (2976 Mussel tissue and Dorm-3a, National Institute of Standards and Technology, Gaithersburg, MD), were used to calibrate results. These SRMs were used as a check for the ICP-MS to determine if results measured were close to known metal concentrations in the material, control for efficiency of digestion and to counter and instrumental bias.

Sample blanks were included as a check for preparation technique. Any signal registered in these samples would indicate a contamination issue during digestion or preparation to loading of samples into the ICP-MS. The duplicate of an individual was used as a measure of the precision of results produced by the ICP-MS.

Matrix spikes and matrix spike duplicates have a dual purpose. They are used to see if the matrix of the sample being analyzed, in this case the structure of the fish white muscle, biases results. Also, it serves as an additional measure of precision during sample preparation and testing to calculate how much of the spike is recovered upon testing. The blank with the matrix spike added is also an additional check for any contamination problems that may result during preparation that would affect results.

A pilot study was performed to determine the concentrations of metals used in the matrix spikes. Prior to all samples being digested, two randomly selected individuals (LI6160, LI6161) were analyzed on the ICP-MS for each metal to be tested (Ag, Al, As, $\mathrm{Cd}, \mathrm{Cr}, \mathrm{Cu}, \mathrm{Mn}, \mathrm{Ni}, \mathrm{Pb}, \mathrm{Se}$, and $\mathrm{Zn})$. The amount in sample tissue was calculated in nanograms per gram. This was then multiplied by 5 and compared to optimum recovery targets in the ICP-MS for each element (targets: $\mathrm{Ag}=100 \mathrm{ng}, \mathrm{Al}=250 \mathrm{ng}, \mathrm{As}=750 \mathrm{ng}$, $\mathrm{Cd}=75 \mathrm{ng}, \mathrm{Cr}=1000 \mathrm{ng}, \mathrm{Cu}=100 \mathrm{ng}, \mathrm{Mn}=500 \mathrm{ng}, \mathrm{Ni}=100 \mathrm{ng}, \mathrm{Pb}=75 \mathrm{ng}$, and $\mathrm{Zn}=$ 
$12,500 \mathrm{ng})$. The appropriate amount needed accounting for dilution was determined and converted back into parts per million (ppm) to obtain the information needed to dispense spikes. Each matrix spike and matrix spike duplicate had its own spike for its corresponding sample duplicate. For the first batch, the following spike solution was added to match its sample duplicate (LI6160): $50 \mu \mathrm{L}$ of $[\mathrm{Ag}]=2 \mathrm{ppm}, 50 \mu \mathrm{L}$ of $[\mathrm{Al}]=5$ ppm, $50 \mu \mathrm{L}$ of $[\mathrm{As}]=50 \mathrm{ppm}, 50 \mu \mathrm{L}$ of $[\mathrm{Cd}]=1 \mathrm{ppm}, 75 \mu \mathrm{L}$ of $[\mathrm{Cr}]=10 \mathrm{ppm}, 100 \mu \mathrm{L}$ of $[\mathrm{Cu}]=25 \mathrm{ppm}, 50 \mu \mathrm{L}$ of $[\mathrm{Mn}]=10 \mathrm{ppm}, 50 \mu \mathrm{L}$ of $[\mathrm{Ni}]=10 \mathrm{ppm}, 50 \mu \mathrm{L}$ of $[\mathrm{Pb}]=1 \mathrm{ppm}$, $50 \mu \mathrm{L}$ of $[\mathrm{Se}]=50 \mathrm{ppm}, 50 \mu \mathrm{L}$ of $[\mathrm{Zn}]=250 \mathrm{ppm}$. For the second batch, the spike was slightly different (in $\mathrm{As}, \mathrm{Cd}, \mathrm{Cr}, \mathrm{Cu}, \mathrm{Ni}, \mathrm{Pb}$ and $\mathrm{Se}$ ) to match its associated sample duplicate (LI6161): $50 \mu \mathrm{L}$ of $[\mathrm{Ag}]=] 2 \mathrm{ppm}, 50 \mu \mathrm{L}$ of $[\mathrm{Al}]=] 5 \mathrm{ppm}, 75 \mu \mathrm{L}$ of $[\mathrm{As}]=10$ ppm, $75 \mu \mathrm{L}$ of $[\mathrm{Cd}]=1 \mathrm{ppm}, 50 \mu \mathrm{L}$ of $[\mathrm{Cr}]=20 \mathrm{ppm}, 100 \mu \mathrm{L}$ of $[\mathrm{Cu}]=10 \mathrm{ppm}, 50 \mu \mathrm{L}$ of $[\mathrm{Mn}]=10 \mathrm{ppm}, 50 \mu \mathrm{L}$ of $[\mathrm{Ni}]=10 \mathrm{ppm}, 75 \mu \mathrm{L}$ of $[\mathrm{Pb}]=1 \mathrm{ppm}, 50 \mu \mathrm{L}$ of $[\mathrm{Se}]=25 \mathrm{ppm}$, $50 \mu \mathrm{L}$ of $[\mathrm{Zn}]=250 \mathrm{ppm}$.

Sample preparation, digestion, and testing. For testing, $12 \mathrm{~g}$ of tissue were excised above the lateral line at the midbody and placed into vials which were frozen in the $-80^{0}$ freezer on site for later use. All tissue was weighed using a precision balance (Mettler Toledo Corp., model PB303-S/Fact) within \pm 0.005 g. Only white muscle tissue was collected, great care was taken to not include bone, other connective tissue, nervous tissue, or red muscle in any of the tissue taken for later analysis.

Individually labeled trace-metal-clean Teflon bomb tubes were then weighed using the electric scale to $0.001 \mathrm{~g}$ and these weights were recorded (Bomb empty weights). It was determined that all samples could be digested with proper quality 
control measures in two batches. From each fish, $0.75 \mathrm{~g} \pm 0.02 \mathrm{~g}$ of the archived tissue after thawing was placed into bomb tubes using trace-metal-clean knives, probes or spatulas. For SRMs, $0.25 \mathrm{~g} \pm 0.02 \mathrm{~g}$, weighed to an accuracy of $0.005 \mathrm{~g}$ was added to the appropriate bomb tube. The bomb tubes were then reweighed to determine Bomb Wet weights. In addition, at least one gram of tissue was also taken and placed in clean, dry pre-weighed plastic dishes (dish empty weight) for moisture content analysis. This was necessary to adjust results in solution to equivalent amounts in tissue.

To digest the tissue and prepare samples for the ICP-MS, the samples were acidified. Six milliliters of nitric acid (69-70\%, Trace metal grade, JT Baker, Miami, Florida) was added to the bomb tubes. Pre-determined spikes (noted above) were also added to the matrix spike, matrix spike duplicate, and blank spike bomb tubes at this time. Acid and spikes were added using a pipetteman (Thermo Labsystems, Waltham, Massachussets) that had been calibrated and documented in the lab to consistently deliver the precise amount needed, adding them directly into the bomb tube.

The bomb tubes were arranged symmetrically in randomly determined position in a Teflon sleeve carousel and placed into an automated microwave accelerated reaction system (MARS 5 Xpress, model 194A06, CEM Corp, Matthews, North Carolina) to digest the tissue. The MARS software controls and allows for precise heating and cooling temperatures, pressures and times to be maintained for all samples. All digestions used a program that had 20 minutes of rapid ramp up of temperature at 1600 Watts at 250 Psi to $195^{\circ} \mathrm{C}$, a hold time of 15 minutes at that temperature, and a 20 minute cool down period. The tubes were then carefully removed from the MARS, and allowed 
to cool for approximately one hour, after which samples were carefully vented in a fume hood to remove nitrogen gas. No liquid in the tubes was lost during venting.

Subsequent to venting, $7 \mathrm{~mL}$ of Milli-Q water (filtered by the Milli-Q Plus system with Millipone purification pack located in the lab) was added to each bomb tube using a pipetteman and the liquid remaining was extracted into pre-weighed, trace-metal-clean poly bottles (I-Chem, Rockwood, Tennessee). Milli-Q water was then added carefully by dropper to every vial while on the electric metric scale, to bring the total solution weight up to $20 \mathrm{~g} \pm 0.05 \mathrm{~g}$, which was recorded (Solution $\mathrm{Wt}$ ). The poly bottles were then sealed and agitated by hand to homogenize the liquid contained.

Prior to testing on the ICP-MS, the samples required loading into trace-metalclean test tubes so that they could be mounted into racks for automated testing. One milliliter of each poly bottle was dispensed into its own tube by pippetteman as was 25 $\mu \mathrm{L}$ of an internal standard. The standard is an in-house solution of Rhodium ( $\mathrm{Rh})$, Thulium (Tm), Germanium (Ge), each at a concentration of 25 parts per billion. The Rh, Tm, and Ge elements were chosen because they are rare elements that would not likely be found in tissue samples in even trace quantities and were non-reactive with elements that were analyzed. This internal standard was used as another quality control measuring the precision of the ICP-MS. The machine extracted aliquots for each of the 11 metals measured. An additional calibration verification solution (Instrument Calibration Standard 1, Cat. No. CL-CAL-1, manufactured by Spex Cetriprep, Metuchen, New Jersey) was run prior to testing as an internal ICP-MS measurement check. 
Testing on the ICP-MS was managed by the internal software (KIT Software Version 2.1) in an automated process over approximately 8 hours per batch. The machine diluted samples up to $10 \mathrm{~mL}$ MQ water, so all results delivered were at 10x dilution.

Moisture content analysis. Dishes containing tissue for moisture content analysis were weighed on the electric top loading balance to obtain a tissue wet weight and then placed in a drying oven (VWR BioE, Washington DC), set at $75^{\circ} \mathrm{C}$. After two days, the dishes were removed and re-weighed with the desiccated tissue in them to get a tissue dry weight. From this information, and using the specific gravity for the acidified sample solutions of 1.16, Percent Moisture, Dry Weight of samples, and Dilution Factors could be calculated using MS Excel software.

These calculations were necessary to convert data obtained by the ICP-MS in solution to the equivalent amounts in tissue (i.e., accounting for dilution). Percent Moisture was determined using the following formula:

$$
\text { Percent Moisture }=\frac{(\text { Tissue Wet Wt. }- \text { Tissue Dry Wt. })}{(\text { Tissue Wet Wt. }- \text { Dish Empty Wt. })} X 100
$$

Dry Weight could then be determined using the following equation:

$$
\text { Dry Weight }=(\text { Bomb Wet Wt. }- \text { Bomb Empty Wt. }) X\left[1-\left(\frac{\text { Percent Moisture }}{100}\right)\right]
$$

Finally, this allowed for Dilution Factor to be calculated using the equation below:

$$
\text { Dilution Factor }=\frac{\left(\frac{\text { Solution Wt. }}{1.16}\right)}{\text { DryWeight }}
$$


Quality assurance of data. Quality assurance procedures of the SRMs indicated that measurements were good. Measurements of SRMs were within 99\% confidence limits in both batches for each element for at least one of the SRMs, the exceptions being $\mathrm{Ag}, \mathrm{Cr}, \mathrm{Pb}$ and $\mathrm{Se}$. Chromium was outside of $99 \%$ confidence limits for the known values in the SRMs for both batches ([Cr] of SRM $=5.90 \& 2.68 \mathrm{ppm}$ for the batches), but data were deemed still good for this element since measurements of $\mathrm{Cr}$ within the spike were within acceptable limits. Measurements of $\mathrm{Pb}$ and $\mathrm{Se}$ were outside the $99 \%$ confidence limits in the second batch, but again measurements of these elements within the spike were within acceptable limits, so the data were kept. Silver was outside acceptable limits for the SRMs in both batches as well as for Ag in the spike for the second batch, likely due to moisture and not from contamination. This is not uncommon when evaluating Ag with the ICP-MS, since any moisture that contains solubilized chloride ions will affect performance (USEPA 1998). Additionally, since Ag was not detected often in samples (see data filtering section below), this problem had no effect on statistical analyses.

Other analyses also showed that matrix interference or contamination were not issues in sample processing. As mentioned briefly above, spike recoveries were within acceptable limits for all elements except $\mathrm{Ag}$ in the second batch of samples. In the first batch, spike recoveries averaged $100 \%$ with a standard deviation of $14.4 \%$, while the second batch (excluding $\mathrm{Ag}$ ) averaged a 101\% recovery with a standard deviation of 9.1\%. These results indicated that the tissue matrix was not interfering with measurements of the heavy metals. In addition, there was not a single detection of any of 
the metals investigated in the blanks for both batches, signifying that sample contamination during preparation prior to testing on the ICP-MS did not affect results.

Data filtering. Prior to analysis, two steps were taken to filter the data used.

First, samples with extraordinarily high metal concentrations were removed from the analysis to make sure that outliers did not bias results. Three individuals (CS 6159, KL 6173, KL 6224) had metal concentrations for at least four different metals a few orders of magnitude higher than the average concentrations of other samples (Table 3).

Table 3: Chemical concentrations for three outliers that were removed from analysis. Average chemical concentrations for detections are listed for comparison. Values in red were below detection limits while those in blue were below method detection limits.

\begin{tabular}{|c|c|c|c|c|c|c|c|c|c|c|c|}
\hline & Ag & Al & As & Cd & $\mathrm{Cr}$ & $\mathbf{C u}$ & Mn & $\mathrm{Ni}$ & $\mathbf{P b}$ & $\mathbf{S e}$ & $\mathbf{Z n}$ \\
\hline $\begin{array}{c}\text { CS } \\
6159\end{array}$ & 0.02 & 9.39 & 2.72 & $\mathbf{0 . 3 1}$ & 1509.55 & 18.98 & 35.02 & 313.09 & 0.02 & 2.52 & 141.42 \\
\hline $\begin{array}{l}\text { KL } \\
6173\end{array}$ & 0.026 & 9.39 & 0.25 & 0.05 & 85.10 & 3.22 & 44.66 & 266.62 & 0.01 & 2.10 & 195.06 \\
\hline $\begin{array}{l}\text { KL } \\
6224\end{array}$ & 45.25 & 10191.99 & 316.01 & 72.76 & 1193.53 & 790.76 & 474.48 & 212.48 & 40.24 & 1737.95 & 8724.43 \\
\hline Avg & 0.04 & 9.44 & 1.18 & 0.02 & 1.37 & 1.06 & 0.49 & 0.31 & 0.01 & 2.46 & 13.65 \\
\hline SD & 0.07 & 0.32 & 0.72 & 0.02 & 3.12 & 0.41 & 0.29 & 1.64 & 0.02 & 1.03 & 6.34 \\
\hline
\end{tabular}

Although there is no indication of widespread contamination in any of the samples, as stated in the methods, the metal concentrations for these three individuals were not included to obtain the best conservative estimate possible for metal concentrations of Striped Bass in the SFE and to avoid tainting any analysis. None of the data for these three individuals were included in any of the analyses, even those concentrations which 
were near total sample means, thus reducing the total sample population to 70 individuals.

Detection rates for each metal, excluding mercury, were examined for the remaining 70 individual samples. Detection of heavy metals in samples was variable for each element investigated. The ICP-MS has minimum detection limits (MLs) and method detection limits (MDLs) for each element investigated (Table 4).

Table 4: Minimum detection limits (in red), method detection limits (in blue), number of detections and percent detetcted for each chemical concentration measured. Metals with percent detections in red were not used in analyses due to low detection rates.

\begin{tabular}{|c|c|c|c|c|c|c|c|c|c|c|c|}
\hline & Ag & Al & As & Cd & $\mathrm{Cr}$ & $\mathrm{Cu}$ & Mn & $\mathbf{N i}$ & $\mathbf{P b}$ & Se & Zn \\
\hline ML & 0.02 & 9.40 & 0.08 & 0.01 & 0.82 & 0.34 & 0.19 & 0.02 & 0.01 & 0.96 & 4.97 \\
\hline MDL & 0.06 & 25.00 & 0.25 & 0.03 & 2.00 & 1.00 & 0.50 & 0.06 & 0.03 & 2.00 & 15.0 \\
\hline$\#<\mathbf{M L}$ & 51 & 70 & 0 & 46 & 19 & 0 & 7 & 29 & 64 & 1 & 0 \\
\hline$\#<\mathrm{MDL}$ & 11 & 2 & 3 & 5 & 49 & 38 & 39 & 12 & 5 & 29 & 53 \\
\hline$\#>M D L$ & 10 & 0 & 69 & 21 & 4 & 34 & 26 & 31 & 3 & 42 & 19 \\
\hline$\%>$ MDL & 13.9 & 0.0 & 95.8 & 29.2 & 5.6 & 47.2 & 36.1 & 43.1 & 4.2 & 58.3 & 26.4 \\
\hline$\%>M L$ & 29.2 & 2.8 & 100.0 & 36.1 & 73.6 & 100.0 & 90.3 & 59.7 & 11.1 & 98.6 & 100.0 \\
\hline
\end{tabular}

The ML for each element denotes the smallest concentration that can be detected by the machine. The MDL for each element signifies the lowest concentration that can be detected within $99 \%$ confidence limits. A metal was considered "detected" if measured above the ML for each sample. Detection rates for each metal were computed using the following formula: 


\section{Detection Rate $($ percent $)=\frac{\# \text { of samples detected }}{\text { total \# of samples }}$}

Statistical analyses only included elements that were detected above the ML at least half of the time (As, $\mathrm{Cr}, \mathrm{Cu}, \mathrm{Mn}, \mathrm{Ni}, \mathrm{Se}$, and $\mathrm{Zn}$; Table 4). $\mathrm{Ag}, \mathrm{Al}, \mathrm{Cd}$, and $\mathrm{Pb}$ were not included in statistical analyses because they were detected less than half the time.

For the remaining metal concentrations, non-detections were replaced with concentrations of the ML minus $0.001 \mathrm{ppm}$ for each metal to avoid missing data from skewing statistical tests and principal component analysis (PCA), which only impacted $\mathrm{Cr}$ and Ni concentrations. This was done both to obtain the most conservative result possible for each statistical test, since zeroes are known to have strong effect on results, and to load factors in the PCA software that did not have $100 \%$ detection rates. A PCA was done using only $100 \%$ detected concentrations to check if relationships were different for those metals, and no measurable difference was found.

Metal concentration comparisons. Some metal concentrations were evaluated to determine any potential hazards in consuming Striped Bass fillets. This was determined by two methods. First, average metal concentrations of detections were compared to screening values generated by the Mid-Atlantic Risk Assessment Calculator (http://epa-prgs.ornl.gov/cgi-bin/chemicals/csl_search). Screening values were calculated for fish for $\mathrm{Ag}, \mathrm{Al}, \mathrm{Cd}, \mathrm{Cu}, \mathrm{Mn}$, methyl mercury, and Se (no applicable option was available or information in the database for total $\mathrm{Cr}, \mathrm{Mn}$, and $\mathrm{Pb}$ ). The resultant screening values are in Table 3 and concur with information researched in the Agency for Toxic Safety and Disease Registry (ATSDR) literature and other Environmental Protection Agency (EPA) documents (EPA 2000; ATSDR 1990; ATSDR 1999; ATSDR 
2003; ATSDR 2004; ATSDR 2005a; ATSDR 2005b; ATSDR 2007a; ATSDR 2007b;

ATSDR 2008a; ATSDR 2008b; ATSDR 2008c). The calculation was based on the following formula:

$S L(p p m)=\frac{365 \frac{\text { days }}{y r} * \text { Exposure Duration } * \text { Body Weight }}{\left(\text { Exposure Frequency } * \text { Exposure Duration } * \frac{1}{R f D} * \text { Ingestion Rate } * \frac{0.00001 \mathrm{~kg}}{\mathrm{mg}}\right.}$

Where Exposure Duration $=30$ years, Body Weight $=78 \mathrm{~kg}$, Exposure Frequency $=$ 350days $/ \mathrm{yr}, \mathrm{RfD}=$ chronic reference dose for the metal, Ingestion rate $=54000 \mathrm{mg} /$ day . It also should be noted that exposure duration was estimated from a 70 year lifespan.

An SL value of 0.4 ppm was used for mercury since this is commonly used evaluations of Striped Bass body burden levels of Striped Bass in the SFE (Greenfield et al., 2005). Frequency of mercury concentrations above the SL was also calculated by catch group to determine if there was any location with more fish of hazardous levels. A chi-square test was used to tests if differences of actual numbers of individuals above the SL with the expected number of individuals (computed from the overall average) for each location were statistically significant.

Hazardous levels of known toxic metals were also calculated for intermediate exposures for a more conservative estimate of possible hazards. Levels of concern (LOC) were estimated for As, Cd, $\mathrm{Hg}$, and Se from ATSDR literature (ATSDR 2008a ; ATSDR 2007a; ATSDR 2003; ATSDR 1999) or EPA studies (EPA 2000). When available, the Minimum Response Levels (MRLs) of intermediate exposure length (15365 days) for a given metal was used as Exposure Limits (ELs). When no MRL was available, a rough average of all Lowest Observable Affected Exposure Levels 
(LOAELs) of oral exposures of intermediate length was used instead. Absorption coefficients are estimated gastrointestinal absorption rates in toxicokinetic data for each metal provided by ATSDR.

It should be noted that the chemical species of the metal is extremely important for assessing toxicity. Valence state has great influence on its rate of absorption and its effect on bodily processes. All metal concentrations measured in this thesis are total concentrations, the sum of all species concentrations for that metal. Of these four metals, total elemental concentrations are either good estimates of toxic species $(\mathrm{Hg}, \mathrm{Se})$ or have no known metabolic purpose in fish $(\mathrm{Cd})$, total concentrations are good estimates of toxicity (EPA 2000). Total arsenic has only a small portion of the total concentration of the metal in the tissue that is toxic to humans since most arsenic is bound in the organic molecule arsenobetaine (EPA 2000), so an average estimate of the hazardous portion was used to give a conservative estimate for toxicity purposes (Lunde 1977).

Meals per Month (MPM) allowed for each metal were calculated derived from EPA guidelines (EPA 2000), summarized in the following formula:

$$
\mathrm{MPM}=\frac{\text { Exposure Level } * \text { Body Wt }}{\text { Mean Metal Concentration } * \text { Absorption Coeffecient }}
$$

where body weights of males was $78 \mathrm{~kg}$, of females was $65 \mathrm{~kg}$, and of children was 14.5 $\mathrm{kg}$ (EPA 2000).

Statistical analyses. All factors in statistical analyses were assessed for normality in SYSTAT using the one sample Kolmogorov-Smirnov test for normal distributions. On the rare occasion in which data were found to be non-normal, as in number of movements, the data in question was transformed by the base $10 \log$ of each 
data point and rechecked for normality again using the same Kolmogorov-Smirnov test. All factors were also checked for homoscedacity using the Bartlett and Leven test available under the equality of variances hypothesis testing option in SYSTAT. All factors used in every ANOVA passed for equal variances.

All data used in statistical tests were checked for normality and homoscedacity using SYSTAT prior to each statistical test. Normality was checked for each group in a test using the one sample Kolmogorov-Smirnov test for normal distributions. If data were non-normal, it was transformed most often by taking the natural log of the data. On rare occasions, this did not normalize the data, so the inverse of the data $(=1 / x)$, the square root of the data $(=\sqrt{x})$, the exponent of the data $\left(=\mathrm{e}^{\mathrm{x}}\right)$, or the inverse of the exponent of the data $\left(=e^{\frac{1}{e^{x}}}\right)$ was used depending on the distribution of the data. Then homoscedacity among groups in a test was tested using the Bartlett and Leven tests available in SYSTAT. If homoscedacity tests failed, the data were transformed using the above transformations where applicable and then re-checked for normality.

In almost all cases, data were sufficient after this process to be used in standard parametric tests available in SYSTAT. There were two exceptions. In one case, when examining copper and nickel concentrations of fish that used saline habitats, data had homoscedacity but was non-normal despite all transformations. This was examined using the non-parametric Mann Whitney U test. Additionally, in chromium concentrations among fish that used saline habitats, the data were both non-normal and heteroscedastic among groups. This data were not examined further but the groups were considered 
different from one another since all parameters examined were already shown to be different, which is the rational of all statistical tests (Zar 1999).

T-tests and ANOVAs were the most commonly used statistical tests when examining the data. All statistical tests used $\alpha=0.05$ for evaluating whether a null hypothesis should be rejected. If the null hypothesis was not rejected, a power analysis was done using SYSTAT. If the null hypothesis was rejected in an ANOVA, Tukey's pair-wise comparison test was used to determine which group or groups were responsible for rejection of the null.

Mercury concentrations were also plotted versus size and age of fish for each individual to examine the predictive strength of this information. Predictive strength $\left(\mathrm{r}^{2}\right)$ was used in evaluations instead of statistical significance ( $p$-value) because it is of more use when evaluating plots and regressions (Zar 1999). Effect of age and size were evaluated because they were used as guidelines in setting current fishing regulations of Striped Bass in the SFE.

Data collected from otolith chemistry was applied to tissue chemistry data in several statistical analyses. All groups based on catch group or residence designations followed the rationale presented in the methods of the first chapter of this thesis. When analyzing metal concentrations by catch location, those with sample sizes with a single individual ( $\mathrm{n}=1)$ were not included (South Bay, Central Bay).

Metal concentrations were compared among genders when information was available. Sex of individuals was not always recorded in catch information. Whole fish 
that were archived were re-examined to determine gender when available. Total sample sizes for mercury and other metals were 63 individuals and 52 individuals respectively.

Principal component analysis. Principal component analysis (PCA) was used to examine relationships among metal concentrations in Striped Bass tissue as well as a method to compare these concentrations with movement and residence data derived from otolith chemistry. The PCA was computed using the suite of Canoco 4.5 for Windows software. Data for each factor were organized as suggested (Lepš and Šmilauer 2003) in Excel and then converted for use using the CanoMerge program. They were then analyzed using the Canoco control panel software and graphs presented were all generated by the CanoDraw program using the factorial analysis option. Graphs were modified for centering and labeling presentation purposes only. Variability explained by the axes in each PCA was very high (99.7\% variability described for the 2 axes).

When using the Canoco control panel software, only standard presets for the PCA option was used. Data based on each factor were examined (“only species data” option) through indirect gradient analysis. Data were detrended by segments by the software and no transformation or weighting was applied to the data by the program.

The PCA used all metal concentrations, habitat estimates using otolith chemistry data, total lengths, and ages for individuals. Habitat factors included strontium isotope ratios for total life and for the last three years of life prior to capture, proportion of life spent in fresh water, longest duration spent in fresh water, longest duration spent in salt water, and number of movements into and out of the Delta system. Consult the first chapter of this thesis to examine how these factors were derived. 
When examining the PCA graphs, factors which were orthogonal to one another ( $\sim 90^{\circ}$ angle between factors) denote factors that are not correlated (Harris 1975).

Conversely, factors which are $\leq 45^{\circ}$ or $\geq 135^{\circ}$ to one show strong correlation with one another (Harris 1975). The strength of each factor in the data is denoted by the length of the arrow for that factor.

\section{Tissue Chemistry Results}

Metal concentrations in tissue. Concentrations of metals were examined to determine average concentrations for samples. Almost all average concentrations were less than screening levels (Table 5). The mean concentration of mercury was indistinguishable from the SL for that metal.

Table 5: Screening levels (SLs) and mean concentrations. SLs were derived using the Mid-Atlantic Risk Assessment Calculator.

\section{Chemical}

Aluminum

Cadmium (Diet)

Copper

Manganese (Diet)

Methyl Mercury

Selenium

Silver

\section{$\underline{\text { SL (ug/g) }}$}

1350

1.35

54.1

189

0.400

6.76

6.76

\section{Avg in detections (ug/g)}

11.04

0.041

1.058

0.522

0.391

2.486

0.089

The average mercury concentration for all individuals is very close to the SL of $0.4 \mu \mathrm{g} / \mathrm{g}$ wet weight. Although the average concentration was below the SL, 95\% 
confidence limits did extend above the SL (Figure 3). The frequency of Striped Bass exceeding screening levels throughout the population was $36.5 \%(n=115)$.

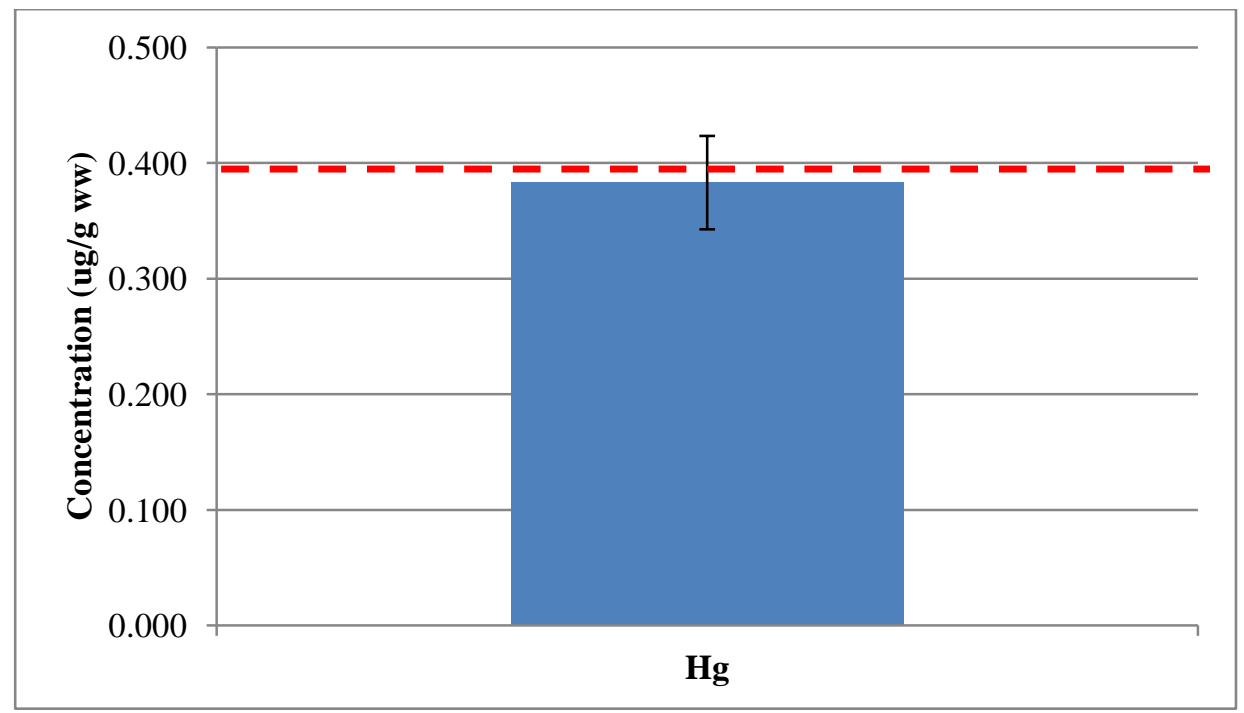

Figure 14: Average concentration of mercury with $95 \%$ confidence intervals for all samples analyzed $(n=115)$. Red dotted line denotes screening level for mercury $(0.4 \mathrm{ug} / \mathrm{g} \mathrm{ww})$.

Other average metal concentrations were well below any associated SLs. Aluminum and zinc were the greatest concentrations found, where silver, cadmium and lead were the lowest concentrations measured (Fig. 15). The greatest variability was seen in chromium, nickel and zinc measurements. 


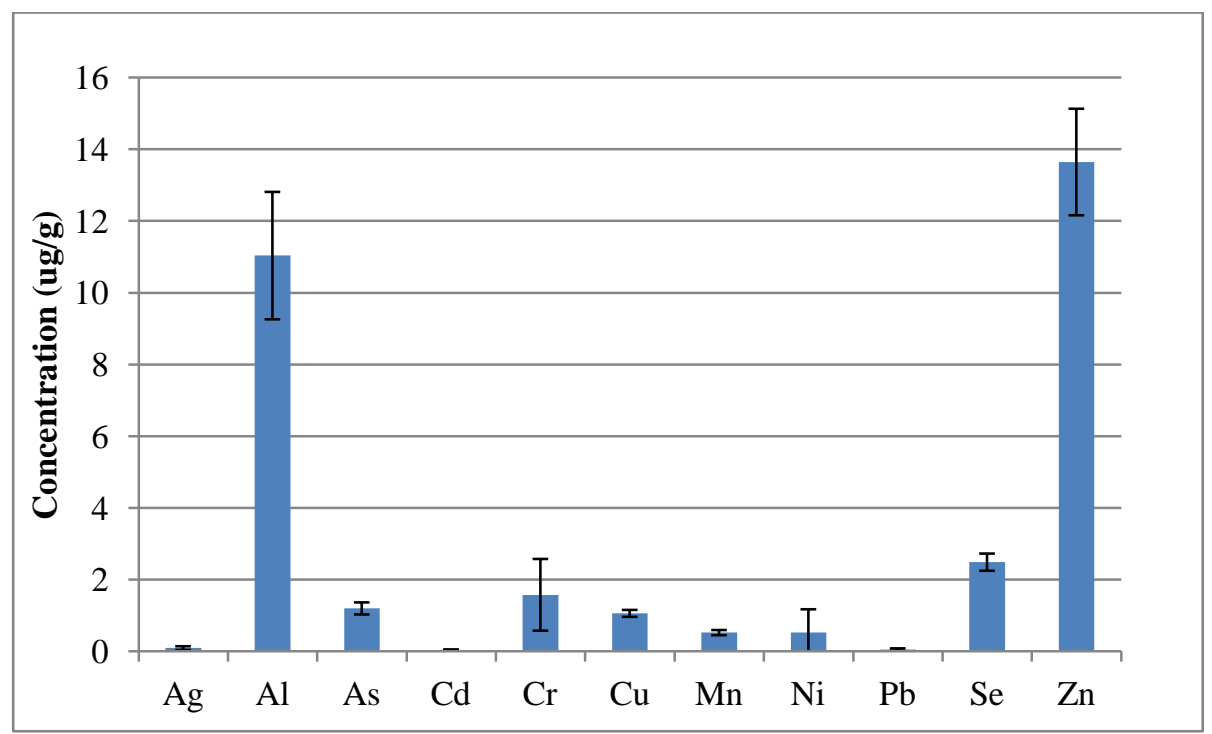

Figure 15: Average concentrations with $95 \%$ confidence intervals for all 2006 samples without outliers $(n=70)$.

Mercury, cadmium, selenium, and arsenic were also compared against the calculated number of meals to reach a dangerous level (MPMs). These concentrations are safe only for arsenic, while consumption of mercury, cadmium, and selenium indicate low numbers of meals to reach a dangerous level (Table 6). 
Table 6: Meals per month (MPM) calculations for $\mathrm{As}, \mathrm{Cd}, \mathrm{Hg}$, and Se. These represent conservative estimates of the amount needed to reach levels of concern (LOC) for each type of consumer.

\begin{tabular}{|c|c|c|c|c|}
\hline & $\underline{\text { As }}$ & $\underline{\mathrm{Cd}}$ & $\underline{\mathrm{Se}}$ & $\underline{\mathrm{Hg}}$ \\
\hline Average & 1.196 & 0.041 & 2.486 & 0.383 \\
\hline $\mathrm{n}=$ & 69 & 23 & 69 & 115 \\
\hline Absorption & 0.32 & 0.05 & 0.90 & 0.95 \\
\hline LOC (ug/g) & 1.200 & 0.0005 & .760 & 0.400 \\
\hline Toxic Fraction & 0.4 & -- & -- & -- \\
\hline Total for Adult Male $(\mathrm{kg})$ & 244.6 & 19.2 & 235.7 & 85.7 \\
\hline Total for Adult Male (lbs) & 538.1 & 42.2 & 518.4 & 188.6 \\
\hline Total for Adult Female (kg) & 203.8 & 16.0 & 196.4 & 71.5 \\
\hline Total for Adult Female (lbs) & 448.4 & 35.2 & 432.0 & 157.2 \\
\hline Total for Child (kg) & 45.5 & 3.6 & 43.8 & 15.9 \\
\hline Total for Child (lbs) & 100.0 & 7.9 & 96.4 & 35.1 \\
\hline MPM Adult Male & 35.9 & 2.8 & 34.6 & 12.6 \\
\hline MPM Adult Female & 29.9 & 2.3 & 28.8 & 10.5 \\
\hline MPM Child & 8.1 & 0.6 & 7.8 & 2.8 \\
\hline
\end{tabular}


Habitat utilization. The effect of habitat utilization was examined to see if there was a trend in increasing mercury concentrations with fresh water habitation. Residents of the Delta had slightly higher mercury concentrations in their tissue than fish that spent time outside of the Delta (Fig. 16).

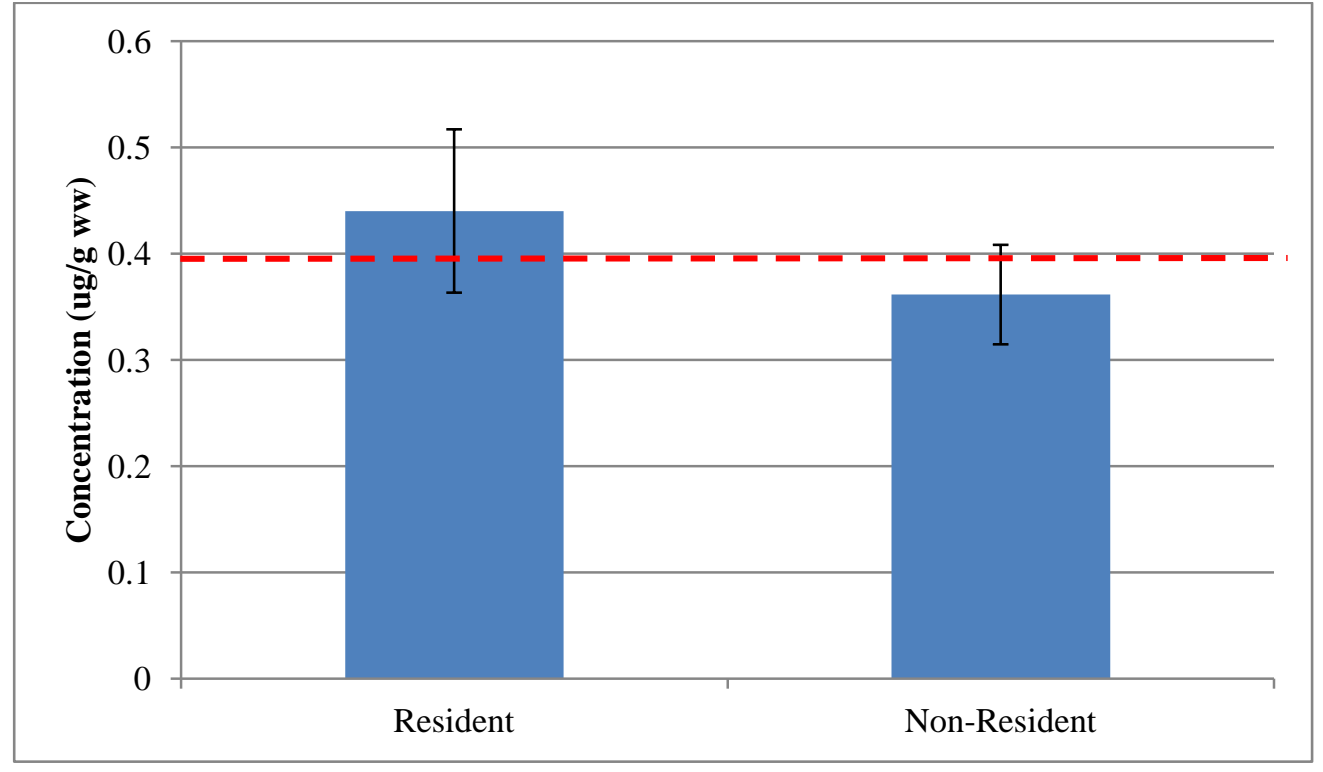

Figure 16: Mean mercury concentrations for resident $s$ and non-residents with $95 \%$ confidence intervals. Red dotted line denotes screening level for mercury $(0.4 \mathrm{ug} / \mathrm{g} \mathrm{ww})$.

A t-test was performed on square-root transformed mercury concentrations to test differences among residents and migrants, and no significant difference was found $(t=$ 1.561, $\mathrm{p}=0.121, \mathrm{df}=113$ ). Power was not sufficient to confidently avoid Type II errors. To achieve sufficient power, 153 residents and migrants each would be needed for the test.

Habitat utilization also appeared to have no effect on most other metal concentrations. Concentrations appeared roughly equal for all metals except for arsenic (Fig. 17). 


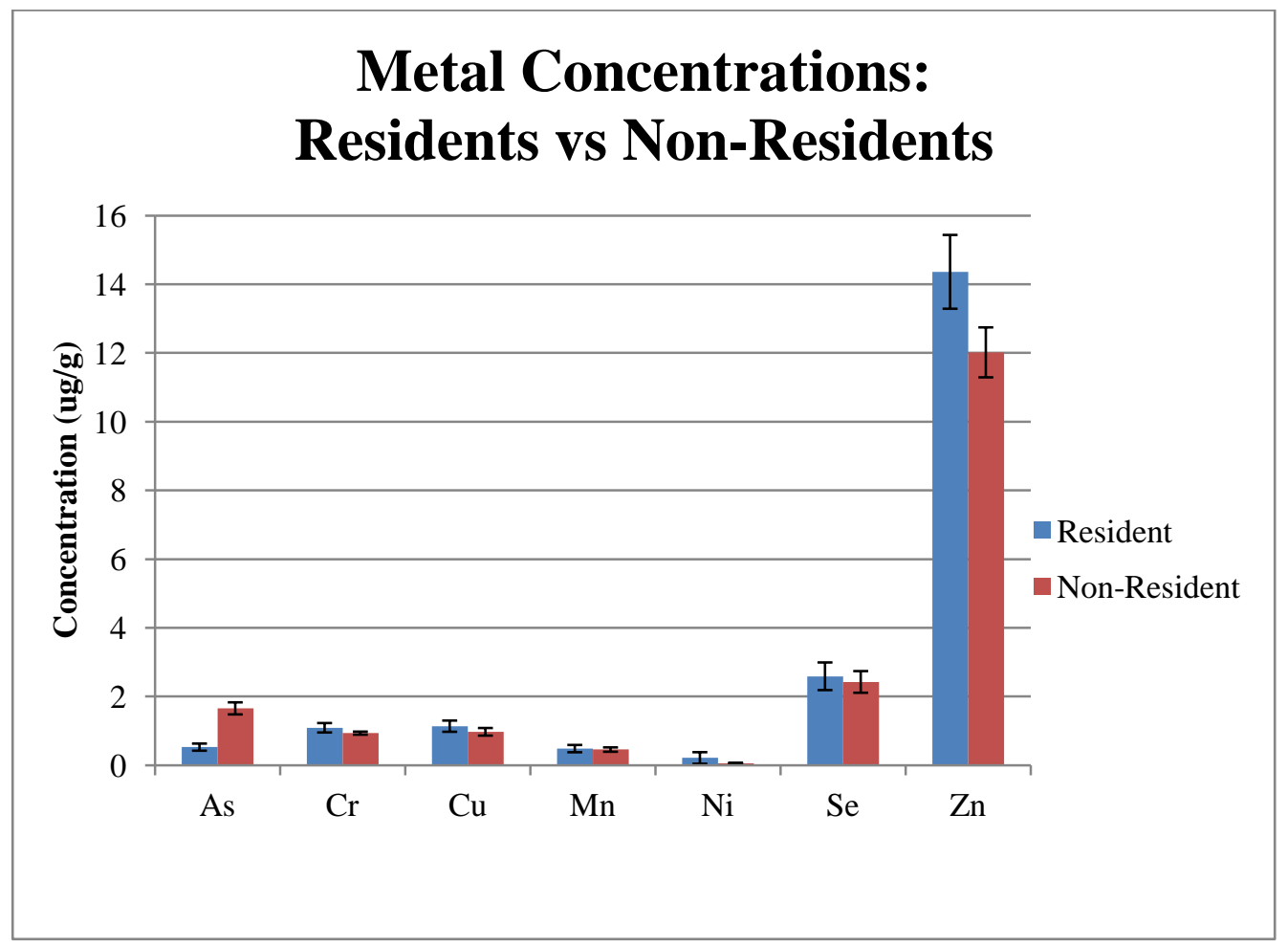

Figure 17: Other average metal concentrations with $95 \%$ confidence intervals for resident and non-resident groups.

The mean arsenic concentration in residents was approximately a third of the mean concentration in those that used areas outside of the Delta.

For most metals, no significant difference was found among these concentrations (Table 7). 
Table 7: Mean metal concentrations for residents and non-residents along with p-values for t-tests comparing differences. Samples sizes for power of 0.8 , if applicable, represent total sample sizes if all groups have equal numbers.

$\begin{array}{rccccccc} & \underline{\mathrm{As}} & \underline{\mathrm{Cr}} & \underline{\mathrm{Cu}} & \underline{\mathrm{Mn}} & \underline{\mathrm{Ni}} & \underline{\mathrm{Se}} & \underline{\mathrm{Zn}} \\ \text { Non-Resident Avg } & 1.66 & 0.94 & 0.98 & 0.46 & 0.06 & 2.43 & 12.02 \\ \text { SD } & 0.56 & 0.14 & 0.35 & 0.20 & 0.05 & 1.00 & 2.32 \\ \text { SE } & 0.09 & 0.02 & 0.06 & 0.03 & 0.01 & 0.16 & 0.37 \\ \text { 95\% CI } & 0.18 & 0.04 & 0.11 & 0.06 & 0.02 & 0.32 & 0.73 \\ & & & & & & & \\ \text { Resident Avg } & 0.53 & 1.09 & 1.14 & 0.49 & 0.21 & 2.59 & 14.36 \\ \text { SD } & 0.28 & 0.37 & 0.44 & 0.29 & 0.45 & 1.09 & 2.90 \\ \text { SE } & 0.05 & 0.07 & 0.08 & 0.05 & 0.09 & 0.21 & 0.55 \\ 95 \% \text { CI } & 0.10 & 0.14 & 0.16 & 0.11 & 0.17 & 0.40 & 1.07 \\ & & & & & & & \\ \text { p-value } & 0.00 & 0.74 & 0.08 & 0.96 & 0.68 & 0.51 & 0.18 \\ \text { n= for sufficient Power } & -- & 5948 & 162 & 251486 & 3568 & 1192 & 282\end{array}$

Chromium, manganese, nickel, selenium, and zinc concentrations had high p-values, strongly suggesting that there was no effect of habitat utilization with respect to these metal concentrations. Unfortunately, power was also low for these analyses (Table 7) so the ability to determine if the groups are truly not different from one another is hampered by low sample sizes. However, arsenic concentrations were significantly different $(\mathrm{p}=$ $0.000, \mathrm{df}=68)$ where fish with excursions out of the Delta had higher arsenic concentrations. 
All concentrations were examined again after bifurcating the fish with habitation outside the Delta into Delta-caught and Bay-caught subgroups. Results indicated that the Delta-caught individuals had the lowest mean $\mathrm{Hg}$ concentration, even lower than resident fish (Fig. 18).

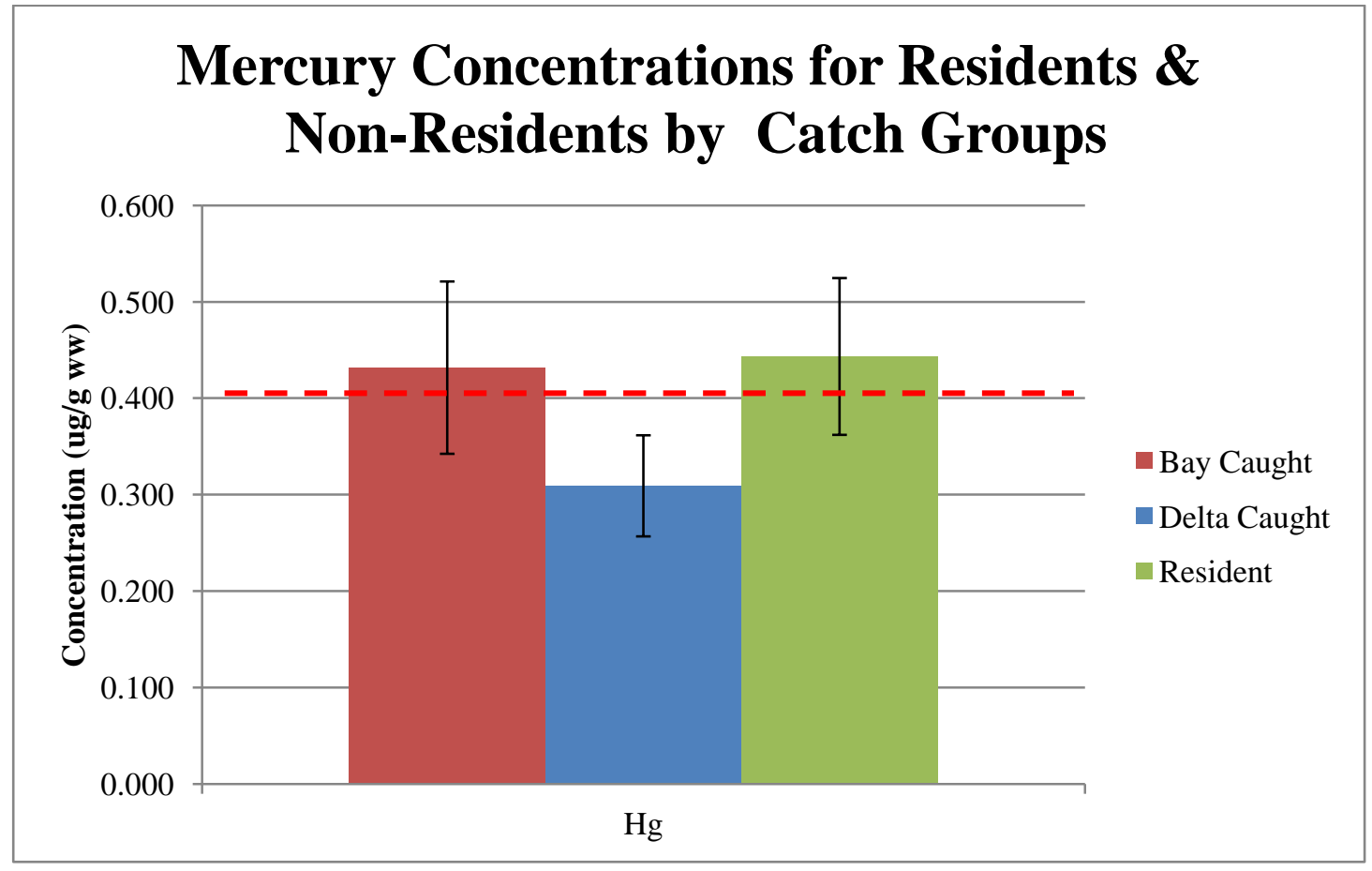

Figure 18: Mean mercury concentrations for Bay-caught non-residents, Delta-caught non-residents, and Delta residents with associated $95 \%$ confidence intervals. Red dotted line denotes screening level for mercury (0.4 ug/g ww).

Mean $\mathrm{Hg}$ concentrations for Delta residents and Bay-caught fish were roughly equal and greater than screening values.

Mean concentrations of other metals did not show any clear pattern among these groups. The highest average concentrations for $\mathrm{Cr}, \mathrm{Cu}, \mathrm{Hg}, \mathrm{Ni}$, and $\mathrm{Zn}$ were in residents, while Delta-caught migrants had the highest concentrations of As, Mn, and Se (Fig. 19). 


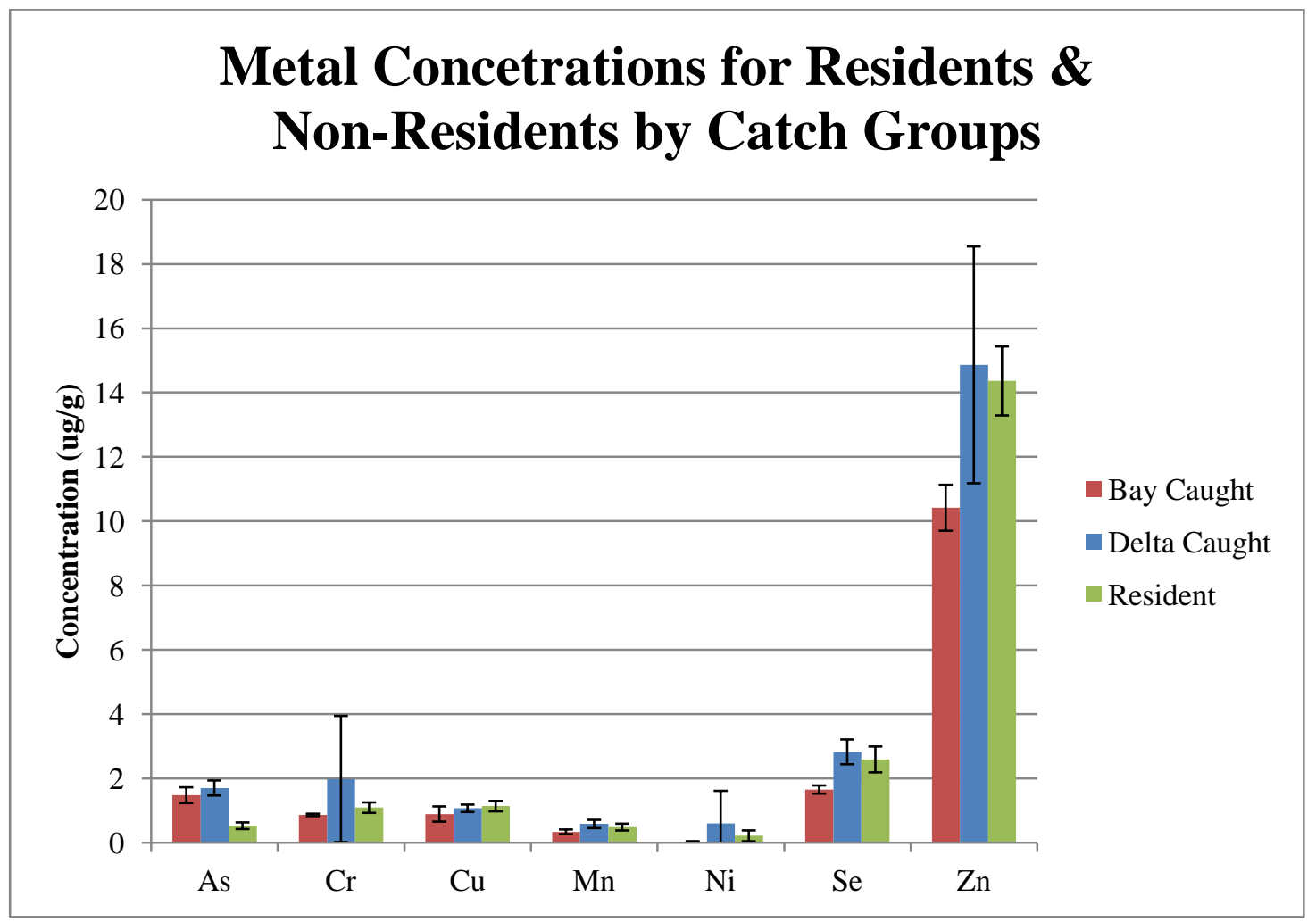

Figure 19: Averages of other metal concentrations with $95 \%$ confidence intervals for Bay-caught non-residents, Delta-caught non-residents, and Delta residents.

However, $95 \%$ confidence limits overlapped for all groups for each metal with the exception of As.

Tests for these differences did show that differences seen in metal concentrations were significantly different from one another. In all cases, p-values indicated differences seen amongst groups were significant. (Table 8). 
Table 8: Average concentrations of metals for Bay-caught non-residents, Delta-caught non-residents, and Delta residents along with p-values from t-tests comparing differences.

\begin{tabular}{|c|c|c|c|c|c|c|c|c|c|}
\hline & & As & $\mathrm{Cr}$ & $\mathrm{Cu}$ & Mn & $\mathbf{N i}$ & $\mathbf{S e}$ & Zn & $\mathrm{Hg}$ \\
\hline Bay- & Avg & 1.479 & 0.865 & 0.894 & 0.338 & 0.031 & 1.655 & 10.417 & 0.432 \\
\hline \multirow[t]{3}{*}{$\mathrm{n}=16$} & SD & 0.500 & 0.077 & 0.484 & 0.148 & 0.035 & 0.260 & 1.459 & 0.182 \\
\hline & SE & 0.125 & 0.019 & 0.121 & 0.037 & 0.009 & 0.065 & 0.365 & 0.046 \\
\hline & $95 \% \mathrm{CI}$ & 0.245 & 0.038 & 0.237 & 0.073 & 0.017 & 0.127 & 0.715 & 0.089 \\
\hline Delta- & Avg & 1.703 & 1.982 & 1.072 & 0.583 & 0.595 & 2.826 & 14.862 & 0.309 \\
\hline \multirow[t]{3}{*}{$n=26$} & SD & 0.608 & 5.107 & 0.301 & 0.337 & 2.652 & 1.006 & 9.582 & 0.136 \\
\hline & SE & 0.119 & 1.002 & 0.059 & 0.066 & 0.520 & 0.197 & 1.879 & 0.027 \\
\hline & $95 \% \mathrm{CI}$ & 0.234 & 1.963 & 0.116 & 0.130 & 1.020 & 0.387 & 3.683 & 0.052 \\
\hline Resident & Avg & 0.528 & 1.139 & 1.139 & 0.486 & 0.214 & 2.591 & 14.361 & 0.443 \\
\hline \multirow[t]{3}{*}{$\mathrm{n}=28$} & SD & 0.281 & 0.441 & 0.441 & 0.286 & 0.454 & 1.088 & 2.899 & 0.219 \\
\hline & SE & 0.053 & 0.083 & 0.083 & 0.054 & 0.086 & 0.206 & 0.548 & 0.041 \\
\hline & $95 \% \mathrm{CI}$ & 0.104 & 0.163 & 0.163 & 0.106 & 0.168 & 0.403 & 1.074 & 0.081 \\
\hline & & 0.000 & -- & 0.004 & 0.003 & 0.001 & 0.000 & 0.000 & 0.000 \\
\hline
\end{tabular}

For Mn, Se, and Zn, the Bay-caught fish had lower concentrations than other groups.

There was no difference between Delta-caught fish with saline habitation and Delta residents. For As, Delta residents had lower levels than the fish which had lived at least some portion outside the Delta. There was no difference between fish that had utilized saline waters regardless of whether they were caught inside or outside the Delta. In the case of $\mathrm{Hg}$, data indicated that Delta-caught fish that had utilized saline waters had lower Hg concentrations than Bay-caught fish and Delta residents. 
Tests for differences in $\mathrm{Cu}$ and $\mathrm{Ni}$ concentrations among Delta residents, Baycaught fish, and Delta-caught fish that had used saline waters, indicated statistically significant lower concentrations in Bay-caught fish $(\mathrm{Cu}: \mathrm{p}=0.004, \mathrm{Ni}: \mathrm{p}=0.001)$. Chromium concentrations could not be tested because variance among groups had too much heteroscedacity. However, since means and variances of the groups were so radically different, it is reasonable to assume that real differences exist (Zar 1999) indicating that lower concentrations of $\mathrm{Cr}$ in Bay-caught fish may also follow the trends seen in $\mathrm{Cu}$ and $\mathrm{Ni}$.

Metal concentrations by catch locations. There was no clear pattern of concentrations with catch locations. The highest mean was in the "Other" grouping, which consisted of Toe Drain, Rio Vista, Cache Slough, Miners Slough, and Catchment Slough individuals (Fig. 20).

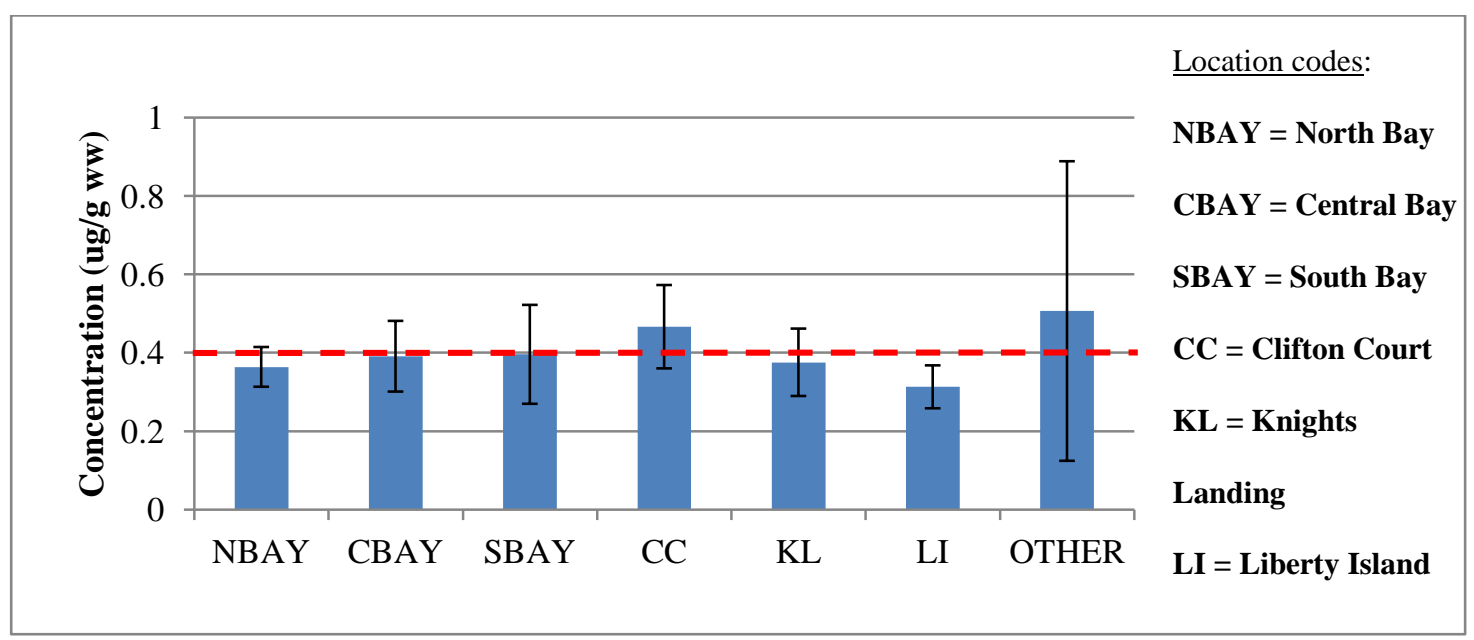

Figure 20: Average mercury concentrations with $95 \%$ confidence intervals for all catch groups. Red dotted line denotes screening level for mercury $(0.4 \mathrm{ug} / \mathrm{g} \mathrm{ww})$ 
The lowest mean mercury concentration was found in the Liberty Island catch group. Interestingly, the highest concentration in an individual was found in a three-year-old female, $593 \mathrm{~mm}$ total length in the Catchment Slough that had a very high mercury concentration of $1.85 \mu \mathrm{g} / \mathrm{g}$ wet weight. An ANOVA was used to test for differences among the groups, no significant difference was found $(\mathrm{p}=0.286, \mathrm{df}=6)$. To reach sufficient power, 34 individuals per catch group are needed, which was satisfied only by the North Bay group.

The frequency of mercury levels above SL increased slightly with proximity to Clifton Court. The highest frequency was in Clifton Court, while the lowest was in Liberty Island (Table 9).

Table 9: Numbers and frequencies of individuals above the screening level for mercury.

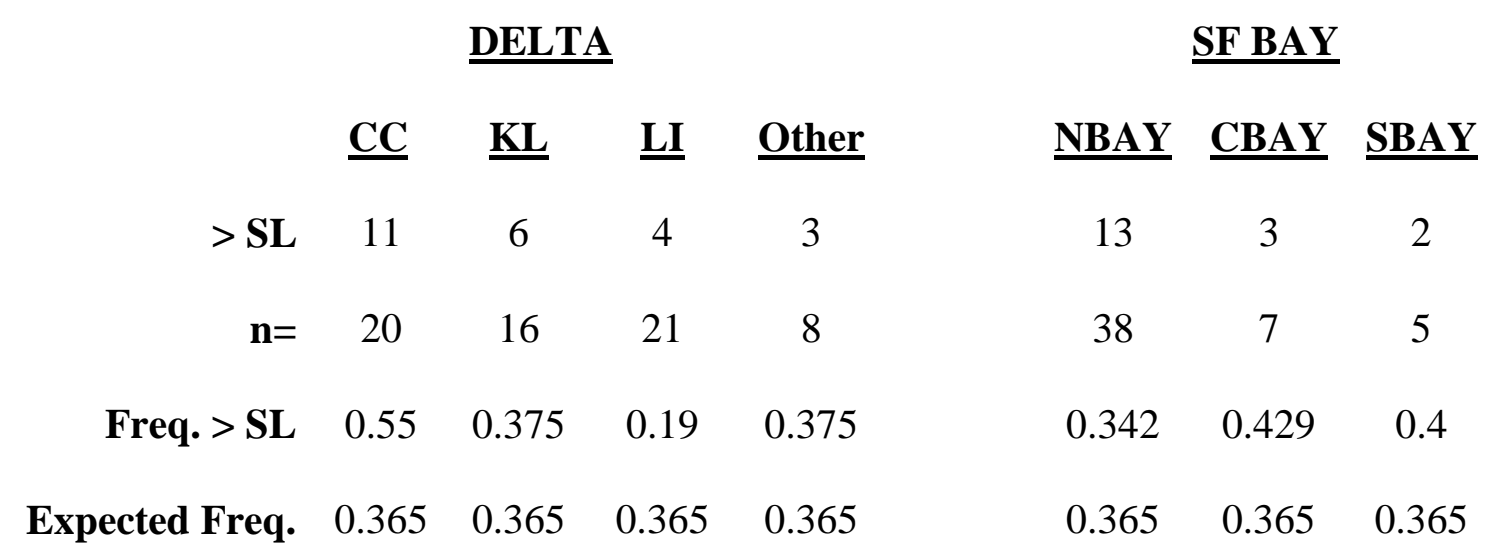

To compare actual numbers of individuals with expected numbers of individuals per catch group (expected number of individuals $=\mathrm{n} * 0.375$ for each group), a Chisquare was performed on groups where the expected number of individuals was at least 
five (Clifton Court, Knights Landing, Liberty Island, and North Bay). No significant difference was found in frequencies $\left(\chi_{\text {obs }}=3.72, \mathrm{df}=3, \chi_{\text {crit }}=7.82\right)$.

There was considerable more variability of other metal concentrations among catch locations than $\mathrm{Hg}$ concentrations. Arsenic, chromium, and selenium had higher concentrations on average in Liberty Island than other catch groups (Fig. 21).

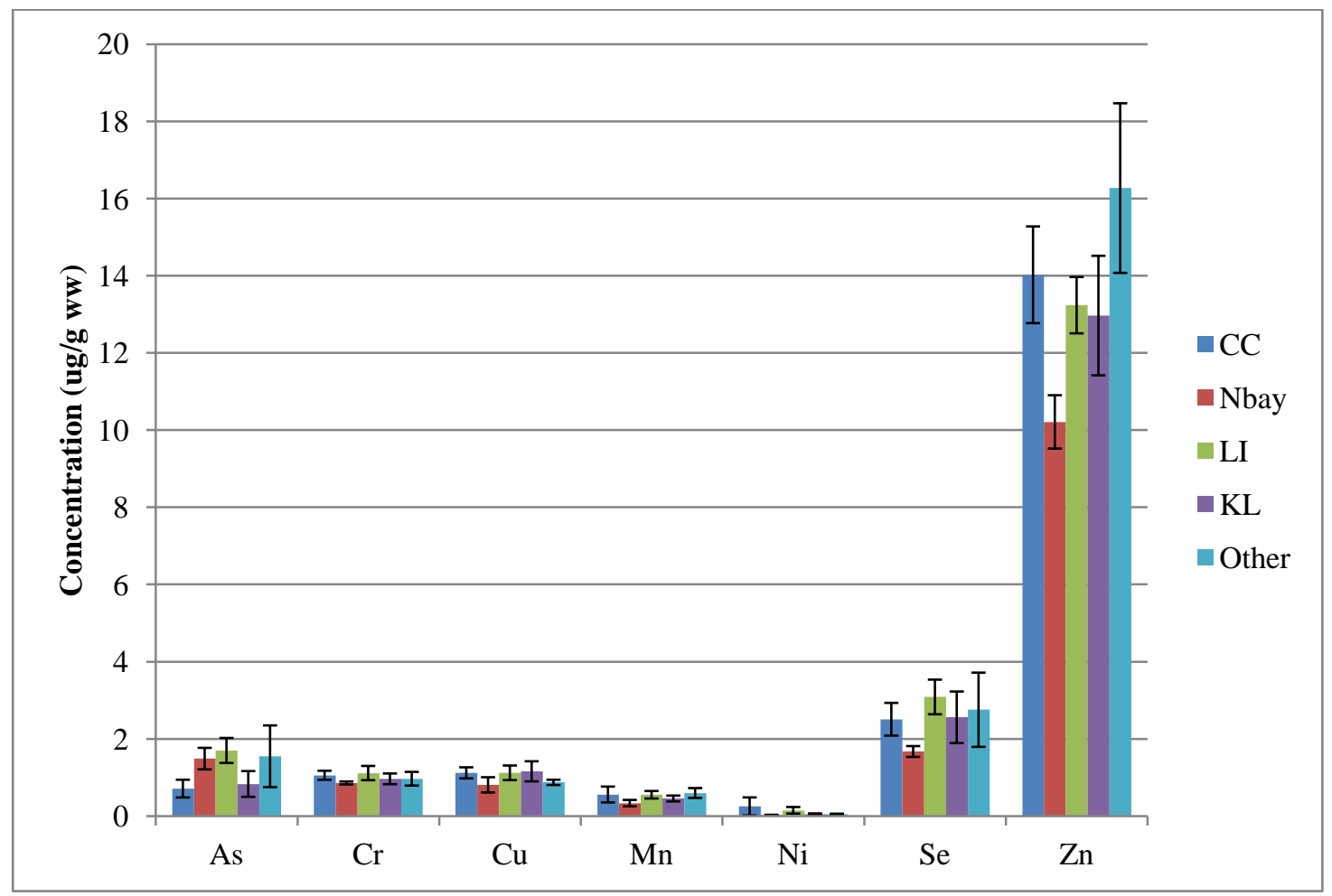

Figure 21: Mean concentrations of other metals for all catch groups with associated $95 \%$ confidence intervals.

Fish caught in Knights Landing had higher average copper and nickel levels in their tissue. Manganese and zinc concentrations were highest in Clifton Court and individuals from "other" sites in the Delta. The lowest mean concentrations for these metals were in the North Bay group with the exception of arsenic. 
Although differences in these metal concentrations amongst catch locations were often small, ANOVAs determined that the differences seen among many catch locations were significant. Comparison of As concentrations among catch groups showed that there was a significant difference $(\mathrm{p}=0.000, \mathrm{df}=4)$ where As concentrations were higher in North Bay and Liberty Island fish than Clifton Court and Knights Landing fish. An ANOVA for copper concentrations was significant as well $(\mathrm{p}=0.019, \mathrm{df}=4)$ indicating that lower $\mathrm{Cu}$ concentrations existed in North Bay fish than Clifton Court fish. The ANOVAs of Mn concentrations and Se concentrations, without one outlier, were also significant $(\mathrm{Mn}: \mathrm{p}=0.023$, df $=4$; Se: $\mathrm{p}=0.002$, df $=4)$. This resulted from lower concentrations in the North Bay than Liberty Island individuals for both metals. Furthermore, the ANOVA for inverse-transformed Ni concentrations was likewise significant $(\mathrm{p}=0.000, \mathrm{df}=4)$, where lower concentrations in North Bay fish from all other groups was responsible for the significant difference.

The lone ANOVA which did not reject the null hypothesis was for $\mathrm{Cr}$ concentrations $(\mathrm{p}=0.062, \mathrm{df}=4)$. Power was fair for this test; one group (Clifton Court) had more than enough samples to reach sufficient power $(=0.8$ when $n=17)$ and three other groups were close to the required number of samples (Knights Landing, Liberty Island and North Bay).

Changes in mercury concentrations with time. Changes in mercury concentrations in San Pablo Bay imply that $\mathrm{Hg}$ concentrations are increasing for Baycaught fish. The lowest mean concentration was found in the 2000 catch group, while the highest was in the 2006 catch groups (Fig. 22). 


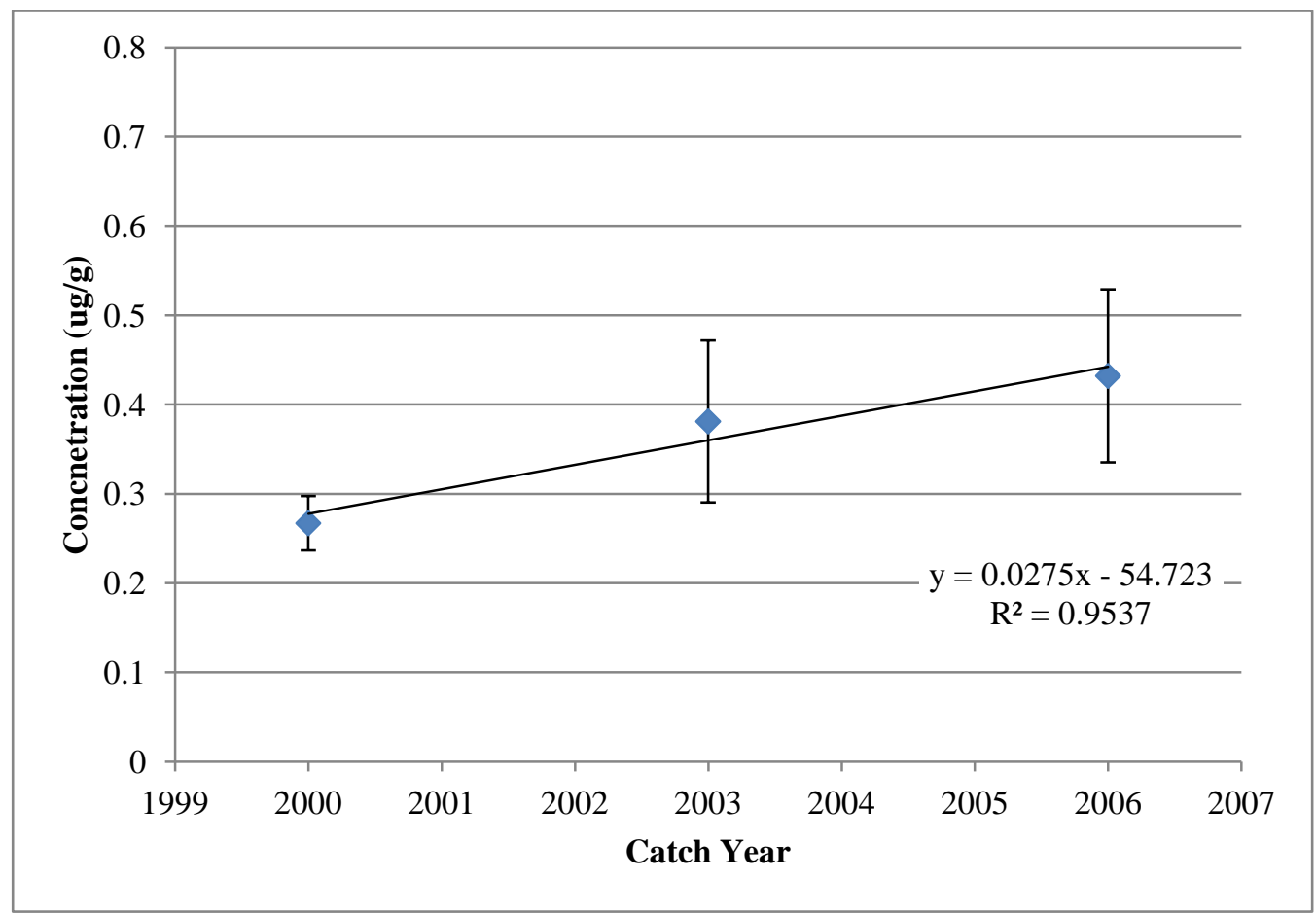

Figure 12: Average mercury levels with $95 \%$ confidence intervals of fish caught in San Pablo Bay by catch year. Asterisk indicates that 2000 was significantly lower than other catch years. Trendline is shown with $\mathbf{r}^{2}$ value and slope.

An ANOVA of the square root-transformed Hg concentrations showed that this difference was significant $(\mathrm{p}=0.01, \mathrm{df}=2)$. A Tukey's pair-wise comparison determined that this result was due to fish caught in 2006 having higher mercury levels than those caught in 2000. There was no significant difference between 2000 and 2003 caught fish, but the $\mathrm{p}$-value was close to being significant $(\mathrm{p}=0.08)$. Although there are only data for three catch years, regression of the data yields a tight correlation $\left(r^{2}=0.95\right)$. The data suggest that in the San Pablo Bay, average mercury tissue concentrations increased in Striped Bass $0.0275 \mu \mathrm{g} / \mathrm{g}$ (wet weight) per year for the time period. 
Changes in mercury with size and age. Mercury concentrations generally increased with size and age. There was a trend of increasing mercury levels with increasing size, but the fit of the trend line was poor (Fig. $\left.23, \mathrm{r}^{2}=0.11\right)$.

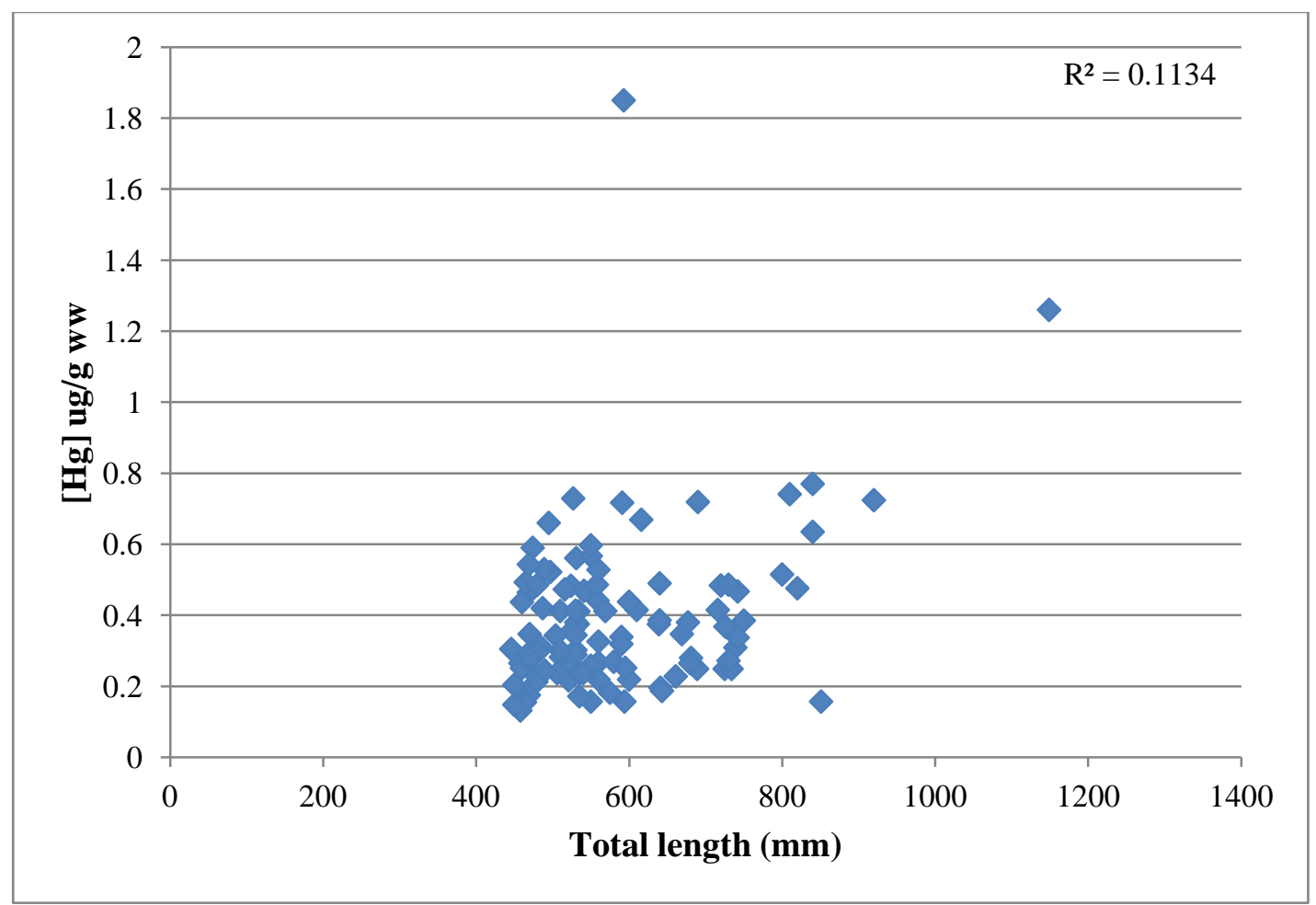

Figure 23: Plot of mercury concentration with total length for each individual.

Age was also plotted against mercury concentrations to see if the trend could be tighter ( $n=115$, Fig. 24). There was a positive trend with mercury and age, but the fit was still poor $\left(r^{2}=0.23\right)$. 


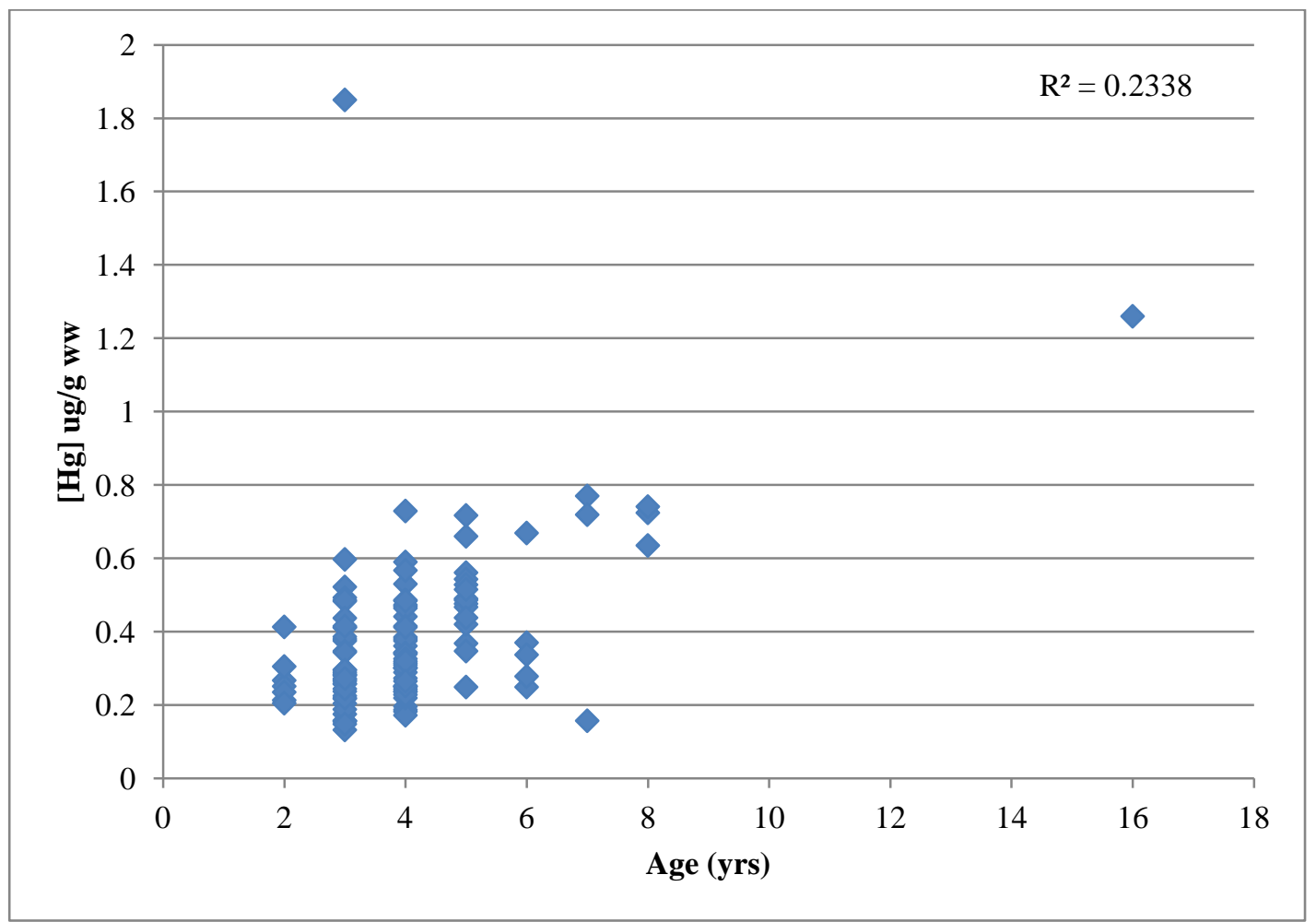

Figure 24: Plot of mercury concentration with age estimate for all individuals.

Differences due to sex. No significant relationship was found between mercury concentrations and gender of individuals. For mercury, males on average had a higher concentration than females, but variance was much higher in females (Fig. 25). 


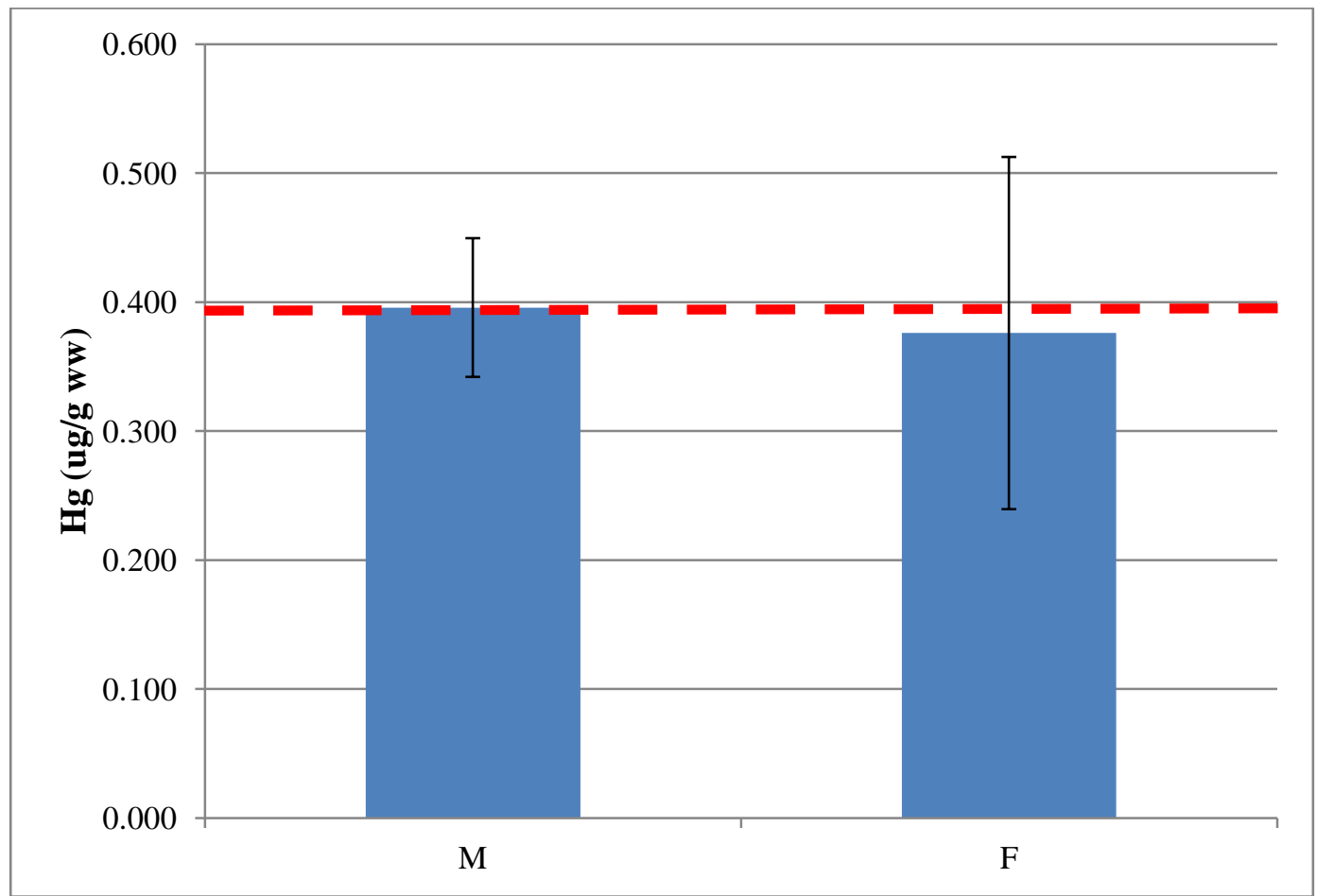

Figure 25: Mean mercury concentrations with $95 \%$ confidence intervals for individuals with gender information. Red line denotes screening level for mercury $(0.4 \mathrm{ug} / \mathrm{g} \mathrm{ww})$.

A t-test was performed on the log-transformed data and the difference was not significant. Power analysis showed that 278 fish total (139 individuals of each gender) was needed to get sufficient power.

Other metals also showed no significant relationship with gender. Males had higher concentrations than females for $\mathrm{Cr}, \mathrm{Mn}, \mathrm{Ni}, \mathrm{Se}$, and $\mathrm{Zn}$, where females had higher As and $\mathrm{Cu}$ (Fig. 26). 


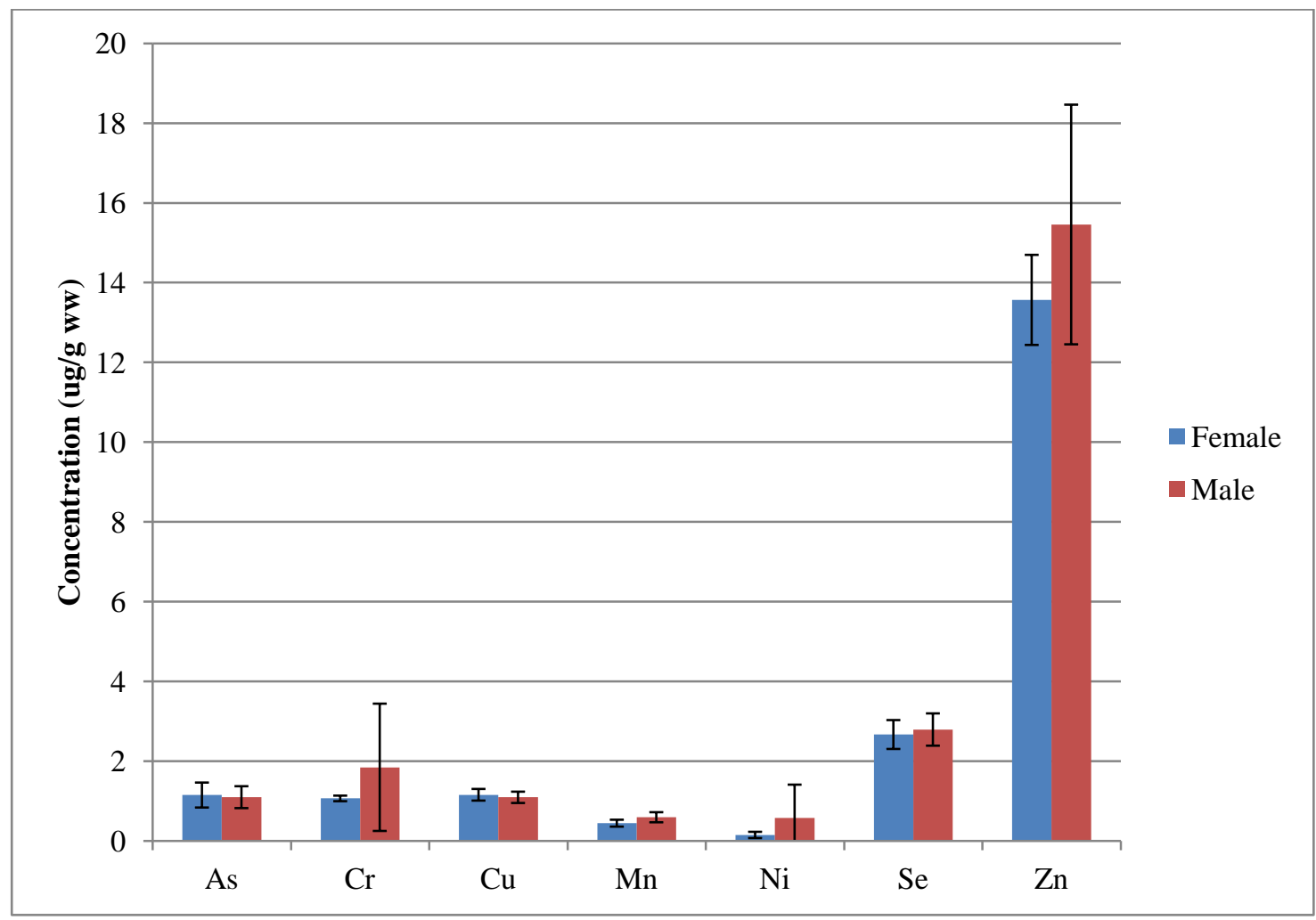

Figure 26: Averages of other metals concentrations with associated $95 \%$ confidence intervals for each gender (when available).

However, most of these differences were very small. T-tests were performed to check for significant differences on $\mathrm{As}, \mathrm{Cu}, \mathrm{Mn}, \mathrm{Se}$, and $\mathrm{Ni}$ concentrations and it all cases they were not significant (Table 10). 
Table 10: Mean concentrations and p-values for each metal examined. Sample sizes for power of 0.8 , if applicable, represent total sample sizes if all groups have equal numbers. Asterisk on mercury indicates sample sizes of $\mathbf{n = 2 7}$ for females and $\mathbf{n = 3 6}$ for males.

$\begin{array}{llllllll}\text { As } & \mathrm{Cr} & \mathrm{Cu} & \mathrm{Mn} & \mathrm{Ni} & \mathrm{Se} & \mathrm{Zn} & \mathrm{Hg}^{*}\end{array}$

Female

$(\mathbf{n}=\mathbf{2 0})$

$\begin{array}{lllllllll}\text { Avg } & 1.15 & 1.066 & 1.157 & 0.445 & 0.15 & 2.668 & 13.567 & 0.362 \\ \text { SD } & 0.714 & 0.16 & 0.334 & 0.198 & 0.179 & 0.826 & 2.577 & 0.362\end{array}$

Male

$(\mathbf{n}=32)$

$\begin{array}{lllllllll}\text { AVG } & 1.097 & 1.846 & 1.093 & 0.594 & 0.576 & 2.793 & 15.458 & 0.396\end{array}$

$\begin{array}{lllllllll}\text { SD } & 0.792 & 4.606 & 0.41 & 0.365 & 2.411 & 1.168 & 8.673 & 0.165\end{array}$

$\begin{array}{rcccccccc}\text { p-value } & 0.733 & -- & 0.432 & 0.054 & 0.453 & 0.798 & -- & 0.201 \\ \mathbf{n =} \text { Power } 0.8 & 3378 & -- & 672 & 128 & 770 & 6356 & -- & 278\end{array}$

Power was also very low for most of these tests. Chi-square tests were performed for $\mathrm{Cr}$ and $\mathrm{Zn}$ since assumptions for a t-test could not be met with these data. Both of these tests were not close to rejecting the null hypotheses $\left(\mathrm{df}=1, \chi_{\text {crit }}=3.84, \chi_{\text {obs Cr }}=0.01, \chi_{\text {obs Zn }}=\right.$ $0.00)$.

PCA. Out of all factors examined, size of Striped Bass explained the most variance in the data. In general, essential metals excluding copper and zinc had correlations with size (Fig. 27). 


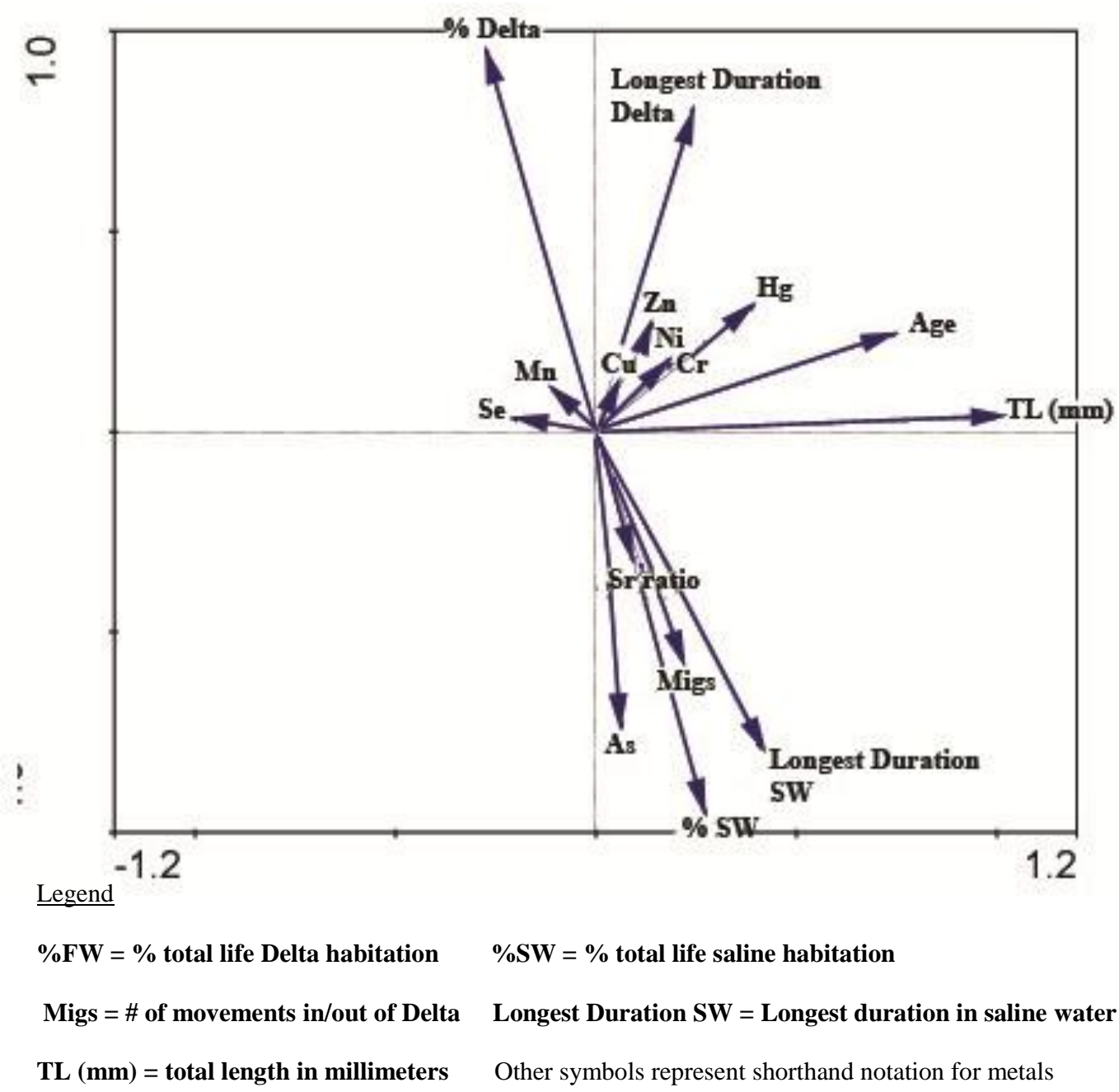

Figure 27: Principal component analysis diagram depicting relation of factors to one another. Factors which are orthogonal to one another are not correlated. Axes together represent $99.7 \%$ of total variability in data set.

Mercury, nickel and chromium were positively correlated with size where manganese and selenium were inversely correlated with size of individuals.

The second most important factor explaining variance was movement patterns. Almost all metals showed weak to no correlations with habitat factors except in a few cases. Arsenic showed strong positive correlation with more movements in general and more time spent in salt water habitats. Mercury also showed a strong positive correlation 
with longer durations in fresh water. Also, most essential metals $(\mathrm{Cr}, \mathrm{Cu}, \mathrm{Ni}$ and $\mathrm{Zn})$ were positively correlation with long durations spent in fresh water.

Most other metal concentrations were either weakly or not correlated to one another at all. However, there were some exceptions to this. Mercury showed a positive correlation with $\mathrm{Ni}$ and $\mathrm{Cr}$, but the strength of that relationship was fairly weak in explaining a lot of variance in the data set. Mercury did show a fairly strong inverse relationship with selenium. Selenium and manganese were also positively correlated with one another.

The PCA strongly emphasized some other key points. There was no relationship between many of the habitat factors that were examined with mercury concentrations. Strontium isotope ratios, proportion of life spent in fresh water habitats, durations of salt water residency and numbers of movements into and out of the Delta. In fact, most habitat and movement factors poorly explained many of the metal concentrations with the exception of arsenic. Additionally, results indicated that there was virtually no difference in the last three years of residency from that of whole life habitat residency.

\section{Tissue Chemistry Discussion}

Since Striped Bass are an extremely popular target for recreational fishing activities, one of the aims of this study was to evaluate the applicability of current fishing regulations to safety in consuming Striped Bass. Potential toxicity can be evaluated by comparing concentrations of nonessential metals with their respective screening levels (Table 5). By and large, most of concentrations were very low and rarely detected. 
There is no threat to public health for silver, aluminum, and lead. However, mercury and cadmium do pose potential problems for consumers.

Mercury, as expected, poses the most danger to human consumers. Mercury was detected in every sample and over a third of those samples were above the screening value. Additionally, when the amount of meals necessary to reach regulatory thresholds was calculated, it showed that not many meals were needed to get to a mercury content consumed to a dangerous level, especially for children. Furthermore, those that derive a large portion of their diet from fishing are also at risk if they primarily eat Striped Bass. This study clearly shows that eating Striped Bass is a health risk for children, pregnant women, and those that eat more than a few meals of Striped Bass per month. Advisories to protect these groups are appropriate.

Cadmium may also be a potential health concern when eating Striped Bass. Cadmium was only detected in about a third of the samples, but when detected it was enough to pose a potential health risk. Cadmium levels were below screening levels, but when MPM was calculated, it showed that levels of cadmium were high enough to warrant concern. Only about two meals were needed for adults to get to potentially problematic levels of cadmium. Since cadmium has excretion rates on the order of decades in humans (ATSDR 2008a; Ryan et al., 1982), even occasional high doses of cadmium over very long periods of time can affect health of individuals. Furthermore, cadmium is not often deposited in muscle tissue in fish. Because cadmium deposition in fish is primarily in the kidneys and other viscera, much lower concentrations are seen in portions that would be consumed in fillets. There is evidence that cadmium 
concentrations in skin can be an order of magnitude higher than that of muscle, and as much as 50 times higher in fish liver than fish muscle (Blood and Grant 1975). Even at low levels seen in our detections, this could be a real public hazard for consumers who eat Striped Bass with the skin on (SFEI 2000).

Comparisons of mercury and cadmium with previous studies show that levels in fish tissue are increasing. Cadmium was measured at approximately $0.39 \mathrm{ppm}$ dry weight and mercury at 0.22 ppm dry weight in Striped Bass in the San Francisco BayDelta estuary (Setzler-Hamilton et al., 1988). The concentrations reported in this thesis, which are wet weight, either exceed or are comparable to these values, which is troublesome since concentrations per wet weights are several times lower than those measured in concentrations per dry weights. This is because wet weights are often more diluted due to the moisture content remaining in the tissue. Additionally, the tissue data from San Pablo Bay individuals show that mercury levels in muscle tissue continue to gradually increase.

Selenium also poses concern for human consumption of Striped Bass. The average selenium level was below screening levels (put the average or appropriate values here please) but MPM calculations indicate that children could reach harmful levels of selenium in their systems with approximately 8 meals in a month. These calculations indicate that selenium levels in Striped Bass should be investigated further in the future.

There is also evidence that these metal concentrations are adversely affecting the Striped Bass populations. The level of selenium also signals that the population is stressed. Evidence in other fish populations show that a concentration of $2.6 \mu \mathrm{g} / \mathrm{g}$ wet 
weight Se is associated with adverse effects and a declining population (Lemly 1993a, Lemly 1993b). Existence of measurable cadmium levels in muscle tissue are also of concern for Striped Bass due to the deleterious effects of cadmium during Striped Bass development (Spearow et al., 2011).

Mercury concentrations are also of concern to Striped Bass populations. This study shows that mercury levels are increasing over time in the Striped Bass caught in San Pablo Bay, a trend consistent with previous studies (Greenfield et al., 2005). Furthermore, there is evidence in the literature of maternal transfer of xenobiotics into eggs (Ostrach et al., 2008) including mercury (Ostrach et al., 2006) which poses serious adverse impacts on a vulnerable life stage of the species. The difference in mercury concentrations between Delta-caught fish that had used saline habitats and other groups can be used as an estimate of maternal transfer to Striped Bass eggs. This is feasible because fish were collected during times of spawning runs and it is likely the lower concentration of mercury in Delta-caught fish that had used saline habitats is due to excreting mercury prior to capture in spawning products. The most likely sink for this excretion is in eggs, as evidenced by the lower mercury concentration in females in this study. If all of the mercury was transferred into eggs, this was be large amount, approximately $0.1 \mathrm{ug} / \mathrm{g} \mathrm{Hg}$ transferred to young, a quarter of the SL for much larger adult fish. Contaminants from maternal transfer would likely cause life threatening developmental defects during the critical lifestage for an already struggling SFE population (Spearow et al., 2011). Factors that negatively affect early life stages in this 
population are extremely important to quantify and understand to aid in restoring declining stocks of Striped Bass in the San Francisco Estuary.

For the most part, movements of fish did not affect concentrations in Striped Bass for potential health hazards. Mercury was not significantly different between residents and nonresidents, even though residents on average had slightly higher mean mercury concentrations. The PCA also showed that more time spent away from methylation areas like the Delta did not equate to lower contamination levels.

Fish size was the best predictor by far for Striped Bass mercury concentrations. There was a strong correlation between freshwater residency and mercury concentrations but this result is better explained by sizes of individuals. Residents probably had larger average mercury levels because most of the larger individuals sampled were residents and most of these individuals were in Clifton Court. The lone test that showed movement affecting mercury concentrations was in Delta-caught fish that had used saline habitats, which had lower mean concentrations than Bay-caught fish and resident fish. However, this is better explained by the timing of sampling. Samples were largely collected on spawning runs, and the difference probably shows mercury transfer into products of spawning.

Essential metal concentrations did indicate that habitat use did affect concentration levels of arsenic. Arsenic levels in migrants were clearly higher than in residents by three-fold. These levels are not likely to be of harm to the public, since arsenic is commonly bonded to organic complexes in fish that are inert and do not breakdown into harmful valence states upon digestion (Lunde 1977). Even in worst case 
scenario, where inorganic arsenic would constitute $40 \%$ of the total arsenic seen, dangerous levels from consumption would not occur for adults unless they were eating at least one meal of Striped Bass per day. However, it does provide an important additional confirmation for strontium isotope data used in habitat residency estimates. This agrees well with many other studies showing offshore fishes having higher arsenic concentrations than their inshore neighbors due to the prey they feed upon (Friberg et al., 1979, Windam et al., 1973). If strontium isotope work is too expensive or unavailable for future studies of Striped Bass movements, arsenic concentrations in muscle tissue are a plausible alternative to differentiating nonresident and residents in the San Francisco Estuary system.

Catch location also had little effect on non-essential metal concentrations in most situations. Mercury showed no difference due to catch location, even with higher frequencies of contaminated individuals in Clifton Court. This is likely due to size of individuals sampled, and as such size regulations for Striped Bass already in effect limit exposure of the public to harm. There was not enough data to examine catch location effects on cadmium due to low detection rates, but all samples that detected cadmium were in fresh water Delta locations. However, more sampling for cadmium is needed to see if this is an artifact of low detection in our sampling rather than a true effect.

There was a clear effect of catch location upon essential metal concentrations. Although these metals are never at a level of concern for human consumption, and therefore have no effect on regulations to protect the public, they do offer an interesting insight to biological rates within Striped Bass. Freshwater streams in this region are 
sources for these metals (Alpers et al., 2000), so it is not surprising that catch locations in the Delta had higher concentrations of copper, manganese, nickel, selenium and zinc than their North Bay compatriots. This information could be useful to give estimates of clearance rates for cycling of these metals out of Striped Bass muscle tissue.

Additionally, the concentration levels of arsenic add additional evidence for separate habitat use groups in Striped Bass discussed in the first chapter of this thesis. North Bay fish showed much greater dissimilarity to Knights Landing fish in the strontium isotope data, and this appears again in arsenic levels between those two areas. Since North Bay fish habitat utilization was very different from Delta caught individuals, it is possible that these metals could be used as tracers for movements to track contingents and determine mixing patterns in the Striped Bass population. Further studies should focus on the different essential metal concentration in muscle tissue to determine their efficacy as tracers in a few locations, since sample sizes in this study showed that power was low to avoid Type II errors in analysis.

Findings in this study agree with current regulations currently in place to protect the public from toxic metals. Mercury levels in Striped Bass put pregnant women, children and subsistence consumers most at risk, and size restrictions do provide a measure of protection from consuming the most toxic fish in the population. Although size of the fish caught was the most powerful factor in determining mercury concentration of the fish, there is still a very loose correlation between size and concentration level. 
This study clearly shows that habitat use and resident vs. nonresident status are poor predictors. This could be due to one of three factors, or a combination of one or more of them. First, these findings may just reflect the poor state of the San Francisco Estuary region with regards to mercury contamination. It is well known that mercury is of concern in this region, and this study indicated that things are likely getting worse as concentrations significantly increased in San Pablo Bay samples over time, confirming previous studies showing a similar result (Greenfield et al., 2005). One could interpret that since habitat utilization has no effect on mercury body burden, methyl mercury available to Striped Bass could be ubiquitous among areas and prey species commonly exploited by Striped Bass. The accuracy of this hypothesis unfortunately is outside the scope of this thesis, since using otolith chemistry only gives regional estimates of fish movements. Finer movements, such as examining if individuals are spending time in specific sloughs in the Delta, cannot be estimated using otolith chemistry. Given the nature of localized methylation in the Delta (Heim, 2003), further detail of specific locations used could possibly show more specific habitat utilization estimates are better predictors of metal body burden than indicated here.

Secondly, these findings show that concentrations of mercury could be better predicted by factors not examined by this study. Mercury is thought to accumulate in Striped Bass populations due to their piscivorous and opportunistic feeding patterns (Moyle 2002). Examination of diet or estimation of general trophic feeding in carbon isotope studies could provide the missing factor in better determining mercury concentration in an individual. There is some evidence for this in the individuals caught. 
The most contaminated individual in the study was a three year old fish caught at the Toe Drain location in the Delta, even though older individuals and bigger individuals were caught at Clifton Court. The Toe Drain fish caught was rather larger for a three year old, which is conceivably due to exceptional feeding of this individual. If rates of feeding and trophic level of said feeding could be measured in Striped Bass, it could give an additional predictor for mercury concentrations. It should be noted that archival tissue for each individual which had a full screening for metal concentrations exists, so further investigation is possible should someone be interested.

Last, mercury concentrations are likely also affected by internal functions. It has been shown in other studies that organic complexes, called metallothioneins, are used by individuals to combat toxic levels of mercury concentrations in the individual (Spearow et al., 2011). Rate of production of metallothioneins are likely based on environmental cues, stress of the animal, and genetic predisposition (Andersen et al., 1986). If these elements could be measured in future studies examining Striped Bass mercury concentrations, it might provide more information about how to predict toxic individuals. Though possible, this hypothesis does seem unlikely since all individuals in the SFE are descendant from only a few hundred individuals (Scofield 1928). This genetic bottleneck would suggest that most individuals in the SFE have a very similar genetic makeup, although this was outside the scope of this thesis.

There were some weaknesses in this study that hampered analysis. Uneven and low sample sizes made it difficult to assess if Type II errors were avoided, as indicated by low power in several analyses. It is likely that stronger inferences could be made if more 
individuals were caught, and fishing effort was concentrated in just a few areas instead of all over the SFE. Unfortunately, Striped Bass fishing effort was mostly opportunistic since several other species were targeted during the RMP and FMP surveys. Those surveys sought to examine mercury concentrations throughout the fish assemblage, not Striped Bass alone. Lack of information on the gender of individuals also made it extremely difficult to test differences with sufficient power. The sample sizes needed to be more robust and more balanced to examine the effects of gender and catch location on metal concentrations in greater depth. If the aim of these surveys had been more Striped Bass centric, it is likely more could be gleaned from the data.

However, this thesis provides corroborative evidence that metals pose an additional threat to Striped Bass populations which have suffered dramatic declines over the past several decades. The sharp decline in 1980s and 1990s is well documented in many studies. The minimum size limit in fishing regulations attempts to preserve younger age classes from recreational fishing pressure with the hopes that the population can rebound. However, it is apparent from other studies that more obstacles must be overcome before a full recovery can occur, and metal and other contaminant pollution is a likely player in the decline of this species in this area (Ostrach et al., 2009; Ostrach et al., 2008; Stevens et al 1985). Previous studies indicate diversions of flows for the California aqueduct might confuse potential spawners and inhibit prey and young Striped Bass accumulations at the typical location in Suisun Bay (Callahan et al., 1982). This study also provides evidence that Striped Bass eggs could be receiving as much as 0.1 $\mu \mathrm{g} / \mathrm{g}$ wet weight of $\mathrm{Hg}$ which could have dramatic development consequences for age 
classes that are crucial for recovery. In addition, cadmium and selenium levels indicate that the Striped Bass population is stressed, and further increases in $\mathrm{Hg}$ in potential spawners measured in the San Pablo Bay could delay recovery or signal that further declines may occur in the future.

Other than mercury concentrations, there are very limited data in the literature regarding fish tissue concentrations of metals. Outside of the RMP and FMP surveys, there is very little concentration data available, and these surveys are only performed every three years. There is a lot of work in this area that could benefit both potential health threats to the public from contaminants and evaluating future avenues for tracing fish movements. Although Striped Bass do resemble some behaviors seen in East coast populations, this thesis already provides enough information that the population is different from those studies. Contingents of moving fish and resident Striped Bass exist in the SFE, but more variability in movements in the SFE population than East coast populations is apparent from the otolith chemistry data in this thesis and other recent studies (Ostrach et al., 2009). It should not be a surprise since the San Francisco BaySacramento Delta estuary is a very different system than the areas where Striped Bass is more thoroughly studied on the East coast. There needs to be more background information generated on chemical concentrations and Striped Bass movements of individuals, not just composites. Metal concentrations from several types of tissues and other classes of contaminants, such as organic pesticides and PBDEs, would provide a more comprehensive representation of threats to this Striped Bass population and human consumers from chemical contaminants. This study shows that tissue samples in general 
are at present inadequate to test for differences among sexes and catch locations for potentially toxic metals. This is important if recovery of Striped Bass is a priority, because more information is needed to evaluate potential recovery efforts, especially where selenium and cadmium might be affecting the populations. This will take time and effort, but Striped Bass is an extremely popular sport fish; there is money to be saved and made by doing so and ensuring a population that can be fished by anglers and can keep people from getting sick. This is a natural resource that is in crucial need of more information, in order for it to be proactively managed effectively.

Striped Bass in the San Francisco Estuary system are found close to large industry developed urban and industrial areas, as such long-term surveys and studies that collect data focusing on chemical contaminants must continue, if for no other reason than to get better background information on potential risks to human health. Hopefully, this study can serve as a pilot study for future endeavors. 


\section{References}

Alpers, C.N. \& M.P. Hunerlach. (2000). Mercury contamination from historic gold mining in California. U.S. Geological Survey Fact Sheet FS-061-00, 2000, 6.

Alpers, C.N., R.C. Antweller, H.E. Taylor, P.D. Dileanis, \& J.L. Domagalski. (2000). Metals Transport in the Sacramento River, California, 1996-1997. U.S. Geological Survey, Water-Resources Investigations Report 00-4002.

Andersen, R., J. Frazier, \& P.C. Huang. (1986). Transition metal-binding proteins from three ChesapeakeBay fish species. Environmental Health Perspectives, 65, $149-156$.

Agency for Toxic Substances and Disease Registry (ATSDR). (1990). Toxicological Profile for Silver. Agency for Toxic Substances and Disease Registry, U.S. Public Health Service. Retrieved from http://www.atsdr.cdc.gov/ToxProfiles/tp146.pdf

ATSDR. (1999). Toxicological Profile of Mercury. Agency for Toxic Substances and Disease Registry, US Department of Health and Human Services. Retrieved from http://www.atsdr.cdc.gov/toxprofiles/tp46.html

ATSDR. (2003). Toxicological Profile for Selenium. U.S. Department of Health and Human Services, Public Health Service, Agency for Toxic Substances and Disease Registry. Retrieved from http://www.atsdr.cdc.gov/ToxProfiles/tp92.pdf ATSDR. (2004). Toxicological Profile for Copper. U.S. Department of Health and Human Services, Public Health Service, Agency for Toxic Substances and Disease Registry. Retrieved from http://www.atsdr.cdc.gov/ToxProfiles/tp132.pdf 
ATSDR. (2005a). Toxicological Profile for Nickel. U.S. Department of Health and Human Services, Public Health Service, Agency for Toxic Substances and Disease Registry. Retrieved from http://www.atsdr.cdc.gov/ToxProfiles/tp15.pdf

ATSDR. (2005b). Toxicological Profile for Zinc. U.S. Department of Health and Human Services, Public Health Service, Agency for Toxic Substances and Disease Registry. Retrieved from http://www.atsdr.cdc.gov/ToxProfiles/tp60.pdf ATSDR. (2007a). Draft Toxicological Profile for Arsenic. U.S. Department of Health and Human Services, Public Health Service, Agency for Toxic Substances and Disease Registry. Retrieved from http://www.atsdr.cdc.gov/ToxProfiles/tp2.pdf ATSDR. (2007b). Toxicological Profile for Lead. U.S. Department of Health and Human Services, Public Health Service, Agency for Toxic Substances and Disease Registry. Retrieved from http://www.atsdr.cdc.gov/ToxProfiles/tp13.pdf ATSDR. (2008a). Draft Toxicological Profile for Cadmium. U.S. Department of Health and Human Services, Public Health Service, Agency for Toxic Substances and Disease Registry. Retrieved from http://www.atsdr.cdc.gov/ToxProfiles/tp5.pdf ATSDR. (2008b). Draft Toxicological Profile for Chromium. U.S. Department of Health and Human Services, Public Health Service, Agency for Toxic Substances and Disease Registry. Retrieved from http://www.atsdr.cdc.gov/ToxProfiles/tp7.pdf 
ATSDR. (2008c). Toxicological Profile for Manganese. U.S. Department of Health and Human Services, Public Health Service, Agency for Toxic Substances and Disease Registry. Retrieved from http://www.atsdr.cdc.gov/ToxProfiles/tp151.pdf ATSDR. (2009). Toxicological Profile for Aluminum. U.S. Department of Health and Human Services, Public Health Service, Agency for Toxic Substances and Disease Registry. Retrieved from http://www.atsdr.cdc.gov/ToxProfiles/tp22.pdf Barkuloo, J.M. (1970). Taxonomic status and reproduction of Striped Bass (Morone saxatilis) in Florida. Technical Papers of the Bureau of Sport Fisheries and Wildlife, 44.

Beamish, R.J. \& D.A. Fourier. (1981). A method for comparing the precision of a set of age determinations. Canadian Journal of Fisheries and Aquatic Sciences, 38(8), 982-983.

Bennett, W.A., D.J. Ostrach, \& D.E. Hinton. (1995). Larval Striped Bass condition in a drought-stricken estuary: evaluating pelagic food-web limitation. Ecological Applications, 5(3), 680-692.

Benoit, J.M., C.C. Gilmour, A. Heyes, R.P. Mason, \& C.L. Miller. (2003). Geochemical and biological controls over methylmercury production and degradation in aquatic ecosystems. In ACS Symposium series 835, Biochemistry of Environmentally Important Trace Elements, (p. 262-297). American Chemical Society Publications. 
Bielmyer, G., M. Grosell, \& K. Brix. (2006). Toxicity of silver, zinc, copper, and nickel to the copepod Acartiatonsa exposed via a phytoplankton diet. Environmental Science and Technology, 40, 2063-2068.

Blood, E.R., \& G.C. Grant. (1975). Determination of cadmium in fish tissue by flameless atomic absorption with a tantalum ribbon. Analytical Chemistry, 47(8), 1438-1441.

Bloom, N.S. (1992). On the chemical form of mercury in edible fish and marine invertebrate tissue. Canadian Journal of Fisheries and Aquatic Sciences, 49(5), 1010-1017.

Bolster, B.C. (1986). Movement Patterns of Striped Bass (Morone saxatilis) in Clifton Court Forebay, Contra Costa County California. Master of Science Thesis, California State University, Sacramento.

Brim, M.S., S.K. Alam, \& L.G. Jenkins. (2001). Organochlorine pesticides and heavy metals in muscle and ovaries of Gulf Coast Striped Bass (Morone saxatilis) from the Apalachicola River, Florida, USA. Journal of Environmental Science and Health, Part B, 36, 25-27.

Byington, A.A. (2007). Photo-degradation of Methylmercury in the Sacramento-San Joaquin Delta Estuary. Masters Thesis, Moss Landing Marine Laboratories. Calhoun, A.J. (1949). California Striped Bass catch records from the party boat fishery; 1938-1948. California Fish and Game, 35(4), 211-253.

Calhoun, A.J. (1952). Annual migrations of California Striped Bass. California Fish and Game. 38(3), 391-403. 
Callahan, J., A.C. Fisher, \& S. Templeton. (1989). The San Francisco Bay/Delta Striped Bass Fishery: Anatomy of a Decline. UC Berkeley: Department of Agricultural and Resource Economics, UBC. CUDARE Working Paper No. 499. Retrieved from: http://escholarship.org/item/8r94j0rn

Campana, S.E. (1999). Chemistry and composition of fish otoliths: pathways, mechanisms and applications. Marine Ecology Progress Series, 188, 263-297.

Campana, S.E. \& S.R. Thorrold. (2001). Otoliths, increments, and elements: keys to a comprehensive understanding of fish populations? Canadian Journal of Fisheries and Aquatic Sciences, 58, 30-38.

California Department of Fish and Game (CDFG). (1987). Factors affecting Striped Bass abundance in the Sacramento-San Joaquin River system. Interagency Ecological Study Program for the Sacramento-San Joaquin Estuary Technical Report 20. Sacramento, California.

CDFG. (2006). 2006 Freshwater Sport Fishing Regulations. California Department of Fish and Game, Sacramento, California.

Chadwick, H.K. (1967). Catch records from the Striped Bass sport fishery in California. California Fish and Game, 48(3), 153-177.

Chang, W.Y.B. (1982). A statistical method for evaluating the reproducibility of age determination. Canadian Journal of Fisheries and Aquatic Sciences, 39(8), 1208-1210.

Clark, J.R. (1936). A second report on Striped Bass tagging. California Fish and Game, 22(4), 272-283. 
Clark, J.R. (1968). Seasonal movements of Striped Bass contingents of Long Island Sound and the New York Bight. Transactions of the American Fisheries Society, 97, 320-343.

Davis, J.A., R. Hoenicke, A. Gunther, \& B. Thompson. (2000). An overview of contaminant-related issues identified by monitoring in San Francisco Bay. Environmental Monitoring and Assessment, 64, 409-419.

Davis J.A., D. Yee, J.N. Collins, S.E. Schwarzbach \& S.N. Luoma. (2002). Potential for increased mercury accumulation in the estuary food web. San Francisco Estuary and Watershed Science, 1(1), art. 4.

Domagalski, J. (2001). Mercury and methylmercury in water and sediment of the Sacramento River Basin, California. Applied Geochemistry, 16, 1677-1691.

Dorazio, R.M., K.A. Hattala, C.B. McCollough, \& J.E. Skjeveland. (1994). Tag recovery estimates of migration of Striped Bass from spawning areas of the Chesapeake Bay. Transactions of the American Fisheries Society, 123(6), 950-963.

Dudley, R.G., A.W. Mullis, \& J.W. Terrell. (1977). Movements of adult Striped Bass (Morone saxatilis) in the Savannah River, Georgia. Transactions of the American Fisheries Society, 106(4), 314-322.

Environmental Protection Agency (EPA). (2000). Guidance for Assessing Chemical Contaminant Data for Use in Fish Advisories, Vol 2: Risk Assessment and Fish Consumption Limits, Third Edition. Office of Science and Technology, Office of Water. U.S. Environmental Protection Agency, Washington DC. 
EPA. (2001). Mercury update: impact on fish advisories. United States Environmental Protection Agency fact sheet, EPA-823-F-01-011 Retrieved from http://www.epa.gov/waterscience/fishadvice/mercupd.pdf

Feyrer, F., M.L. Nobriga, \& T.R. Sommer. (2007). Multidecadal trends for three declining fish species: habitat patterns and mechanisms in the San Francisco Estuary, California, USA. Canadian Journal of Fisheries and Aquatic Sciences, 64, 723-734.

Friberg, L., G.F. Nordberg, \& V.B. Vouk (eds). (1979). Handbook on the Toxicology of Metals. Amsterdam; New York: Elsevier/North-Holland Biomedical Press; New York.

Gilmour, C.C., E.A. Henry, \& R. Mitchell. (1992). Sulfate stimulation of mercury methylation in freshwater sediments. Environmental Science and Technology, 26, 2281-2287.

Greenfield, B.K., J.A. Davis, R. Fairey, C. Roberts, D. Crane, \& G. Ichikawa. (2005). Seasonal, interannual, and long-term variation in sport fish contamination, San Francisco Bay. Science of the Total Environment 336, (2005), 25-43.

Harris, R.J. (1975). A Primer of Multivariate Statistics. Academic Press, Inc., New York, New York.

Heim, W.A. (2003). Methyl and total mercury in surficial sediments of the San Francisco Bay-Delta. Masters Thesis, Moss Landing Marine Laboratories. 
Hilborn, R. \& C. Walters. (1992). Quantitative fisheries stock assessment and management: choice, dynamics, and uncertainty. New York, NY: Chapman and Hall.

Hudson, R.J.M., S.A. Gherini, C.J. Watras \& D.P. Porcella. (1994). Modeling the biogeochemical cycle of mercury in lakes: The mercury cycling model (MCM) and its application to the MTL study lakes. In J.Watras \& J.W. Huckabee (eds.) Mercury Pollution: Integration and Synthesis (p 473-526).

Ingram, B.L. \& D. Sloan. (1992). Strontium isotopic composition of estuarine sediments as paleosalinity-paleoclimate indicator. Science, 255(5040), 68-72.

Jassby, A.D., W.J. Kimmerer, S.G. Monismith, C. Armor, J.E. Cloern, T.M. Powel, J.R. Schubel, \& T.J. Vendlinski. (1995). Isohaline position as a habitat indicator for estuarine populations. Ecological Applications, 5, 272-289.

Kalish, J.M. (1991). Determinants of otolith chemistry: seasonal variation in the composition of blood plasma, endolymp and otoliths of bearded rock cod Pseudophycis barbatus. Marine Ecology Progress Series, 74, 137-159.

Katsuna, M. (ed). (1968). Minamata Disease. Japan: Kumamoto University.

Kennedy B.D., C.L. Folt, J.D. Blum, \& C.P. Chamberlain. (1997). Natural isotope markers in salmon. Nature, 387, 766-767.

Korthals, E.T., \& M.R. Winfrey. (1987). Seasonal and spatial variations in mercury methylation and demethylation in an oligotrophic lake. Applied Environmental Microbiology, 53, 2397-2404. 
Kraus R.T. \& D.H. Secor. (2004). Incorporation of strontium into otoliths of an estuarine fish. Journal of Experimental Marine Biology and Ecology, 302, 85-106.

Lemly, D.A. (1993a). Guidelines for evaluating selenium data from aquatic monitoring and assessment studies. Environmental Monioring and Assessment, 28, 83-100.

Lemly, D.A. (1993b). Metabolic stress during winter increases the toxicity of selenium to fish. Aquatic Toxicology, 27, 133-158.

Leppard, G.G. \& NATO. (1983). Trace element speciation in surface waters and its ecological implications. In NATO Advanced Research Workshop Program on Trace Elements Speciation in Surface Waters and Its Ecological Implications, New York: Published in cooperation with NATO Scientific Affairs Division [by] Plenum Press.

Lepš, J. \& P. Šmilauer. (2003). Multivariate Analysis of Ecological Data using CANOCO. Cambridge University Press, Cambridge, United Kingdom.

Lowe, S., R. Hoenicke, J. Davis, \& G. Scelfo. (1999). Quality assurance project plan for the Regional Monitoring Program for Trace Substances. San Francisco Estuary Institute. Retrieved from http://www.sfei.org/rmp/reports/1999_QAPP/99_QAPP.html

Lunde, G. (1977). Occurrence and transformation of arsenic in the marine environment. Environmental Health Perspectives, 19, 47-52. 
Marvin-DiPasquale, M., \& J. Agee. (2002). Direct Measurements of Microbial Mercury Cycling in Sediments of the San Francisco Bay-Delta. Report prepared for Sacramento Regional County Sanitation District and CALFED. United States Geologic Service, Menlo Park, California.

Mason, R.P., D. Heyes, \& A. Sveinsdottir. (1994). Methylmercury concentrations in fish from tidal waters of the Cheasapeake Bay. Archives of Environmental Contamination and Toxicology, 51, 425-437.

McLaren, J.B., J.C. Cooper, T.B. Hoff, \& V. Lander. (1981). Movements of Hudson River Striped Bass. Transactions of the American Fisheries Society, 110, $158-167$.

Mehrle, P.M., L. Cleveland, \& D.R. Buckler. (1987). Chronic toxicity of an Environmental contaminant mixture to young (or larval) Striped Bass. Water, Air and Soil Pollution, 35, 107-118.

Merriam, D. (1941). Studies on the Striped Bass (Roccus saxatilis) of the Atlantic Coast. U.S. Fish and Wildlife Service, Fishery Bulletin, 50, 1-77.

Moyle, P. (2002). Inland Fishes of California. University of California Press, Berkeley and Los Angeles, California.

Office of Environmental Health Hazard Assessment (OEHHA). (1997). Health advisory on catching and eating fish interim sport fish advisory for the San Francisco Bay. Office of Environmental Health Hazard Assessment, California, Environmental Protection Agency. Retrieved from http://w ww.oehha.org/fish/nor_cal/int-ha.html 
Ostrach, D.J. (2006). Implications of sublethal contaminant exposure on the early life stages of Striped Bass (Morone saxatilis) in the San Francisco estuary. Ph.D. thesis, University of California, Davis.

Ostrach, D.J. (2007). The role of contaminants, within the context of multiple stressors, In the collapse of the Striped Bass population in the San Francisco estuary and its watershed. Year 1 Progress Report for DWR Agreement No. 4600004664.

Ostrach, D.J., J.M. Low-Marchelli, K.J. Eder, S.J. Whiteman, \& J.G. Zinkl. (2008). Maternal transfer of xenobiotics and effects on larval Striped Bass in the San Francisco Estuary. Proceedings of National Academy of Sciences, USA, 105, 19354-19359.

Ostrach, D.J., J.M. Groff, P.K. Weber, T.R. Ginn, F.J. Loge, K.J. Eder, J.L. Spearow, E.D.H. Durieux, R.S. Kota, C.C. Phillis, J.H. Walsh, P.S. Fitzgerald, D.K. Naydan, L.Prak, C.C.Chin, G.E. Whitman, R.K. Hoang, \& T.S. Vaught. (2009). The role of contaminants, within the context of multiple stressors, in the collapse of the Striped Bass population in the San Francisco Estuary and its watershed. Final Year 2 Report for DWR Agreement No. 4600004664.

Orsi, J.J. (1971). The 1965-1967 migrations of the Sacramento-San Joaquin estuary striped bass population. California Fish and Game, 57, 257-267.

Polgar, T.T., R.A. Cummins, D.G. Heimbuch, J.K. Summers, \& K.A. Rose. (1985). Investigation of Relationships among pollutant loadings and fish stock landings in northeastern estuaries. Estuaries, 8(2), 125-135. 
Radovich, J. (1963). Effect of ocean temperature on he seaward movements of striped bass, Roccus saxatilis, on the Pacific Coast. California Fish and Game, 49(3), $191-206$.

Raney, E.C., E.F. Tresselt, E.H. Hollis, V.D. Vladykov, \& D.H. Wallace. (1952). The Striped Bass, Roccus saxatilis. Bulletin of the Bingham Oceanographic Collection, volume XIV, article 1. Peabody Museum of Natural History, Yale University.

Ricker, W.E. (1975). Computation and interpretation of biological statistics of fish populations. Bulletin of the Fisheries Research Board of Canada, 191, 1-382.

Robson, M. (2003). Methadologies for assessing exposure to metals: human host factors. Ecotoxicology and Environmental Safety, 56, 104.

Rolfhus, K.R. \& W.F. Fitzgerald. (1995). Linkages between atmospheric mercury deposition and the methylmercury content of marine fish. In Water, Air, \& Soil Pollution, 80(1-4), International Conference on Mercury as a Global Pollutant, Whistler, British Columbia, Canada, 10-14 Jul 1994.

Ryan, J.A., H.R. Pahren, \& J.B. Lucas. (1982). Controlling cadmium in the human chain: review and rationale based on health effects. Environmental Research, 28, 251.

Sasso, A.F., S.S. Isukapalli, \& P.G. Georgopoulos. (2010). A generalized physiologically base toxiokinetic modeling system for chemical mixtures containing metals. Theoretical Biology and Medical Modeling, 7, 17. 
Scofield, E.C. (1928). Striped Bass studies. California Fish and Game, 14, 29-37.

Scruggs, G.D. (1957). Reproduction of resident Striped Bass in Santee-Cooper Reservoir, South Carolina. Transactions of the American Fisheries Society, 85(1),144-159.

Scruggs, G.D. \& J.C. Fuller. (1955). Indications of a freshwater population of Striped Bass, "Roccus saxatilis" (Walbaum), in Santee-Cooper Reservoir. Proceedings Southeastern Association Game Fish Commission, 1954, 64-70.

Seber, G.A.F. (1970). The effects of trap response on tag recapture estimates. Biometrics, 26(1), 13-22.

Secor, D.H. (1992). Application of otolith microchemistry analysis to investigate anadromy in Chesapeake Bay Striped Bass, Morone saxatilis. Fishery Bulletin, 90, 798-806.

Secor, D.H. (1999). Specifying divergent migrations in the concept of stock: The contingent hypothesis. Fisheries Research, 43(1-3), 13-34.

Secor, D.H, T.M. Trice, \& H.T. Hornick. (1994). Validation of otolith-based aging in Chesapeake Bay Striped Bass by mark-recapture with a comparison of otolith and scale-based aging. Fishery Bulletin, 93, 186-190.

Secor, D.H., A. Henderson-Arzapalob, \& P.M. Piccoli. (1995). Can otolith microchemistry chart patterns of migration and habitat utilization in anadromous fishes? Journal of Experimental Marine Biology and Ecology, 192, 15-33. 
Secor, D.H. \& P.M. Piccoli. (1996). Age- and sex-dependent migrations of Striped Bass in the Hudson river as determined by chemical microanalysis of otoliths. Estuaries, 19(4), 778-793.

Secor, D.H., J.R. Rooker, E. Zlokovitz, \& V.S. Zdanowicz. (2001). Identification of riverine, estuarine, and coastal contingents of Hudson River Striped Bass based upon otolith elemental fingerprints. Marine Ecology Progress Series, 211, $245-253$

Setzler, E.M., W.R. Boynton, K.V. Wood, H.H. Zion, L. Lubbers, N.K. Mountford, P. Frere, L. Tucker, \& J.A. Mihursky. (1980). Synopsis of biological data on Striped Bass, Morone saxatilis (Walbaum). NOAA Technical Report NMFS Circular 433, FAO Synopsis No. 121. National Oceanic and Atmospheric Administration, National Marine Fisheries Service.

Setzler-Hamilton, E.M., J.A. Whipple, \& R.B. MacFarlane. (1988). Striped Bass populations in Cheasepeake and San Francisco Bays: Two environmentally impacted estuaries. Marine Pollution Bulletin, 19(9), 466-477.

San Francisco Estuary Institute (SFEI). (2000). San Francisco Bay seafood consumption study. Richmond (CA): San Francisco Estuary Institute, California Department of Health Services. Retrieved from http://www.sfei.org/rmp/sfcindex.htm

Smith, W.G. \& A. Wells. (1977). Biological and Fisheries Data on Striped Bass, Morone saxatilis (Walbaum). Technical Series Report No. 4. National Marine Fisheries Service, National Oceanic and Atmospheric Administration. 
Snodgrass, J.W., C.H. Jagoe, A.L. Jr. Bryan, H.A. Brant, \& J. Burger. (2000). Effects of trophic status and wetland morphology, hydroperiod, and water chemistry on mercury concentrations in fish. Canadian Journal of Fisheries and Aquatic Sciences, 57(1),171-180.

Spearow, J.L., R.S. Kota, \& D.J. Ostrach. (2011). Environmental contaminant effects on juvenile Striped Bass in the San Francisco Estuary, California, USA. Environmental Toxicology and Chemistry, 30, 393-402.

Stevens, D.E. (1977). Striped Bass (Morone saxatilis) year class strength in relation to River flow in the Sacramento-San Joaquin Estuary, California. Transactions of The American Fisheries Society, 106(1), 34-42.

Stevens, D.E., D.W. Kohlhorst, L.W. Miller, \& D.W. Kelley. (1985). The decline of Striped Bass in the Sacramento-San Joaquin Estuary, California. Transactions of the American Fisheries Society, 114, 12-30.

Suedel, B.C., J.A. Boraczek, R.K. Peddicord, P.A. Clifford, \& T.M. Dillon. (1994). Trophic transfer and biomagnification potential of contaminants in aquatic ecosystems. Reviews of Environmental Contamination and Toxicology, 136, 21-89.

Thompson, B., R. Hoenicke, J.A. Davis, \& A. Gunther. (2000). An overview of contaminant-related issues identified by monitoring in San Francisco Bay. Environmental Monitoring and Assessment, 64, 409-419. 
Thompson, B., T. Adelsbach, C. Brown, J. Hunt, J. Kuwabara, J. Neale, H. Olendorf, S. Schwarzbach, R. Spies, \& K. Taberski. (2007). Biological effects of anthropogenic contaminants in the San Francisco Estuary. Environmental Research. 105(1), 156-174.

Thorrold, S.R., C.M. Jones, \& S.E. Campana. (1997b). Response of otolith microchemistry to environmental variations experienced by larval and juvenile Atlantic croaker (Micropogonias undulatus). Limnology and Oceanography, 42, 102-111.

Turner, J.L. (1976). Striped Bass spawning in the Sacramento and San Joaquin rivers in Central California from 1963 to 1972. California Fish and Game, 62(2), 106-118.

Turner, J.L. \& H.K. Chadwick. (1972). Distribution and abundance of the young-ofthe-year Striped Bass, Morone saxatilis, in relation to river flow in the Sacramento-San Joaquin estuary. Transactions of the American Fisheries Society, No.3: 442-452.

United States Environemental Protection Agency. (1998). Method 3051A, Microwave assisted acid digestion of sediments, sludges, soils, and oils. Revision 1.

Waldman, J.R., D.J. Dunning, Q.E. Ross, \& M.T. Mattson. (1990). Range dynamics of Hudson River Striped Bass along the Atlantic Coast. Transactions of the American Fisheries Society, 119, 910-919.

Walther, B.D. \& SR Thorrold. (2006). Water, not food, contributes the majority of strontium and barium deposited in the otoliths of a marine fish. Marine Ecology Progress Series, 311, 125-130. 
Wang, J.S. (1998). Accumulation and depuration of aqueous and dietary PCB (Aroclor 1254) by Striped Bass (Morone saxatilis). Bulletin of Environmental Contamination and Toxicology, 60(1), 104-11.

Wiener, J.G. \& D.J. Spry. (1996). Toxicological significance of mercury in freshwater fish. In W.N. Beyer, G.H. Heinz, \& A.W. Redmon (eds). Environmental contaminants in wildlife: interpreting tissue concentrations. Lewis Publishers, Boca Raton, Florida.

Windam, H., R. Stickney, R. Smith, D. White, \& F. Taylor. (1973). Arsenic, cadmium, copper, mercury and zinc in some species of North Atlantic finfish. Journal of the Fisheries Research Board of Canada, 30, 275-9.

Winger, P.V., P.J. Lasier, D.H. White, \& J.T. Seginak. (2000). Effect of contaminants in dredge material from the Lower Savannah River. Archives of Environmental Contamination and Toxicology, 38(1), 128-36.

Yamagata, N. (1973). Manifestation of cadmium poisoning in Japan and geochemical approach to environmental pollution. In E Ingerson (ed.), Proceedings of the Symposium in Hydrogeochemistry and Biogeochemistry, Tokyo, September 7-8, 1970, (vol 2, pp 330-336). The Clarke Company, Washington DC.

Zar, J.H. (1999). Biostatistical Analysis, fourth edition. Prentice-Hall, Inc. Upper Saddle River, New Jersey.

Zlokovitz, E.R., D.H. Secor, \& P.M. Piccoli. (2003). Patterns of migration in Hudson River Striped Bass as determined by otolith microchemistry. Fisheries Research, $63,245-259$. 